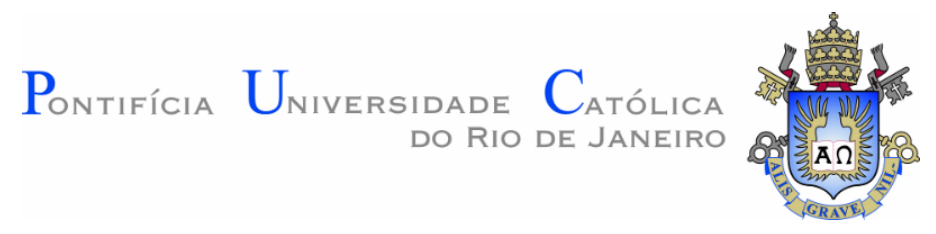

Beatriz Helena Kury Costa Pereira

\title{
Three Essays on Export Promotion Services and Systems: Overcoming Export Barriers
}

Tese de Doutorado

Thesis presented to the Programa de Pós-Graduação em Administração de Empresas of PUC-Rio in partial fulfillment of the requirements for the degree of Doutor em Ciências - Administração de Empresas.

Advisor: Prof. Angela Maria Cavalcanti da Rocha

Rio de Janeiro

May 2018 


\title{
Beatriz Helena Kury Costa Pereira
}

\section{Three Essays on Export Promotion Services and Systems: Overcoming Export Barriers}

Thesis presented to the Programa de Pós-Graduação em Administração de Empresas of PUC-Rio in partial fulfillment of the requirements for the degree of Doutor em Ciências - Administração de Empresas. Approved by the undersigned Examination Committee.

\author{
Prof. Angela Maria Cavalcanti da Rocha \\ Advisor \\ Departamento de Administração - PUC-Rio
}

Prof. Marcus Wilcox Hemais

Departamento de Administração - PUC-Rio

Prof. Renato Dourado Cotta de Mello

UFRJ

Prof. Ariane Cristine Roder Figueira

UFRJ

Prof. Luis Antonio da Rocha Dib

Instituto Coppead de Administração/UFRJ

Prof. Augusto Cesar Pinheiro da Silva Coordenador Setorial do Centro de Ciências Sociais - PUC-Rio

Rio de Janeiro, May 11, 2018 
All rights reserved.

\section{Beatriz Helena Kury Costa Pereira}

Holds a Master Degree in Business Administration from the Federal University of Rio de Janeiro (Coppead/UFRJ), followed by a specialization in management at ESSEC - École Supérieure des Études Économiques et Commerciales, France. Graduated in Business Administration at the Brazilian School of Public Administration at the Getulio Vargas Foundation (EBAPE/FGV). Researcher at NUPIN - Center of International Business Research of PUC-Rio - Pontifical Catholic University of Rio de Janeiro - has published in national and international academic journals. Presently engaged in research projects mainly related to service firms' internationalization and to export promotion. Integrated for two years the technical team of PEIEX - a capacity building EPP led by Apex-Brasil, the Brazilian Trade and Investment Promotion Agency, and implemented among inexperienced exporters in the State of Rio de Janeiro by PUC-Rio. Other than her academic background, she has more than 20 years of experience built up at institutions of different sizes, industry sectors and corporate cultures where she occupied mainly senior management positions.

Bibliographic data

Pereira, Beatriz Helena Kury Costa

Three essays on export promotion services and systems: overcoming export barriers / Beatriz Helena Kury Costa Pereira; advisor: Angela Maria Cavalcanti da Rocha. - 2018.

169 f. : il. ; $30 \mathrm{~cm}$

Tese (doutorado) - Pontifícia Universidade Católica do Rio de Janeiro, Departamento de Administração, 2018.

Inclui bibliografia

1. Administração - Teses. 2. Promoção à exportação. 3. Redes de promoção à exportação. 4. Barreiras à exportação. 5 . Internacionalização de clusters. 6. Indústrias criativas. I. Rocha, Angela Maria Cavalcanti da. II. Pontifícia Universidade Católica do Rio de Janeiro. Departamento de Administração. III. Título. 


\section{Acknowledgements}

To my advisor Professor Angela Maria Cavalcanti da Rocha for her incommensurable knowledge and committed partnership.

To the other members of the Examination Committee, specially Professor Marcus Wilcox Hemais, Professor Renato Dourado Cotta de Mello, Professor Ariane Cristine Roder Figueira and Professor Luís Antônio da Rocha Dib who provided insightful comments and great inspiration to perfect my research.

To IAG - PUC-Rio staff, specially Teresa Campos, for assisting me in many ways in several occasions.

To CAPES - Coordenação de Aperfeiçoamento de Pessoal de Nível Superior for the financial support.

To Professor Jorge Carneiro for the financial support that enabled my participation in the International Conference on Export Promotion, held on December 2016 in The Netherlands, organized by Windesheim University of Applied Sciences in collaboration with Shanghai University of International Business and Economics and the Telfer School of Management - University of Ottawa.

To the dear Professor Agrícola Bethlem, who moved to Heaven, but still inspires me every day, and was somehow responsible for my engagement on this $\mathrm{PhD}$ journey.

Finally, embracing the words and feelings of Chilean composer and singer, Violeta Parra, "gracias a la vida que me ha dado tanto." 


\section{Abstract}

Pereira, Beatriz Helena Kury Costa; Rocha, Angela Maria Cavalcanti da (Advisor). Three Essays on Export Promotion Services and Systems: Overcoming Export Barriers. Rio de Janeiro, 2018, 169p. Tese de Doutorado - Departamento de Administração. Pontifícia Universidade Católica do Rio de Janeiro.

Foreign trade provides significant benefits to nations from both macroeconomic and microeconomic perspectives. From a macroeconomic point of view, exports allow the increasing of foreign exchange reserves and generate employment opportunities, consequently leading to improved living standards. From a microeconomic perspective, exports stimulate the development of competitive advantages, reducing idle production capacity, raising technological standards, powering profitability, intensifying return on investments, and enhancing firms' financial stature. SMEs export performance is particularly of utmost importance since they are responsible for a significant portion of economic activities and could amplify substantially exports outcome at the aggregate level. However, export barriers and market failures tend to affect their capacity to access strategic resources necessary to guarantee a successful internationalization process. From a resource-based perspective, the inability of SMEs to successfully expand abroad due to their lack of sufficient internal resources, know-how, and information about foreign markets may be seen as a condition of market failure, therefore endorsing government's participation in export promotion initiatives. In accordance with this rationale and building on the existing knowledge, the aim of this thesis is to contribute to the investigation of export promotion services and systems in three essays. The first essay, entitled "Export Promotion Services and Firm Export Barriers: Do These Literatures Interact?", - aims to thoroughly examine the two literatures, presenting their contributions, gaps, and recommendations for future studies. The second essay, entitled "Export Promotion Initiatives in a Cluster", approaches the long-term development of a Brazilian beachwear cluster, using the case method of investigation and focusing specifically on the attempts to develop exporting activities. Export promotion agents have tried to introduce new practices and attitudes toward cooperation among firms but failed to do so. The key issue, therefore, is to understand why the firms failed to cooperate, despite several 
initiatives and investments to promote collective actions. The paper advances some possible explanations, with implications to other Brazilian clusters. Finally, the conclusion advances some recommendations for public policymakers concerning the design of export promotion programs. The third and last essay, entitled "The Coordination of Export Promotion Networks for the Creative Industries", examines through the use of the case method of investigation the different approaches adopted by three successful countries in supporting the internationalization of their creative industries, adopting an interorganizational perspective, focusing on network coordination. The study provides empirical evidence of how different approaches, from the centralization of an export promotion network to decentralization, and from loose coordination to tight, may be used to promote the exports of firms in the creative industries. The results also suggest that each context may require a different approach to the coordination of Trade Support Institutions' activities. The degree of economic development of each country, the resources available, the maturity of the industry, as well as cultural issues, may play a role in determining which approach could be a better fit for each country and sector.

\section{Keywords}

Export Promotion; Export Promotion Programs; Export Promotion Networks; Trade Support Institutions; Trade Promotion Organizations; Export Promotion Agencies; Export Barriers; Internationalization; Cluster; Clusters' Internationalization; SMEs' Internationalization; Creative Industries, United Kingdom; South Korea; Colombia. 


\section{Resumo}

Pereira, Beatriz Helena Kury Costa; Rocha, Angela Maria Cavalcanti da (Orientadora). Três Ensaios sobre Serviços e Sistemas de Promoção à Exportação: Superando Barreiras à Exportação. Rio de Janeiro, 2018, 169p. Tese de Doutorado - Departamento de Administração. Pontifícia Universidade Católica do Rio de Janeiro.

O comércio exterior garante benefícios significativos para as nações, tanto do ponto de vista macroeconômico quanto microeconômico. Do ponto de vista macroeconômico, as exportações possibilitam o aumento das reservas cambiais e geram oportunidades de emprego proporcionando, consequentemente, melhores condições de vida. Do ponto de vista microeconômico, as exportações estimulam o desenvolvimento de vantagens competitivas, reduzindo a capacidade ociosa, elevando os padrões tecnológicos, potencializando a lucratividade, intensificando o retorno sobre os investimentos e reforçando a grandeza financeira das empresas. $\mathrm{O}$ desempenho das exportações das PMEs é particularmente de extrema importância, uma vez que elas são responsáveis por uma parcela significativa das atividades econômicas e podem ampliar substancialmente o resultado das exportações no nível agregado. No entanto, barreiras à exportação e falhas de mercado tendem a afetar sua capacidade de acesso aos recursos estratégicos necessários para garantir um processo de internacionalização bem-sucedido. Analisando pela ótica da Visão Baseada em Recursos (Resource Based View), a incapacidade das PMEs de obter sucesso em expandir-se internacionalmente devido à falta de recursos internos suficientes, know-how e informações sobre mercados estrangeiros, pode ser vista como uma condição de falha de mercado, endossando a participação do governo em iniciativas de promoção às exportações. A partir desse raciocínio e com base no conhecimento existente, o objetivo desta tese é contribuir para a investigação de serviços e sistemas de promoção às exportações em três ensaios. O primeiro ensaio, intitulado "Serviços de Promoção às Exportações e Barreiras às Exportações da Firma: Há interação entre as duas literaturas?”, visa examinar profundamente estas literaturas, apresentando, apresentando suas contribuições, lacunas e recomendações para estudos futuros. O segundo ensaio, intitulado "Iniciativas de Promoção às Exportações junto a um Cluster", aborda o desenvolvimento de longo prazo de um cluster brasileiro de moda praia, utilizando o método do estudo de caso 
e focando especificamente nas tentativas de desenvolvimento de suas atividades exportadoras. Agentes de promoção às exportações tentaram introduzir novas práticas e atitudes em relação à cooperação entre empresas, mas não obtiveram sucesso. A questão fundamental, portanto, é buscar entender porque as empresas falharam em cooperar, apesar de várias iniciativas e investimentos realizados para promover ações coletivas. O artigo fornece algumas explicações possíveis que sugerem implicações para outros clusters brasileiros. Por fim, a conclusão fornece algumas recomendações para formuladores de políticas públicas sobre o desenho de programas de promoção às exportações. O terceiro e último ensaio, intitulado "A Coordenação de Redes de Promoção às Exportações para as Indústrias Criativas", examina por meio do uso do método do estudo de caso, as diferentes abordagens adotadas por três países bem-sucedidos no apoio à internacionalização de suas indústrias criativas, a partir da perspectiva interorganizacional, com foco na coordenação de redes. O estudo fornece evidências empíricas de como diferentes abordagens, da centralização da rede de promoção às exportações à descentralização dos esforços de promoção, e de uma coordenação mais frouxa até uma mais rigorosa, podem ser usadas para promover as exportações de empresas pertencentes às indústrias criativas. Os resultados também sugerem que cada contexto pode exigir uma abordagem diferente para a coordenação das atividades das Instituições de Apoio ao Comércio Exterior. O grau de desenvolvimento econômico de cada país, os recursos disponíveis, a maturidade da indústria, bem como, questões culturais, podem desempenhar seu papel na determinação da abordagem mais adequada para cada país e setor.

\section{Palavras-Chave}

Promoção às Exportações; Programas de Promoção às Exportações; Redes de Promoção às Exportações; Instituições de Apoio ao Comércio Exterior; Organizações de Apoio ao Comércio Exterior; Agências de Promoção às Exportações; Barreiras às Exportações; Internacionalização; Cluster; Internacionalização de Clusters; Internacionalização de PMEs; Indústrias Criativas, Reino Unido; Coréia do Sul; Colômbia. 


\section{Table of Contents}

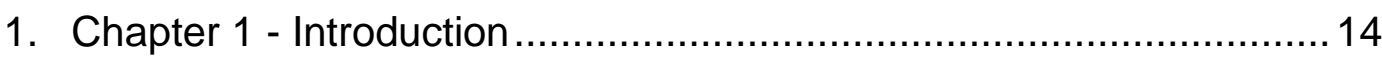

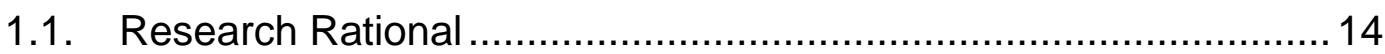

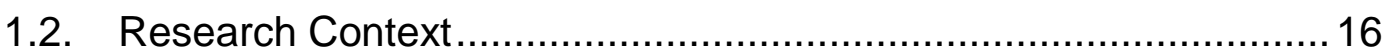

1.2.1. The Creative Industries: the research locus ................................ 18

1.3. Definition of Key Concepts ...................................................... 22

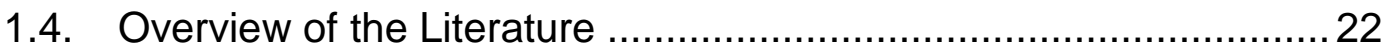

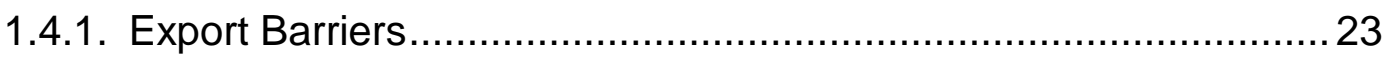

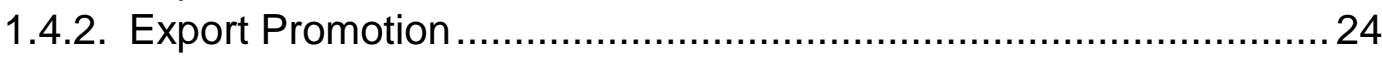

1.5. Theoretical and Practical Relevance ....................................... 25

1.5.1. Theoretical Relevance ....................................................... 26

1.5.2. Methodological Relevance...................................................... 27

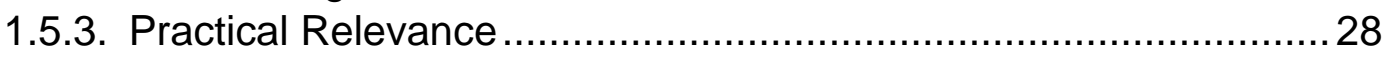

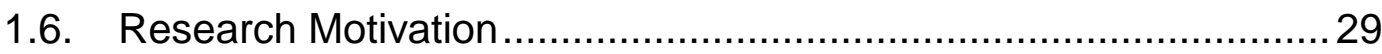

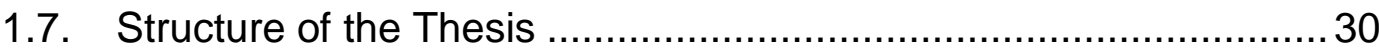

2. Chapter 2 - Essay 1 - Export Promotion Services and Firm Export Barriers: Do These Literatures Interact?............................................ 31

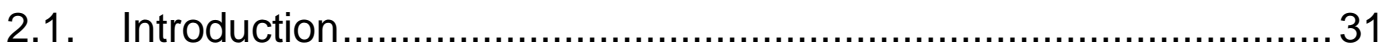

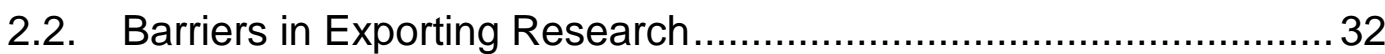

2.2.1. Barriers Perceived by Exporters and Non-Exporters ..................... 34

2.2.2. Export Barriers and the Temporal Dimension................................ 35

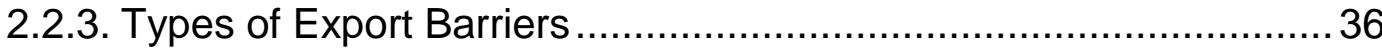

2.2.4. Relative Importance of Export Barriers ....................................... 39

2.2.5. Export Barriers and Export Performance ...................................... 40

2.2.6. Gaps in the Export Barriers Literature ....................................... 41

2.2.7. Summary of the Export Barriers Literature ................................ 43

2.3. The Export Promotion Literature............................................... 44

2.3.1. Export Promotion for Exporters and Non-Exporters and the

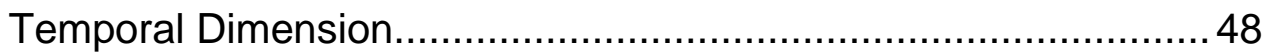

2.3.2. Impact of Export Promotion on Export Performance .................... 49

2.4. Trade Support Institutions (TSIs) ...............................................51

2.5. Export Promotion Conceptual Framework ....................................53

2.6. Gaps in the Export Promotion Literature ....................................54

2.7. Summary of the Export Promotion Literature ...............................55

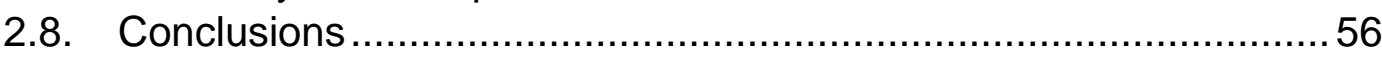

3. Chapter 3 - Essay 2 - Export Promotion Initiatives in a Cluster.........58

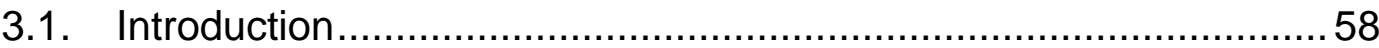

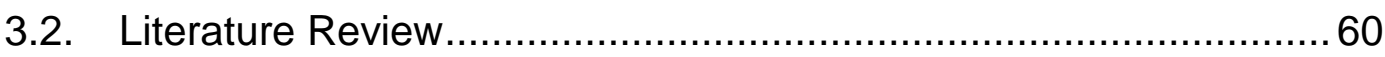

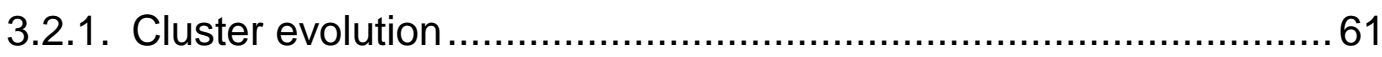

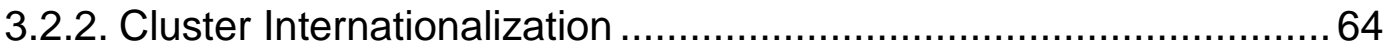

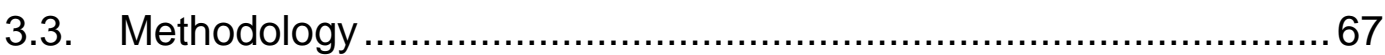

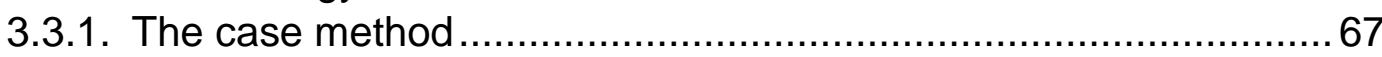




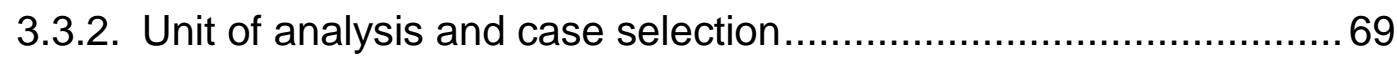

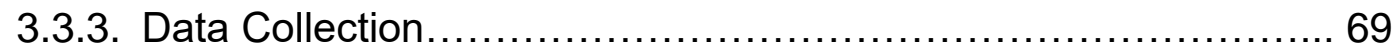

3.4. Case Analysis and Research Limitations ...................................70

3.5. The Cabo Frio Beachwear Cluster ............................................. 71

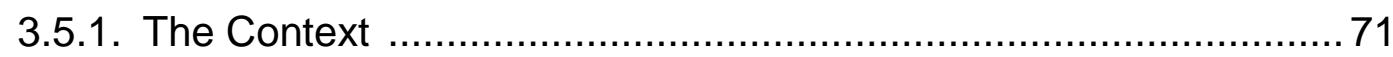

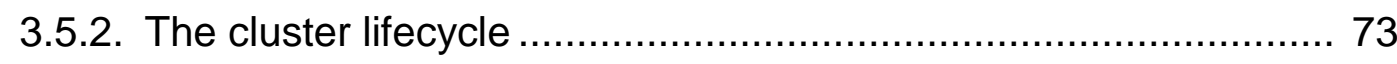

3.5.3. The Pau-Brasil Export Consortium (2003-2004)...........................75

3.5.4. The Strategic Plan (2005-2008)............................................

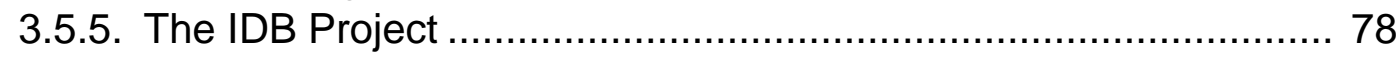

3.5.6. Barriers Identified by Local Entrepreneurs................................... 80

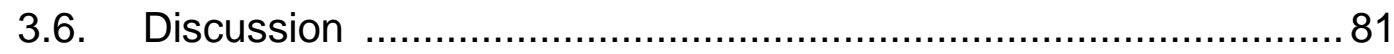

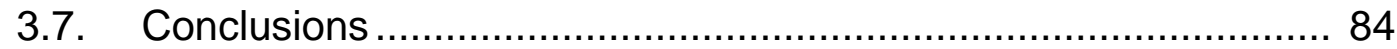

4. Chapter 4 - Essay 3 - The Coordination of Export Promotion

Networks for the Creative Industries ……………………................................ 87

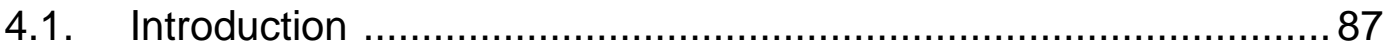

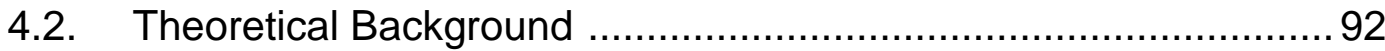

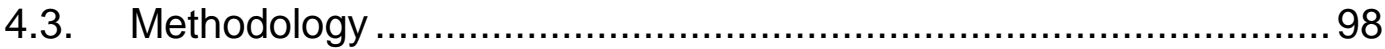

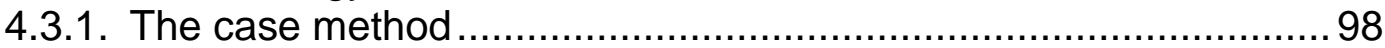

4.3.2. Unit of analysis and case selection.......................................... 100

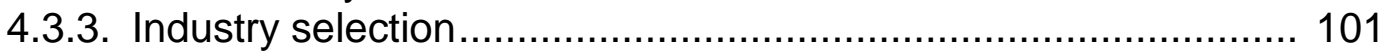

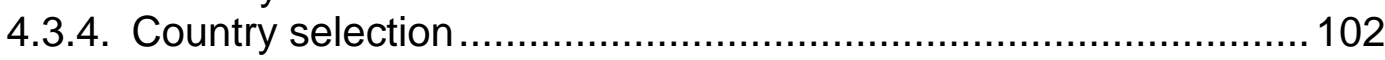

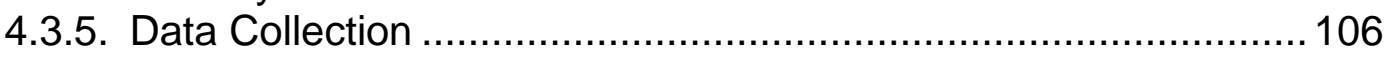

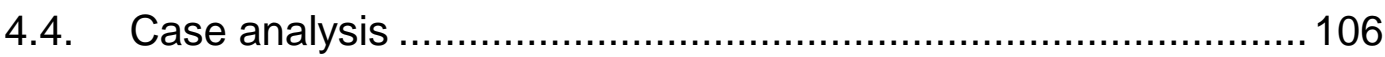

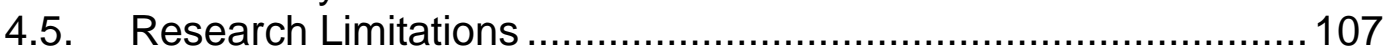

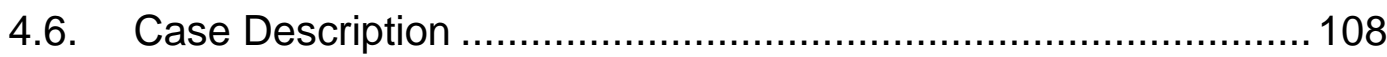

4.6.1. Design in the United Kingdom ............................................ 108

4.6.2. Filmmaking in Colombia ........................................................ 110

4.6.3. Creative Industries in South Korea ........................................ 112

4.7. Cross-Case Comparison ........................................................ 115

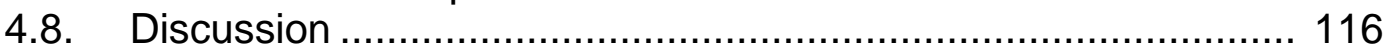

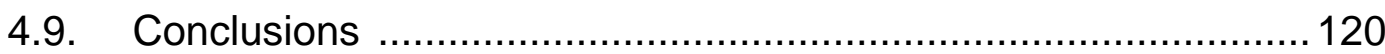

5. Chapter 5 - Conclusions and Avenues for Future Research ........... 122

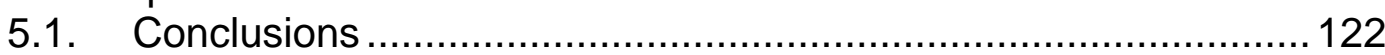

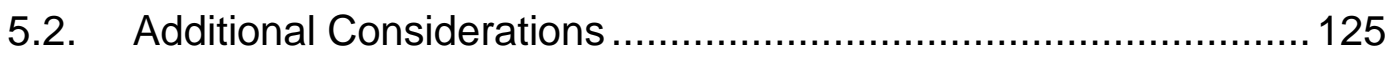

5.3. Avenues for Future Research ............................................. 126

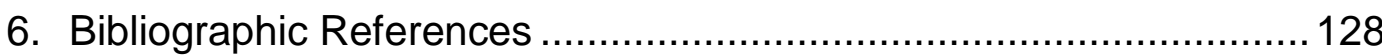

Appendix 1 - Cultural and creative sectors and their range of activities .164

Appendix 2 - Export Barriers Literature Review (1967-2017) ............... 165

Appendix 3 - Export Promotion Literature Review (1990-2018) ............ 166

Appendix 4 - Sources of Secondary Data............................................. 167 


\section{List of Figures}

Figure 1 - Thematic Overview of Export Barriers Research ....................44

Figure 2 - Chronological Development of the Export Promotion

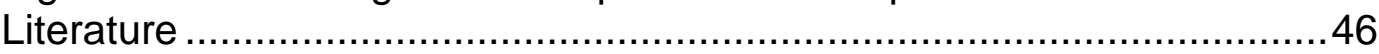

Figure 3 - A Thematic Overview of Export Promotion Research .............56

Figure 4 - Alternative Paths for a Cluster.............................................63

Figure 5 - Evolution of Beachwear Exports - Brazil ...............................73

Figure 6 - Comparison of the UK and Colombian Approaches ..............117

Figure 7 - Korea's tight/loose coordination .........................................119 


\section{List of Tables}

Table 1 - Classification of Export Barriers according to Leonidou

Table 2 - Classification of Export Barriers according to Arteaga-Ortiz and Fernández-Ortiz (2010)

Table 3 - Cluster Lifecycle Stages

Table 4 - Barriers Associated to International Activities Reported by the Entrepreneurs

Table 5 - Issues Concerning the Coordination of Export

Promotion Networks

Table 6 - Main social and economic indicators for the three countries.....102

Table 7 - Tactics employed to increase research's validity and reliability

Table 8 - UK Organisations and the Promotion of the Internationalization of Design

Table 9 - Colombian Organisations and the International Promotion of the Filmmaking Industry

Table 10 - South Korean Organisations and the International

Promotion of the Creative Industries

Table 11 - A Comparison of the Three Export Promotion Networks 
De nuestros miedos nacen nuestros corajes y en nuestras dudas viven nuestras certezas. Los sueños anuncian otra realidad posible y los delirios otra razón. En los extravios nos esperan hallazgos, porque es preciso perderse para volver a encontrarse."

Eduardo Galeno 


\section{1}

\section{Chapter 1 - Introduction}

This introduction chapter sets the foundations that support the development of this $\mathrm{PhD}$ thesis. After introducing the research rationale, it goes on establishing the research context and some key concepts adopted. Subsequently, it offers an overview of both barriers and export promotion literatures, followed by the theoretical and practical relevance of the study, further endorsed by the author's research motivation. The chapter concludes by presenting the structure of the thesis.

\section{1.}

\section{Research Rationale}

Foreign trade provides significant benefits to countries from both macroeconomic and microeconomic perspectives. From a macroeconomic point of view, exports allow increasing foreign exchange reserves and generate employment opportunities, consequently leading to improved living standards. The statistical data collected by World Trade Organization (WTO) to examine the evolution of global trade over the past decade, presented in the most recent edition of World Trade Statistical Review (2017, p.5), confirmed "that trade has continued to support economic growth and development, helping to reduce poverty around the world ${ }^{1}$."

From a microeconomic perspective, exports stimulate the development of competitive advantages, reducing idle production capacity, raising technological standards, powering profitability, intensifying return on investments, and enhancing firms' financial conditions (e.g. Barker and Kaynak, 1992; Julian and O'Cass, 2004; Eldik and Viviers, 2005; Leonidou et al., 2007; Arteaga-Ortiz and Fernández-Ortiz, 2010). Moreover, globalization forces - such as advances in technology, reduction of cross-border trade barriers, increasing consumer demand, convergence of consumer tastes, higher level of competition - have also been acting

\footnotetext{
${ }^{1}$ According to this WTO Report, world merchandise exports reached USD 16 trillion corresponding to an increase in value of around $32 \%$ since 2006, while world exports of commercial services reached a total of USD 4.77 trillion, showing an increase of approximately $64 \%$ for the same period.
} 
as decisive drivers for firms' export growth, particularly to the small and mediumsized enterprises (SMEs).

Moreover, the literature claims that exporting acts as the catalyst of growth opportunities and an important defense of a company's market position in its domestic market, favoring its long-term survival and growth (e.g. Leonidou, Katsikeas and Samiee, 2002; Eldik and Viviers, 2005). Indeed, in their research, Lee et al. (2012), found out that technology-based SMEs' expansion to foreign markets increase their probability of survival, allowing them to avoid the challenges of competing in the domestic market with larger and more experienced firms.

Concurrently, SMEs export performance is of utmost importance since they are responsible for a significant portion of economic activities and could amplify substantially exports outcome at the aggregate level. In fact, according to the Organization for Economic Cooperation and Development - OECD (2017, p.5), "SMEs play a key role in national economies around the world, generating employment and value added and contributing to innovation", besides being fundamental for delivering more inclusive globalization and growth as well as environmental sustainability. As highlighted by Kahiya et al. (2014), a convincing literature has also been produced by economists like Cardoso and Soukiazis (2008), Marin (1992), Narayan et al. (2007), and Siliverstovs and Herzer (2006) to empirically support the benefits of SMEs' export development at country level.

At the same time, $\operatorname{OECD}(2017, \mathrm{p} .15)$ also advocates that "the ability to access strategic resources is critical for SME competitiveness", and called the attention to the fact that

"specific barriers and market failures may prevent SMEs from accessing strategic resources, including finance, management capacity and skills, and knowledge networks, placing them at a competitive disadvantage in the global and digitalised economy (p.15)".

In fact, the relevance of exporting SMEs to the long-term economic and social development of most countries has been motivating policymakers and practitioners to detect ways to encourage their participation in international markets, mitigating export barriers (Kahiya et al., 2014). 
The existence of market failure provides the rationale for government export promotion activities. From a resource-based perspective, the inability of SMEs to successfully expand abroad due to their lack of sufficient internal resources, knowhow, and information about foreign markets may be seen as a condition of market failure, therefore endorsing government's participation in export promotion initiatives (Wilkinson and Brouthers, 2006). Following the advice of Singer (1990), Wilkinson and Brouthers (2006, p.235) stated that "the first step in developing a theoretically-based understanding of export promotion is to address the problem posed by market imperfections which inhibit the exporting efforts of SMEs."

In accordance with this rationale and building on the existing knowledge, the aim of this thesis is to contribute to the investigation of export promotion services and systems in three essays.

\section{2 . \\ Research Context}

The extant International Business literature strongly acknowledges internationalization as decisive for competitiveness and economic development (e.g. Te Velde, 2007; Wright et al. 2007; Dunning and Lundan, 2008; Bannò and Sgobbi, 2010). Indeed, exports have been consistently considered crucial from a government's perspective, impacting fiscal and monetary policies, and ultimately influencing the level of economic and social development of nations. These assumptions are behind the increase of public intervention all around the globe to motivate firms' internationalization. Governments' export promotion policies reveal their commitment to outward orientation and their belief on the important role played by exports on the development of their countries' economies (Miocevic, 2013). In the words of Faroque and Takahashi (2012), "export promotion constitutes an integral part of government's foreign trade policy as well as political manifesto (p.2)".

Many governments, including some of emerging economies, have understood the importance of developing foreign trade promotion strategies for boosting sustainable economic growth. Some examples are presented by Meyer and 
Klasen (2013) in their work about governments' role in supporting their economies. They pointed out, as an example, China's strategic use of government institutions to become a relevant player in trading with the Sub-Saharian Africa, financing the growth of important sectors in Angola, Nigeria, Ghana and Mozambique, such as Construction and Telecommunications, nurturing both domestic and global trade. According to the authors, other countries, such as Russia and Qatar, were also developing financial schemes to support SMEs in diverse sectors to go abroad.

From the academic point of view, issues associated to SMEs exports and internationalization have also attracted growing interest, reflecting not only

"widespread recognition of the potential macroeconomic benefits to be derived from a nation's greater involvement in international trade, but also that -- in an increasingly global marketplace -- export operations often offer individual firms an attractive alternative strategy for survival and growth (Bell, 1997, p. 585)."

However, despite academic researchers' and policymakers' efforts, evidence indicates that SMEs continue to underperform in international markets. As per OECD (2017, p.11),

"overall, SMEs tend to be under-represented in international trade. Across OECD and non-OECD Members, few SMEs export directly and for those that do, exports typically represent a lower share of trade turnover (relative to larger firms) and generally target neighboring countries."

The International Business (IB) body of knowledge claims that exporting is particularly convenient to SMEs as an entry mode to international markets due to its significant degree of flexibility, restricted resource commitment and risk exposure (e.g. Young et al., 1989). Nevertheless, the lack of sufficient resources and capabilities for obtaining the required information to allow successfully expanding to new markets tend to refrain their export endeavors in the absence of government support (e.g. Reid, 1981; Seringhaus and Botschen, 1991; Tannous, 1997; Wilkinson and Brouthers, 2006; Williams, 2008; Durmusoglu, Apfelthaler, Nayir, Alvarez, and Mughan, 2011; Freixanet, 2012; Moore and Carter, 2015). Not surprisingly, export promotion programs are predominantly designed and delivered to SMEs (Zia, 2008). In the critical review by Peiris et al. (2012) covering studies on international entrepreneurship published from 1992 to 2012, government 
assistance appeared in the fifth position among the 14 most important motivations to enter new markets abroad.

The knowledge about the barriers that inhibit non-exporters from expanding abroad and hinder current exporters from maintaining profitable ventures in international markets constitutes the basis upon which stakeholders can develop and successfully deploy export promotion programs (Shoham and Albaum 1995; Crick 2004; Kahiya, 2014). Hilton (2005, p. 20) advocates that "the challenges and barriers to entry that small and medium sized businesses face in the international market is not news. How we deal with these challenges, however, is." Indeed, though many studies to understand the nature and role played by perceived obstacles to exporting have been developed to date, many inconsistencies and gaps still remain.

Regarding the literature on export promotion, the situation is almost the same, that is, there is no conclusive empirical evidence on export promotion adequacy to the SMEs' needs, nor on a positive influence on the firm's export performance, which is eventually the holy grail of export promotion for all interested stakeholders - managers, policymakers and taxpayers (e.g. Gillespie and Riddle, 2004; Brewer, 2009; Freixanet, 2012).

All these shortcomings call for research to reduce the gaps encountered and contribute to enriching export barriers and export promotion knowledge.

\subsection{1.}

\section{The Creative Industries: the research locus}

The increasing relevance of the service sector for both developed and developing countries has turned it into a driving force of global economy, as well as an indicator of economic progress. Indeed, since 2008, services have accounted for more than $50 \%$ of GDP in low-income countries, and their importance shows an upward trend as these economies develop (e.g. Cali et al., 2008). At the same time, the creative industries, specifically, have expanded at a particular fast rate, both in terms of job creation and income and exports (Oliveira et al., 2013). 
Moreover, products and services generated by the creative industries have high income elasticity, allowing their international trade to be less impacted by world crises (Howkins, 2013).

The term creative industries was adopted in the late 1990s to describe a range of activities with strong cultural roots, combining some of the oldest activities known and others which only came to light most recently, with the arrival of digital technology. Nowadays, “... the concept of the 'creative industries', and their importance, is recognized by almost every government in the world and is beginning to give way to a much more inclusive idea of a wider "creative economy", (Newbigin, J., 2018). According to Peters (2010, p.69),

"...there is now widespread agreement among economists, sociologists and policy analysts that creativity, design and innovation are at the heart of the global knowledge economy: together creativity, design and innovation define knowledge capitalism and its ability to continuously reinvent itself. Together and in conjunction with new communications technologies they give expression to the essence of digital capitalism - the 'economy of ideas' - and to new architectures of mass collaboration that distinguish it as a new generic form of economy different in nature from industrial capitalism."

Peters (2010, p.70) goes on stating that knowledge,

"...unlike other commodities... operates expansively to defy the law of scarcity that is fundamental to classical and neoclassical economics and to the traditional understanding of markets... In other words, knowledge and information, especially in digital form, cannot be consumed. The use of knowledge or information as digital goods can be distributed and shared at no extra cost and the distribution and sharing is likely to add to its value rather than to deplete it or use it up."

The definition of the creative industries adopted by each country varies substantially, hindering the process of measuring their economic contribution. Moreover, the impact of the creative activities on other economic sectors, especially in the use of digital technologies, should also be taken into consideration when trying to determine their economic weight. Furthermore, it is important to acknowledge that the combination of culture and commerce, represented by the creative industries, must be seen as a powerful strategy to grant competitive advantage to the image of a country. It is also noteworthy the substantial impact of the creative economy on the level of employment. Contrary to jobs in other industry sectors, which are estimated by researchers at Oxford University to drastically disappear, due to their replacement by machines, a 2015 study by the innovation 
foundation based in the UK - National Endowment for Science, Technology and the Arts (Nesta) -, showed that the creative sector seemed to be considerably immune to this threat. According to Nesta's study, $87 \%$ of highly creative jobs in the UK present minimal or no risk of being substituted by automation (Newbigin, 2018). Indeed, Newbigin (2018) stresses that

“...the more policy analysts and statisticians around the world thought about how to assess the true impact of the creative industries the more it became apparent that much more fundamental rethinking was necessary."

According to a study commissioned by CISAC, the International Confederation of Authors and Composers Societies, to EY ${ }^{2}$, with the participation of Oxford Economics ${ }^{3}$, the cultural and creative industries generated revenues of US $\$ 2,250$ billion in $2013^{4}$, widely exceeding those of telecom services (US $\$ 1,570$ billion globally), as well as India's GDP (US\$1,900 billion), being the driving force of the digital economy. Moreover, they were responsible at that time for the creation of nearly 30 million jobs worldwide (EY, 2015). Furthermore, according to the 2015 Director-General of UNESCO, Irina Bokova,

..."in addition to its economic benefits, the cultural and creative industries generate nonmonetary value that contribute significantly to achieving people-centered, inclusive and sustainable development." (EY, 2015, p.5).

Additionally, the CISAC's research showed that culture and creative industries are crucial for the economic development of both mature and emerging markets, influencing not only income and job generation, but also export revenues. Nevertheless, the study also called the attention to many challenges to the creative industries' growth, reinforcing the need of more structuring supportive policies to tackle them. Indeed, governmental policies and the coordination of public and private efforts seem to be mandatory to guarantee the fertile ecosystems needed to encourage creative industries' growth and consolidation (White et al., 2014; EY, 2015).

\footnotetext{
${ }^{2}$ Formerly Ernst \& Young, EY is one of the world's largest professional services firms.

${ }^{3}$ Oxford Economics is a leader in global forecasting and quantitative analysis.

${ }^{4}$ To measure revenues, the study adopts an approach based on final consumer and business markets (B2C and B2B), primarily at retail prices (without indirect taxes). Informal sales, defined as cultural goods and services sold through unofficial distribution channels by producers and retailers, are included in the estimates, as well as public license fees for the audiovisual sector (TV and radio).
} 
The creative economy is also an important part of global trade. In 2012, the global market for traded creative goods and services amounted approximately to US $\$ 547$ billion, showing an increase of around $83 \%$ in a decade, revealing the strength and resilience of the sector in the face of the slowdown experienced by the global economy (UNCTAD, 2015).

For the purposes of the study Cultural and Creative Industries - CCI encompass industries producing creative goods and services, defined by UNESCO during its 2005 Convention on the Protection and Promotion of the Diversity of Cultural Expressions as "activities, goods and services which... embody or convey cultural expressions, irrespective of the commercial value they may have." Appendix 1 (p. 164) presents the 11 sectors composing cultural and creative industries considered in the research.

\section{3. \\ Definition of Key Concepts}

Definitions of important constructs addressed by this $\mathrm{PhD}$ thesis are presented below:

- Export barriers - any element or factor originated internally or externally that impede, through concretely blocking or simply discouraging firms from engaging and maintaining export endeavors

- Export Promotion Program (EPP) - public or public-private partnerships to encourage firms to internationalize, reduce or eliminate export barriers, assist in planning and preparation for exporting through both financial and nonfinancial support.

- Trade Support Institution (TSI) - a broad set of organisations that offer support to exporters, including export promotion, financing, quality, standards and legal advice. These organizations can be public or private. Other terms that appear in the literature with the same or very similar meaning are: Export Promotion 
Organization (EPO), Export Promotion Agency (EPA), Export Promotion Institution (EPI), Trade Promotion Organization (TPO).

\section{4.}

\section{Overview of the Literature}

Exporting theoretical roots were first settled by economists. Theories developed by Adam Smith, David Ricardo, and Raymond Vernon, among many others, provided important insights into explaining international trade activities, setting the grounds of international business thinking. As stated by Leonidou and Katsikeas (2010), in their bibliographic analysis of IB research on exports from 1960 to 2007, the fact that exporting constitutes the most common way for several firms to expand abroad attracted the attention of many business researchers since the early 1960s, generating plentiful studies on the subject, "establishing it as a legitimate field of academic inquiry within the international business discipline (p.79)". However, the authors also pointed out that, from a business perspective, research into exporting has been frequently questioned and judged fragmented, uncoordinated and repetitive.

Due to its perceived importance from a macroeconomic perspective, government export promotion, specifically awareness of, usage, and effectiveness of export promotion programs, was one of the first key research themes in the field, as well as export barriers. Although showing a declining trend in recent years, it is believed that there is still room for further investigation on both issues (Leonidou and Katsikeas, 2010).

This $\mathrm{PhD}$ thesis departs, therefore, from the literature on export promotion and on export barriers to set the theoretical background to which belong the specific contributions of this work. 


\subsection{1.}

\section{Export Barriers}

Most export barriers' studies either attempt to disclose the structure and nature of export barriers or try to unveil export barriers' influence on the firms' internationalization process and export performance (e.g. Ford and Leonidou, 1991; Barker and Kaynak, 1992; Cavusgil and Yeoh, 1994; Leonidou, 1995a; 1995b; Morgan, 1997; Suarez-Ortega, 2003; Tesfom and Lutz, 2006; Altintas et al., 2007; Da Rocha et al., 2008; Pinho and Martins, 2010; Stoian and Rialp-Criado, 2010; Bianchi and Wickramasekera, 2013).

Regarding the various classification schemes for export barriers, the main criterion used is the locus of origin, that is, if they are internal or external to the organization. Other concerns on the nature of export barriers address the eventual differences in export barriers perceived by current exporters and non-exporters, as well as differences faced by firms from different socio-economic contexts. The dynamic nature of barriers is also reinforced by this literature. Some studies indicate that barriers can be identified all along the internationalization process and their nature, frequency, intensity and importance usually vary from stage to stage (e.g. Czinkota, 1982; Leonidou, 1995b; Suarez-Ortega, 2003).

Concerning the relative importance of export barriers, studies show that informational barriers seem to be the most disturbing ones relatively to SMEs (e.g. Leonidou, 1995a). They tend to be more significant when firms try to enter a new market or to introduce a new product than when they try to expand international activities in countries to which they already export or to increase sales of a previously exported product.

The relationship between export barriers and export performance is also examined. Many studies state that export barriers are among the determinants of export performance and that certain barriers have more effective impact on export performance than others, remarkably informational barriers, lack of firm competence and managerial characteristics (e.g. Stoian and Rialp-Criado, 2010; AlHyari et al., 2012; Karakaya and Yannopoulos 2012). Another interesting finding 
reported is that although not affecting export performance directly, export support activities have an indirect impact on it, reducing the barriers (Stoian and RialpCriado, 2010).

Though many studies to understand the nature and role played by perceived export barriers have been developed to date (e. g. Cavusgil et al., 1979; Leonidou, 1995b; Da Rocha et al., 2008; Doern, 2009; Uner, 2013; Adu-Gyamfi and Korneliussen, 2013; Bianchi and Wickramasekera, 2013, Gil-Pareja et al., 2014; Kahiya, 2017), many inconsistencies and gaps remain still. The absence of a sound theoretical base, together with inadequate methodological choices have been considered the most relevant explanations to these discrepancies. Differences in geographic focus, industry, type of firm, type of product and time frame contexts were also indicated by researchers as important flaws on the extant export barriers' literature.

\subsection{2.}

\section{Export Promotion}

The rationale massively defended by researchers to justify the existence of EPPs is that, by enhancing firms' capabilities and competitiveness, they help firms to overcome export barriers, ultimately boosting global export performance and socioeconomic development.

Studies indicate that informational barriers are the main source of concern to SMEs willing to go overseas, being consistently higher for them than for larger firms (Lederman et al., 2010). Moreover, the need of export promotion is greater when export barriers are high.

The literature shows that the effects of export promotion vary along several dimensions, the temporal being one of them (e.g. Wilkinson and Brouthers, 2006; Ayob and Freixanet, 2014;). While the need for public assistance may decrease over time, regular exporters will still have some unavoidable export barriers to overcome. 
In accordance with export barriers literature, the bulk of the most recent literature on export promotion focus on its relationship to firms' export performance (e.g. Lederman et al., 2010, Freixanet, 2012; Van Biesebroeck et al., 2015). Indeed, the impact of export promotion on export performance have been measured at the firm and country levels. Several empirical studies have been performed to assess the global impact of EPPs (e.g. Lederman et al., 2010; Hayakawa et al., 2014b). Nevertheless, methodological flaws generate inconsistent research findings. Consequently, research interest turned to the impact of EPPs on performance at the firm level.

Studies concerning the impact of EPPs in firms' performance attempted to evaluate specific programs, whereas a few others were carried out to measure the performance of EPPs collectively (Martincus and Carballo, 2010c; Freixanet, 2012). Moreover, EPPs' performance was also evaluated by their adequacy to firms' needs; general perception of their usefulness; degree of their awareness and usage; their indirect effects; and using different performance outcomes.

Despite all the extant literature, empirical evidence to justify the use and evaluate the effectiveness of EPPs on firm export performance remains blurred. The reasons attributed to these results limitations are associated to methodological issues. "In fact, the conceptualization of the relevant constructs and their interrelationships is far from holistic and comprehensive. It is in fact very narrow" (Shamsuddoha et al., 2009b, p.88). Indeed, methodological limitations are among the most relevant challenges in export promotion research and recommendations are made to help scholars to improve future research on the subject, among them, the need to adopt multidimensional measures and to use qualitative techniques.

\section{5.}

\section{Theoretical and Practical Relevance}

This thesis intends to contribute to both the academic literature and public and private management. 


\subsection{1.}

\section{Theoretical Relevance}

Exporting is a central promising area of IB that needs further attention, especially considering the several challenges faced by firms due to the rise of globalization, competition and integration. Export activity presents a complex and dynamic nature, and "as such, systematic attempts aiming to introduce, apply, or even redefine concepts, approaches, and tools are vital in further advancing, expanding, and refining this discipline" (Leonidou and Katsikeas, 2010, p.88).

Interorganizational coordination is a key issue in export promotion programs, but has not been examined in detail in the literature, showing both sides of the problem (firms' and TSIs'). In fact, a recent literature review on exporting (Chabowski et al., 2018), although not considering export promotion as a separate theme in the extant literature, recommends scholars to explore the theme of interorganizational relationships, which "could also be applied in public policy" (p.136). The review also points out that only recently these themes have started to be researched.

Therefore, the theoretical contribution of this $\mathrm{PhD}$ thesis relies on the following aspects:

- First, I confront the literature on export barriers faced by SMEs and export promotion, in order to identify whether the latter has taken into account the problems faced by SMEs in their quest to remove, or reduce, export barriers. I contribute to the literature on exporting by pointing out gaps and commonalities between the two literatures.

- Second, I empirically analyze and point out the mismatch between the firms' needs and the trade support institutions' efforts, and the coordination failures associated to their actions, particularly distrust among firms, and among firms and institutions. 
- Third, I use the literature on interorganizational relationships to examine successful export promotion programs, and reveal to what extent coordination mechanisms may help improve the effectiveness of the networks of TSIs involved in these programs. I theorize on different models of TSI networks, and suggest factors that could explain their adequacy to different country characteristics.

\subsection{2.}

\section{Methodological Relevance}

Research on SMEs' exporting has been largely empirical and descriptive, lacking the theoretical foundations that could guarantee the development of a significant export strategy literature. The same scenario can be observed relatively to export promotion research. Studies on export promotion programs (EPPs) also privileged empirical results over theoretical development and findings on the effectiveness of the services provided were rather mixed and, therefore, inconclusive (Wilkinson and Brouthers, 2006).

It seems that the quantitative research carried out so far on export promotion services has not been able to provide an in-depth understanding of the relationship between export promotion, export barriers and export performance, nor of the processes and strategies pursued by TSIs. Concerning this latter gap, the scarcity of qualitative studies on EPOs (or TSIs) is criticized and its development encouraged by Gillespie and Riddle (2004, p.470), who state that

"... EPO research can be enhanced by in-depth case studies that would fully chronicle how macro- and micro-level variables, such as the EPO institutional environment and EPO's strategic choices, shape an EPO's offerings."

However, more than a decade later, there are very few qualitative studies on EPPs and EPOs, perhaps due to the dominant economic perspective in this research area. 


\subsection{3}

\section{Practical Relevance}

Encouraging expansion and diversification of exports leads to a more dynamic and competitive business environment. An outward oriented economy tends to allocate resources more efficiently, warranting the reduction of the trade deficit, the creation of jobs, the enrichment of business opportunities, the stimulation of technological developments, and the achievement of higher profits (Cavusgil and Yeoh, 1994). In fact, economic growth is fundamental to socioeconomic development. Without generating greater output and income, a country cannot reduce poverty, unemployment, and other important structural shortcomings. These issues are particularly relevant to developing countries and, therefore, the existence of a positive relationship between growth and outward orientation must be taken into consideration when establishing ways to improve living standards. Those are the main motives supporting the practical relevance of researching on export promotion services and systems.

At the same time, understanding how barriers impede the exporting process is crucial in the attempt to understand why and how firms go abroad. Indeed, barriers constitute the basis upon which EPPs are developed and successfully implemented (Kahiya, 2014). By accessing those programs, SMEs may complement their internal firm resources with external capabilities, overcoming several important export barriers, therefore, enhancing the probability of being successful in the international arena. Additionally, SMEs can also profit from the knowledge originated by export barriers literature to develop winning strategies and keep pace with market changes and trends (Kahiya, 2014), reinforcing the practical relevance of the research on export barriers.

The practical relevance of export promotion studies was also supported by Brewer (2009, p.130), who defended his viewpoint about the reasons behind the declining trend of export promotion research and why it should be revived instead:

“...perhaps because of the difficulties in EPP research and the failure of researchers to generate a consensus on outcomes, research in the area has waned significantly over the last several years. This is unfortunate because in a globalizing world the underlying questions of whether to have EPPs, and if so in what form, remain important ones for all governments. Understanding the effectiveness of EPPs is 
also important for firms which would be in a better position to choose to participate or not in such activities".

Finally, public policymakers and TSIs can benefit from the observation of what type of coordination failures may impact their activities, and from the practical cases of TSIs that were successful due to their ability to develop TSI networks to conduct EPPs and coordinate them.

\section{6.}

Research Motivation

During my first year in the Doctoral Program, Apex-Brasil - the Brazilian Trade and Investment Promotion Agency, instituted a research project in collaboration with the Research Center at PUC-Rio to which I am affiliated (NUPIN - Center for International Business Research) to deepen the knowledge of the internationalization process of service companies. I was then personally assigned to investigate EPOs' efforts by leading countries on promoting service companies' internationalization. The experience was extremely rewarding and revealed problems associated to EPOs, as well as to other export promotion issues.

My subsequent engagement as a coach and consultant of an export capacitybuilding program designed by Apex-Brasil to assist particularly SMEs in the preexport stage (PEIEX - Export Qualification Program) ${ }^{5}$, allowed me to dig deeper on the subject, this time from the firms' perspective, further increasing my research interest on the subject.

Those practical experiences dealing with export promotion issues revealed some substantial flaws. The quest for finding answers to mitigate those shortcomings in the economics and IB literatures was frustrating, indicating the need of future research to (i) further explore the interaction between export promotion and export barriers, (ii) examine how to coordinate export promotion

\footnotetext{
${ }^{5}$ PEIEX focuses on disseminating export culture among Brazilian SMEs, enhancing their competitiveness and indicating medium and long terms' efforts necessary to qualify them to operate in foreign markets. This is done by providing coaching and consultancy on best management practices related to strategic management, human resources, finance, marketing, production/services provision and foreign trade.
} 
efforts; and (iii) effectively impact SMEs' export performance, giving birth to this $\mathrm{PhD}$ thesis.

\section{7.}

\section{Structure of the Thesis}

The thesis comprises five chapters. The first one is introductory, presenting the research rationale, context, relevance, motivation, key concepts adopted, and a summary of the pertinent literatures - the export barriers and the export promotion bodies of knowledge, as well as contributions and motivations.

The second chapter consists of an essay - "Export Promotion Services and Firm Export Barriers: Do These Literatures Interact?" - that thoroughly examines the two literatures, presenting their contributions and gaps.

The third chapter presents the essay - "Export Promotion Initiatives in a Cluster" -, which describes how export promotion efforts failed in the evolution of a fashion cluster, and examines the reasons that seem to explain this failure. Particularly, the study looks at coordination failures among firms, and among firms and institutions.

The fourth chapter presents the essay - "The Coordination of Export Promotion Networks for the Creative Industries" -, that examines the different approaches adopted by three successful countries in supporting the internationalization of their creative industries. The study adopts an interorganizational perspective, focusing on network coordination.

The fifth chapter provides the research conclusions, summarizing the contributions of the three essays, emphasizing the theoretical implications of the revealed insights on export promotion services and systems. The chapter closes with reflections on the applicability of the research outcomes and suggestions for future research.

Finally, the sixth chapter presents the Bibliographic References. 


\section{2 \\ Chapter 2 - Essay 1 - Export Promotion Services and Firm Export Barriers: Do These Literatures Interact?}

It has been argued in the introduction chapter that the foundations of this $\mathrm{PhD}$ thesis cover two streams of knowledge: export barriers and export promotion. While the first literature comes mainly from the IB field, the second appears both in the IB and the Economics literatures. This essay thoroughly examines these two streams of studies, which to some extent have developed independently, presents their contributions, identify their gaps, and provides recommendations for future studies.

\section{1.}

\section{Introduction}

Why companies engage in exporting? A myriad of internal and external factors associated with motivations to export are perceived by managers as having a different frequency, intensity, or importance (Leonidou et al., 2007). Some of them systematically seem to perform an important role in enhancing export behavior, despite differences in context, such as the desire to increase sales, profits, and growth; to avoid the troubles of a saturated domestic market; to reduce idle production capacity; to exploit a unique product/service; to decrease home market dependence; and to comply with international unsolicited orders (e.g. Leonidou et al., 2007). These motives are often triggered by the influence of external and internal background factors facilitating or inhibiting export behavior, such as economic scenario, market size, infrastructure availability, corporate goals and strategies, resources at hand, managerial competences and style, among others. In other words, these positive stimuli are considered a necessary, but not sufficient condition to push firms into new international endeavors (Leonidou et al., 2007).

Nevertheless, several other stimulating factors with a lower impact on exports may have a supporting role that should not be despised since they could gain strength under specific circumstances or enhance high impact stimuli (Leonidou et al, 2007). Among those export inducements are those associated to 
export promotion services, such as encouragement by external agents and government export incentives. Indeed, the authors claim that "export stimulation should be seen as the synergistic outcome of a bundle of factors which changes over time and under different conditions" (p. 753). In fact, efforts to increase exports should tackle barriers perceived by managers as impediments to exporting.

The quest that the literature on export barriers should be germane to the export promotion literature, explored by this essay, was supported by some academic researchers. Kahiya (2014), for example, stated that the study of export barriers

“... develops a dais for understanding the problems that inhibit current exporters from sustaining profitable operations in overseas markets. With this wealth of knowledge, various stakeholders can develop need-based stimuli to encourage nonexporters to participate in export development or to equip current exporters with the resources and assets fundamental to long-term international success (p. 333”).

\section{2. \\ Barriers in Exporting Research}

Export barriers are largely defined by the related literature as "any attitudinal, structural, operative or other obstacles that hinder or inhibit companies from taking the decision to start, develop or maintain international activity" (Leonidou 1995a, p. 31). More recently, drawing on the extensive literature about the subject, Arteaga-Ortiz and Fernández-Ortiz (2010) restated this definition, affirming that these obstacles could be described as any element or factor originated internally or externally that impede, through concretely blocking or simply discouraging, firms from engaging and maintaining export endeavors.

Some international trade barriers can be seen as intrinsic to the nature of SMEs. From the firm-level perspective, SMEs have to put up with the liabilities of newness and smallness, while in the international arena they have to struggle with the liabilities of foreignness and outsidership (Stinchcombe 1965; Hannan and Freeman, 1984; Zaheer, 1995; Johanson and Vahlne, 2009; Kahyia, 2014).

However, similarly to what occurs with export stimuli, export barriers alone are not capable to discourage foreign trade. What turns these latent constraints into 
concrete obstacles is the presence of other factors normally associated with distinctive characteristics of the owner-managers, the organization, and the context in which the firm abides (Barrett and Wilkinson, 1985; Leonidou, 2004). In other words, some barriers originate within the organization, that is, internally, and others spring from the context in which the firm is embedded, that is, externally. In the specific case of external barriers, their locus can be the home country as well as the host country.

Barriers in exporting research has its roots in the late 1960s and early 1970 s but it was only in the eighties and nineties that it really blossomed. A literature review on the subject was carried out searching through the main bibliographic databases such as Ebsco, Emerald, Jstor, SciELO, ScienceDirect, Scopus, Web of Science, and other resources available as Google Scholar, assuring that it covered the whole scientific production of the twelve major journals related to International Business (Arenaro e Mello Dias et al., 2014), namely: Academy of Management Journal, International Business Review, International Marketing Review, Journal of Business Research, Journal of International Business Studies, Journal of International Management, Journal of International Marketing, Journal of Management, Journal of Management Studies, Journal of World Business, Management International Review, and Strategic Management Journal. The keywords used in the search were "export barriers", "exporting barriers", "barriers to export", "barriers to exporting", "trade barriers", "barriers to internationalization", “export constraints", "export impediments", "export inhibitors", "export hindrances", "export stimuli". Additionally, the search result was compared with a list of 120 articles published on the topic between 1967 and 2015 prepared by Professor Eldrede T. Kahyia, at Victoria University of Wellington, New Zealand, whose research interests include export barriers, and has recently published several articles related to the theme. The analysis of the literature produced in the last half century, totaling 130 peer-reviewed articles published in English. The topics are organized according to the issues presented in the theoretical and empirical literature on export barriers. 


\subsection{1.}

\section{Barriers Perceived by Exporters and Non-Exporters}

Barriers were examined from the perspective of current exporters, but also from the point of view of non-exporters, that is, those who actually never exported or exported only marginally, but also including those who had already exported and, for some reason, had quitted foreign trade. The study of these multiple perspectives brought to light two main types of export barriers - those related to problems deterring firms from engaging in foreign trade and those associated with problems encountered by firms that already operate internationally (Cavusgil et al., 1979; Tesar and Terleton, 1982; Yaprak, 1985; Kedia and Chhokar, 1986; Burton and Schlegelmilch, 1987; Cavusgil and Naor, 1987; Cheong and Chong, 1988; Hook and Czinkota, 1988; Keng and Jiuan, 1989; Leonidou, 1995b; Kaleka and Katsikeas, 1995; Campbell, 1996; Morgan, 1997; Pinho and Martins, 2010; Katsikeas and Morgan, 1994; Morgan and Katsikeas, 1998; Sharkey et al. 1989; Shaw and Darroch, 2004). Barriers acknowledged by non-exporters are essentially subjective and perceptual, since they correspond to the owner-manager's beliefs and vision towards the subject (Leonidou, 2004; Uner, 2013). On the other hand, barriers reported by actual exporters tend to refer to problems experienced on their current international activities, whereas firms that abandoned their international operations apprehend export barriers both from perceptions and actual experience (Leonidou, 2004).

The main difference from barriers encountered by non-exporters and exporters, as it might be expected, was that the first ones complained especially about issues related to attitudinal obstacles as well as structural and informational constraints (e.g. hurdles to obtain initial financing, lack of information about exporting and foreign markets, and absence of contacts abroad), while the latter indicated mainly barriers associated with procedural and operational matters (e.g. excess of bureaucracy, transport difficulties, lack of trained personnel, shortage of export incentives and working capital) (Kedia and Chhokar, 1986; Leonidou, 1995b). Another interesting result from a pioneer study carried out by Bilkey and Tesar (1977) was that exporters who intentionally embraced export operations 
acknowledged relatively fewer barriers in comparison to those whose operations were restricted to complying with unsolicited orders.

\subsection{2.}

\section{Export Barriers and the Temporal Dimension}

Barriers can be identified all along the internationalization process. Their nature, frequency, intensity and importance vary from stage to stage. Furthermore, barriers differ also among firms in the same export stage (Pavord and Bogart, 1975; Johanson and Wiedersheim-Paul, 1975; Bilkey and Tesar, 1977; Bilkey, 1978; Cavusgil and Nevin, 1980; Cavusgil, 1982; Czinkota, 1982; Tesar and Tarleton, 1982; Thomas and Araujo, 1985; Barrett and Wilkinson, 1985; Ford and Leonidou, 1991; Leonidou, 1995b; Suarez-Ortega, 2003). These findings highlight the dynamic nature of barriers. Indeed, distinctive barriers presented in each stage can even prevent firms to move on to subsequent stages. This phenomenon is essentially due to firms' idiosyncrasies associated to managerial and organizational aspects. These firms' distinctive characteristics are not only responsible for differentiating barriers across stages, but also among firms, that is, each case is unique and companies in the same internationalization stage can perceive distinct barriers.

Another aspect explored by some scholars is the temporal dimension. Some longitudinal studies assess the influence of export barriers over time, assuming that the institutional environment, for the good or for the bad, played a role on internationalization. (Christensen et al., 1987; Tesar and Moini, 1998). Da Rocha et al. (2008) show a considerable stability of barriers' perception over time. Kahiya et al. (2014), instead, found that their influence changes considerably over time, suggesting that when a negative mood prevails in the export sector, barriers tend to be overestimated. Similarly, Da Rocha et al. (2008) also indicate that barriers may be more severely perceived during periods of economic decline. 


\subsection{3.}

\section{Types of Export Barriers}

In the quest to better understand export barriers faced by SMEs, scholars engendered various classification schemes. The main criterion used for this purpose was whether they originate inside or outside the organization's boundaries. Export barriers are then mainly classified as internal or external to the organization. Some researchers go further, separating external barriers into those associated with the country of origin or with the host country (Cavusgil and Nevin, 1981; Cavusgil, 1984a; Cavusgil, 1984b; Gripsrud, 1990; Cavusgil and Yeoh, 1994; Cavusgil and Zou, 1994; Leonidou, 1995a; Morgan, 1997; Tesfom and Lutz, 2006).

Moreover, classification addressed also the nature of the export barriers (Alexandrides, 1971; Pavord and Bogart, 1975; Bilkey and Tesar, 1977; Bilkey, 1978; Rabino, 1980; Tesar and Terleton, 1982; Albaum, 1983; Kaynak and Kothari, 1984; Cavusgil, 1984a; 1984b; Yaprak, 1985; Bauerschmidt et al., 1985; Kedia and Chhokar, 1986; Bodur, 1986; Karafakioglu, 1986; Edmunds and Khoury, 1986; Kaynak et al., 1987; Christensen et al., 1987; Hook and Czinkota, 1988; Miesenbock, 1988; Ghauri and Kumar, 1989; Keng and Jiuan, 1989; Sullivan and Bauerschmidt, 1989; Gripsrud, 1990; Tseng and Yu, 1991; Barker and Kaynak, 1992; Yang et al., 1992; Morgan, 1997; Morgan and Katsikeas, 1997; Leonidou, 2004; Shaw and Darroch, 2004; Tesfom and Lutz, 2006; Da Rocha et al., 2008; Pinho and Martins, 2010).

Leonidou (2004) categorize internal barriers as functional, informational, and marketing-related, whereas external barriers are systematized as procedural, governmental, task-related, and environmental. Table 1 presents Leonidou's detailed breakdown of export barriers into these categories. 
Table 1 - Classification of Export Barriers according to Leonidou

\begin{tabular}{|c|c|c|c|c|}
\hline \multirow{38}{*}{ Barriers } & \multirow{24}{*}{ Internal } & \multirow{4}{*}{\multicolumn{2}{|c|}{ Informational }} & Limited information to locale/analyze markets \\
\hline & & & & Problematic international market data \\
\hline & & & & Identifying foreign business opportunities \\
\hline & & & & Inability to contact overseas customers \\
\hline & & \multirow{4}{*}{\multicolumn{2}{|c|}{ Functional }} & Lack of managerial time to deal with exports \\
\hline & & & & Inadequate/untrained personnel for exporting \\
\hline & & & & Lack of excess production capacity for exporters \\
\hline & & & & Shortage of working capital to finance exports \\
\hline & & \multirow{16}{*}{ Marketing } & \multirow{5}{*}{ Product } & Developing new products for foreign markets \\
\hline & & & & Adapting export product design/style \\
\hline & & & & Meeting export product quality standards/specs \\
\hline & & & & Meeting export packaging/labeling requirements \\
\hline & & & & Offering technical/aftersales service \\
\hline & & & \multirow{3}{*}{ Price } & Offering satisfactory prices to customers \\
\hline & & & & Difficulty in matching competitors' prices \\
\hline & & & & Granting credit facilities to foreign customers \\
\hline & & & \multirow{5}{*}{ Distribuition } & Complexity of foreign distribution channels \\
\hline & & & & Accessing export distribuition channels \\
\hline & & & & Obtaining reliable foreign representation \\
\hline & & & & Maintaining control over foreign middleman \\
\hline & & & & Difficulty in supplying inventory abroad \\
\hline & & & \multirow{2}{*}{ Logistics } & Unavailability of warehousing facilities abroad \\
\hline & & & & Excessive transportation/insurance costs \\
\hline & & & Promotion & Adjusting export promotional activities \\
\hline & \multirow{14}{*}{ External } & \multirow{3}{*}{\multicolumn{2}{|c|}{ Procedural }} & Unfamiliar exporting procedures/paperwork \\
\hline & & & & Problematic communication with overseas customers \\
\hline & & & & Slow collection of payments from abroad \\
\hline & & \multirow{2}{*}{\multicolumn{2}{|c|}{ Governmental }} & Lack of home government assistance/incentives \\
\hline & & & & Unfavorable home rules and regulations \\
\hline & & \multirow{2}{*}{\multicolumn{2}{|c|}{ Task }} & Different foreign customer habits/attitudes \\
\hline & & & & Keen competition in overseas markets \\
\hline & & \multirow{7}{*}{ Environmenta } & \multirow{2}{*}{ Economic } & Poor/deteriorating economic conditions abroad \\
\hline & & & & Foreign currency exchange risks \\
\hline & & & \multirow{2}{*}{ Political-Legal } & Political instability in foreign markets \\
\hline & & & & Strict foreign rules and regulations \\
\hline & & & \multirow{3}{*}{ Socialcultural } & Unfamiliar foreign business practices \\
\hline & & & & Different socialcultural traits \\
\hline & & & & Verbal/nonberbal language differences \\
\hline
\end{tabular}

Source: Leonidou, 2004, p. 283.

Finally, Arteaga-Ortiz and Fernandez-Ortiz (2010), considering the heterogeneity of classifications in the extant literature, made an attempt to homogenize export barriers measurement, clustering them into four generic categories: knowledge, resource, procedure, and exogenous. Table 2 shows these groups in detail. 
Table 2 - Classification of Export Barriers according to Arteaga-Ortiz and Fernández-Ortiz (2010)

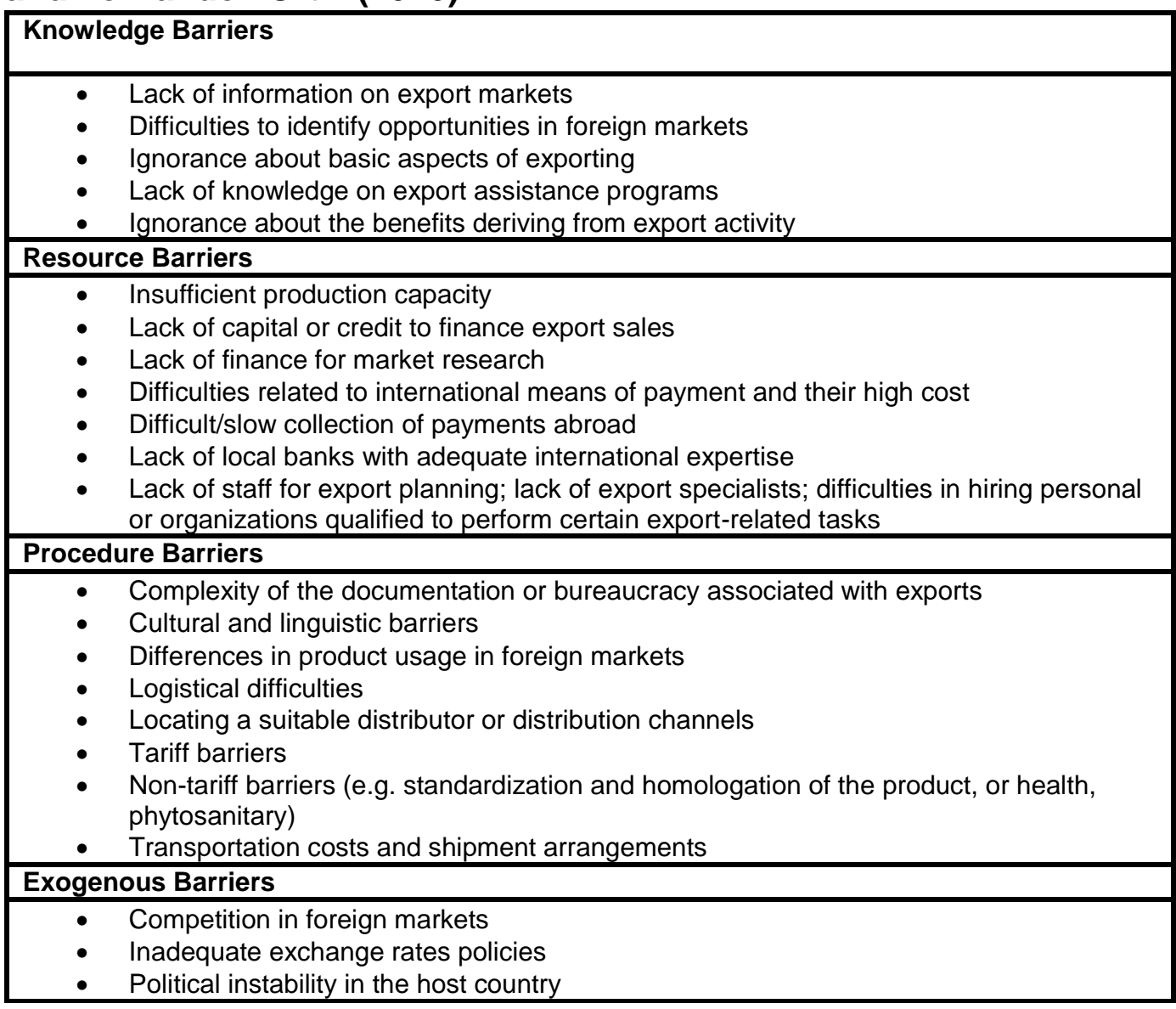

Source: Organized by the author based on Arteaga-Ortiz and Fernandez-Ortiz (2010)

Besides, some firm characteristics that have the potential to influence export barriers are firm age, firm size, firm ownership, export orientation, export experience and frequency of exports (Korth 1991; Shoham and and Albaum, 1995; Campbell, 1996; Leonidou, 2000; Da Silva and Da Rocha, 2001; Hornby et al., 2002; Barnes et al., 2006; López, 2007; Welch et al., 2008; Kahiya, 2013).

Another distinction has to do with the country's level of development; firms from different from different socio-economic contexts may face different barriers. Several studies have been conducted on this assumption (Kahler and Kramer, 1977; Colaiacovo, 1982; Bodur, 1986; Karafakioglu, 1986; Figueiredo and Almeida, 1988; Weaver and Pak, 1990; Brooks and Frances, 1991; Karakaya and Stahl, 1991; Kaleka and Katsikeas, 1995; Burgess and Oldenboom, 1997; Karakaya and Harcar, 1999; Smith et al., 2006; Tesfom and Lutz, 2006; Ahmed et al., 2008; Altintas et al., 2007; Doern, 2009; Köksal and Kettaneh, 2011; Saeed and Vincent, 2011; Adu- 
Gyamfi and Korneliussen, 2013; Uner et al., 2013). Some of the barriers that seem to grieve firms from developing countries are cultural (Kahler and Kramer, 1977; Karakaya and Stahl, 1991); related to product quality acceptance and logistics management (Neupert et al., 2006); originating from financial inhibitors (Ahmed et al., 2008) and, more generally, resulting from the lack of resource commitment (Adu-Gyamfi and Korneliussen, 2013).

A literature review by Tesfom and Lutz (2006) covered the period 19802004 with the aim of classifying export barriers encountered by manufacturing SMEs from developing countries. They conclude that export barriers faced by these firms are multi-dimensional and closely interrelated, suggesting to categorize them into internal barriers (comprising company barriers and product barriers) and external barriers (industry barriers, export barriers and macro environment barriers). Nonetheless, the results of their study led to the conclusion that export barriers faced by manufacturing SMEs in developed and developing countries were very much similar.

Investigating whether diverse cultural settings can generate different barriers, Kaynak and Kothari (1983) are among the first to consider cross-cultural differences associated with export barriers. Later, some other scholars (e.g. Sullivan and Bauerschmidt,1989; Smith et al., 2006) also addressed this issue.

\subsection{4.}

\section{Relative Importance of Export Barriers}

In a review of 35 empirical studies on the impact of export barriers in developed countries (USA and European countries) and emerging Asian economies, Leonidou (1995a) concludes that informational barriers (availability of restricted knowledge on foreign markets) seemed to be the most discouraging barrier for SMEs. This finding was later supported by Julien and Ramangalahy (2003), who point out that research conducted in the prior two decades blamed the lack of SMEs involvement and success in exports ventures to their inability to obtain information and acquire knowledge on foreign markets. 
Despite the advancement of communication technologies, information incompleteness continues to be a hindrance to firms desiring to expand abroad. Nevertheless, international networks seem to unburden the costs of acquisition of information on foreign markets and operations during the firm's export decision process (Gil-Pareja et al., 2014). In fact, the literature on international business networks indicates that information-sharing networks can overcome export barriers among diasporic ethnic minorities or business groups (Rauch, 2001; Anderson and Marcouiller, 2002).

Research findings also indicate that export barriers tend to be more relevant when SMEs try to enter a new foreign market or attempt to introduce a new product (extensive margins) than when they experiment increasing sales of a previously exported product or try to expand their international activities in countries to which they already export (intensive margins) (Martincus and Carballo, 2010a; 2010b; Gil-Pareja et al., 2014). Martincus and Carballo (2010b, p.439) explained that

“...when exporting to a new destination, firms must learn, among other things, about the alternative ways and respective costs of shipping their merchandise, the tariffs/nontariff measures, and technical regulations applied on their goods, both for the home country and for competing countries; domestic consumer preferences relevant for the salability of the good to be traded; the distribution channels, in general, and potential business partners, in particular; and the main marketing strategy of incumbent firms" (p.439).

The authors conclude that gathering all this information demanded performing costly market-specific studies that can prevent firms from pursuing their new foreign endeavors. The lack of information seems also to be more disturbing when exporting differentiated products.

\subsection{5.}

\section{Export Barriers and Export Performance}

The relationship between export barriers and export performance has been considerably investigated (Bauerschmidt et al., 1985; Christensen et al., 1987; Aaby and Slater, 1989; Barker and Kaynak, 1992; Katsikeas, 1996; Leonidou, 1995a; 1995b; 2000; Moini, 1997; Zou and Stan, 1998; Dosoglu-Guner, 1999; Julian and Ahmed, 2005). Altintas et al. (2007), examining SMEs in Turkey, find that certain barriers have more effective impact on export performance than others, such as 
procedural barriers and competition in foreign markets. Mavrogiannis et al. (2008), studying the Greek food and beverage industry, establish that trade barriers and export problems are among the determinants of export performance. Al-Hyari et al. (2012) determine that economic, political, legal, governmental, financial, and informational barriers have a significant negative impact on the export performance of SMEs in Jordan. Karakaya and Yannopoulos (2012) confirm that higher export barriers led to lower export performance and that the most important barrier to export performance is the lack of firm competence. Moreover, although not affecting export performance directly, export support activities have an indirect impact, reducing the barriers. Another study conducted by Stoian and Rialp-Criado (2010) suggest that managerial characteristics may play the role of export barriers and impact export performance. Bianchi and Wickramasekera (2013), while investigating Chilean wineries, assess that exchange rate variability, problems in selecting reliable distribution channels, and limited government support are the major hindrances to firms' export performance. Finally, researching upon the impact of resource commitment, management experience, firm size, and internationalization on export performance, using internal export barriers as an intervening variable, Adu-Gyamfi and Korneliussen (2013) surprisingly show that internal export barriers are positively related to export performance.

\subsection{6. \\ Gaps in the Export Barriers Literature}

The examination of the export barriers literature provides several insights as to its strengths and weaknesses. In this section, some of the gaps in the extant literature are highlighted.

Although many studies on export barriers have been carried out, they show important inconsistencies, due to several reasons. The most relevant is the absence of a sound theoretical base backing up the majority of the literature produced to this date (Kahiya, 2013). Such literature can be considered essentially phenomenabased, which is not unusual in several areas of research in business. For example, Beamish and Lupton (2016) show that part of the research on cooperative business strategies is grounded on phenomena-based research. 
Other flaws relate to differences in context - geographic focus, industry focus, type of firm, type of product, time frame - and differences in research methods (Da Rocha et al., 2008). Despite the efforts of Arteaga-Ortiz and Fernández-Ortiz (2010) to improve the measurement of the export barriers construct, proposing and validating a standardized export barriers scale, there is no measure commonly adopted, thus preventing comparison of results. Another important inaccuracy of export barriers' research is that the bulk of studies concentrates on the perceived dimensions of export barriers, without taking into consideration that perceived and actual barriers do not necessarily match. Indeed, according to Kedia and Chhokar (1986), a barrier considered very important for exporting is not inexorably a major problem for the firm. Equally troublesome is the fact that the majority of the studies are cross-sectional, disregarding the evolutionary character of export barriers (Bell, 1997; Doern, 2009; Kahiya, 2013).

In addition, one of the earliest studies that empirically investigated export barriers, conducted by Alexandrides (1971), already stressed the fact that barriers also varied among industries, that is, many barriers are industry-specific, as later shown by Kedia and Chhokar (1986) and Cheong and Chong (1988). Bell (1997) affirms that many existing sector-specific studies targeted traditional industries, mainly manufacturing ones, setting aside vital industries to post-industrialized economies, such as high-technology and service sectors.

Also, although the geographic scope of empirical studies has been enlarged in recent years, there are still gaps related to export barriers research of emerging countries, since most analyze firms from the United States and from European countries. Besides, cross-national investigations are still very limited (exceptions are Tesfom and Lutz, 2006; Doern, 2009; Saeed and Vincent, 2011; Uner et al., 2013).

More recently, the analysis of the impact of export barriers on International New Ventures (INVs) and Born Globals (BGs) attracted the interest of some scholars (e.g. Uner et al., 2013; Baum et al., 2013; Kahiya, 2013). Baum et al. (2013) conclude that some determinants of international new venturing varied 
depending on the perceived barriers to internationalization. Until then, research on barriers to internationalization was mainly restricted to the direct effects imposed by the potential obstacles to firm growth or firm internationalization. This investigation examined variables that moderate the impact of export barriers. Likewise, Kahiya (2014) suggests another potential effect of export barriers, advocating that export barriers condition the path of internationalization and thus should be modeled as a predictor rather than a dependent variable.

Some scholars believe that the shortcomings in export barriers research in the methodological choices. Kamath et al. (1986) state that the prevalence of logical-empiricist methodologies is responsible for producing incomplete and sometimes even inaccurate insights about the phenomenon. This belief was also shared by Bell (1997, p.592) who advocate that positivist methodologies and especially the use of mail surveys "often fail to provide deeper insights on their nature, underlying causes and ultimate effects", and recommended the adoption of methodological pluralism. Doern (2009, p.275), more than a decade later, insisted on the adoption of "a more rounded methodology" and a qualitative perspective, suggesting the need of "shifting the focus away from prediction to understanding, and away from quantifying what kinds of barriers affect growth to exploring how barriers may influence growth intentions and behaviours."

\subsection{7.}

\section{Summary of the Export Barriers Literature}

Figure 1 summarizes the export barriers literature. As described earlier, the bulk of the literature on export barriers is focused on describing the most important barriers and the relationship of these barriers with specific variables. 


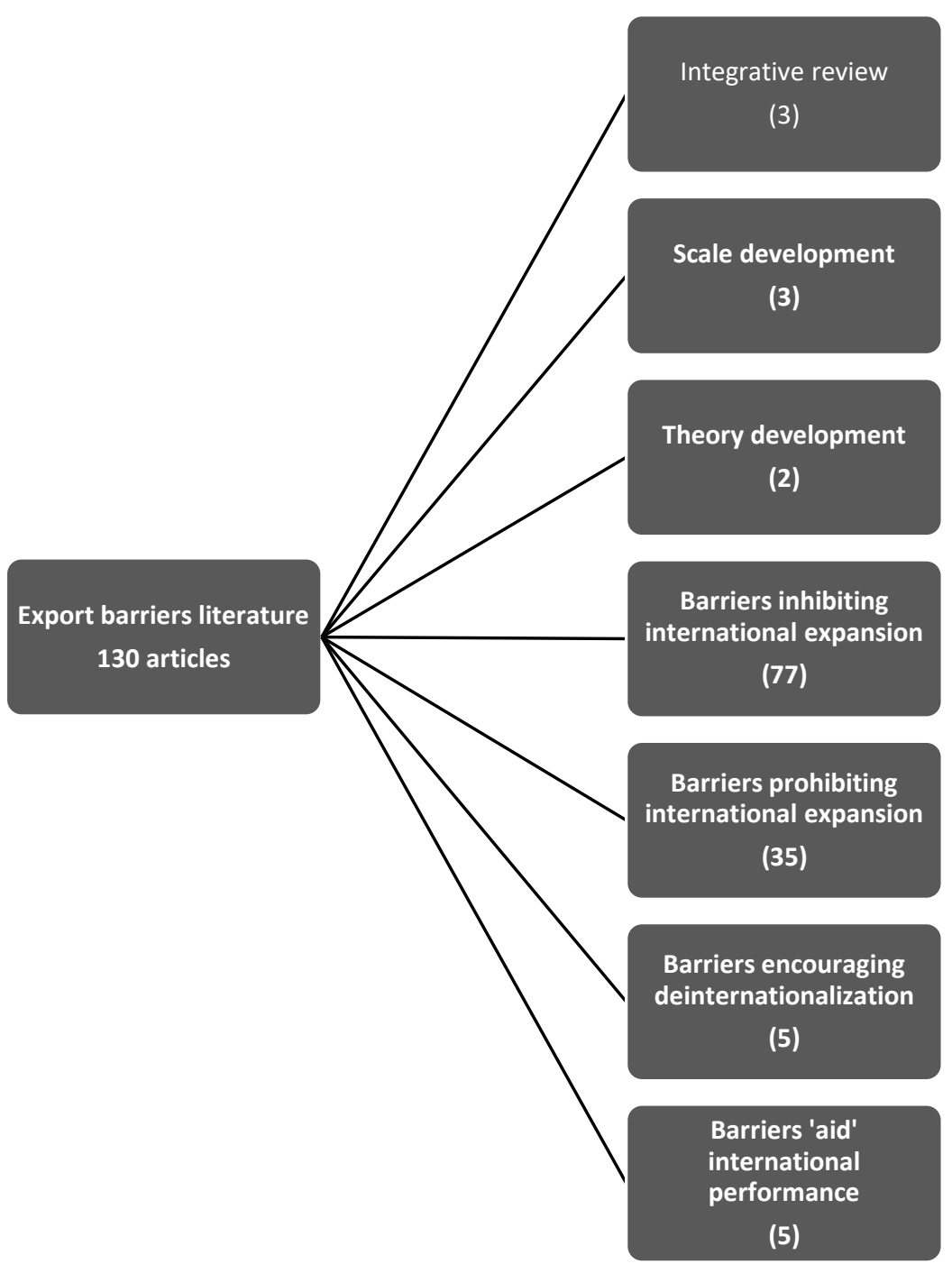

Figure 1 - Thematic overview of export barriers research Source: Adapted from Kahiya, 2017, p. 66

\section{3.}

\section{The Export Promotion Literature}

Broadly, export promotion programs (EPPs) can be viewed as public-private partnerships, in which the initiative of going abroad is provided by the private sector, whereas the public sector is in charge of offering the necessary support to fully operationalize it (Cavusgil and Yeoh, 1994; Miocevic, 2013). EPPs comprise financial and non-financial services. Lederman et al. (2010) suggested that they could be divided into four main categories:

“...1) country image building (advertising, promotional events, but also advocacy); 2) export support services (exporter training, technical assistance, capacity building, including regulatory compliance, information on trade finance, logistics, customs, packaging, pricing); 3) marketing (trade fairs, exporter and importer missions, follow-up services offered by representatives abroad); and 4) market 
research and publications (general, sector, and firm level information, such as market surveys, on-line information on export markets, publications encouraging firms to export, importer and exporter contact databases) [p.257]."

The main purpose of EPPs is to help companies, especially SMEs, to tame export barriers (Wilkinson and Brouthers, 2006; Ayob and Freixanet, 2014), stimulating their internationalization process. They are usually delivered by government agents, trade associations and other private organizations which “...act as catalysts, as often they are the first to trigger change and, in the process, provide direction and support for continuous improvement and further adaptation to new markets (Lefebvre et al., 2003, p.464)."

The literature suggests that the use of export promotion programs enhances firms' informational and experiential knowledge (Kotabe and Czinkota, 1992; Singer and Czinkota, 1994; Shamsuddoha et al., 2009a), encourages managers' positive attitudes and perceptions toward international ventures and boosts export commitment (Singer and Czinkota, 1994; Shamsuddoha et al., 2009a;). Indeed, EPPs can be interpreted as sources of educational knowledge which fill the gap of SMEs internal resources toward achieving their export goals (Shamsuddoha et al., 2009a).

Lederman et al. (2010) advocates that the need for export promotion is greater when export barriers are high. Additionally, reinforcing the findings of export barriers' literature, the extant research on export promotion services indicates that barriers to become a player in the international arena are consistently higher for SMEs than for larger companies. More specifically, studies on export promotion also disclose informational barriers as the primary source of trouble to SMEs willing to get involved in international business, although other obstacles are also revealed, such as capital scarcity, limited management skills, and several other barriers raised by well-established firms and by governments (e.g. Lefebvre, 2003; Tesfom and Lutz, 2008; Ayob and Freixanet, 2014).

Moreover, the effects of export promotion appear to vary along several dimensions. According to Martincus and Carballo (2010a, p.203), "in general, the 
strength of these effects is likely to be related to the severity of the information problems involved in the specific trading operations."

Since the 1960s, the urge to understand different aspects of export promotion has motivated much research interest in the field, but similar to what happened to the export barriers literature, it was only in the nineties that it really evolved. In general, the efforts made by researchers to advance knowledge on export promotion can be classified into three main categories:

- Theoretical and methodological development, i.e., discussions of prescriptive nature aimed at formulators of public policies;

- Empirical research dedicated to the development of methodologies for firms' segmentation to unveil the most adequate type of assistance, and;

- Methodological investigations focused on the evaluation of export promotion programs and instruments.

Figure 2 basically synthesized the evolution of export promotion literature through the sixties until nowadays (Faroque and Takahashi, 2012, p.6)

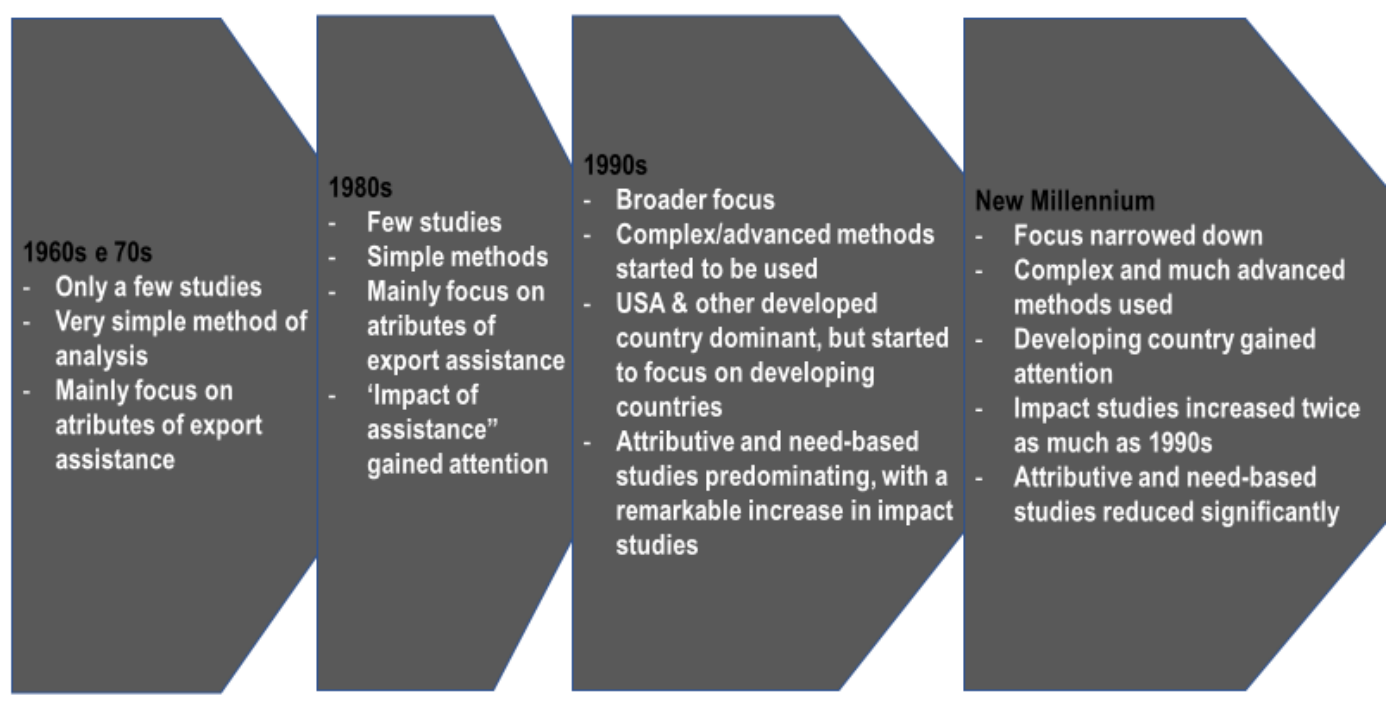

Figure 2- Chronological development of the export promotion literature

Source: adapted from Faroque and Takahashi, 2012 
The literature review on export promotion was carried out searching the main bibliographic databases, such as Web of Science that encompasses most journals with high-impact factors associated to International Business research (Arenaro e Mello Dias et al., 2014), as well as using cross reference search, for the period between 1990 and 2018. Keywords employed comprised "export promotion", "export assistance", "export support", "trade promotion", "trade assistance", "trade support", "export promotion program(me)s", "export promotion agency(ies)", "export promotion organization(s)", "trade promotion organization(s)", "trade support institution(s)". The literature review resulted in around 80 peer-reviewed articles, published in English, including seminal works published before the search period. The analysis of this literature and its main findings are presented next.

\subsection{1. \\ Export Promotion for Exporters and Non-Exporters and the Temporal Dimension}

Similar to the export barriers literature, the literature on export promotion takes into consideration a temporal dimension, that is, the different stages of a firm's export development, including the pre-export stage, i.e. non-exporters.

The literature points out that during the pre-export stage, information and training are fundamental to generate interest in going overseas (Bilkey, 1978; Wiedersheim- Paul, Olson, and Welch, 1978; Morgan and Katsikeas, 1997; Ayob and Freixanet, 2014). The need to improve exporting knowledge, methods and practices - such as to develop foreign market channels, to adapt products and services to foreign consumers' preferences, to learn how to deal with customs procedures and to prepare documents - call for managerial and technical training. In addition, trade fairs, trade missions, and business matching are some examples of EPPs to encourage potential and current exporters to expand abroad, by offering firms the possibility of approaching foreign markets, meeting interested buyers and receiving foreign orders (Wilkinson and Brouthers, 2006; Ayob and Freixanet, 2014). 
In addition to non-financial support, some EPPs also offer financial assistance. The availability of capital to finance SME exporting in its early stages can be paramount to allow those firms to enter foreign markets. However, as indicated by Ayob and Freixanet (2014), commercial banks do not provide loans to most SMEs. Besides, the authors recall that financial support offered through direct and indirect subsidies, such as favorable exchange rate and fiscal incentives, can also play an important role in stimulating new foreign endeavors.

While the need for public assistance may decrease over time, as new exporters evolve in their internationalization process, becoming regular exporters, some support will still be needed to overcome inevitable daily export barriers. According to Ayob and Freixanet $(2014$, p.40), “...continuous assistance from the government, especially on the marketing aspects, will ensure that exporters are able to reach the next stage in the internationalization process and prevent export withdrawal."

Despite consensus in this literature that EPPs should be tailored according to SMEs' specific needs, it seems that very few of these programs are designed to address the different phases of their export development (Lefebvre et al., 2003).

\subsection{2.}

\section{Impact of Export Promotion on Export Performance}

There are many reasons justifying the need to carry out a comprehensive and accurate assessment of EPPs' performance, and by extension, of TSIs. For Freixanet (2012, p.1.066),

"The first motivation is the need to help export promotion organizations (EPOs) to improve program design, adapt programs to company requirements and create better implementation procedures. The second motivation is the importance of increasing EPPs' credibility in the eyes both of public opinion and of governments, which ultimately finance export promotion. Finally it is necessary to give company managers information about the role programs can play in their organizations ( $\mathrm{p}$. 1.066)".

Attempts to measure the impact of export promotion on export performance have been done at the firm and country levels. Several empirical studies have been carried out to produce macro and aggregate evaluations of the global impact of 
EPPs (e.g. Mathur and Mathur, 1997; Mah, 2007; Lederman et al., 2010; Kang, 2011; Hayakawa et al., 2014b; Gil-Pareja et al., 2014; Van Biesebroeck et al., 2015). However, “establishing a causal link between EPO services and national export growth has proved problematic" (Gillespie and Riddle, p. 463). The authors blame methodological weaknesses for inconsistent research findings. To begin with, since not all firms make use of EPO services, it is not possible to obtain trade statistics discriminating firms that use EPOs' services of those that do not. Moreover, the huge number of variables and environmental factors involved in different economic scenarios interferes in national exports figures, making it difficult to attain valid and reliable research results. As a consequence, scholars turned their efforts to measuring the impact of EPPs on performance at the firm level.

A substantial number of studies concerning the impact of EPPs on firms' performance attempted to evaluate specific programs (e.g. Brouthers and Wilkinson, 2006; Brewer, 2009; Creusen and Lejour, 2013; Gil-Pareja et al., 2015). On the other hand, some efforts were also made to measure the performance of EPPs collectively, using different methodologies, varying from surveys to costbenefit analysis and causal inference techniques (e.g. Pointon, 1978; Freixanet, 2012).

According to Freixanet (2012), EPPs' performance was also appraised by their adequacy to firms' needs (e.g. Crick, 1995; Naidu and Rao, 1993); general perception of their usefulness (e.g. Clarke, 1991); degree of their awareness and usage (e.g. Martanges and Van Gent, 1991; Kanda et al., 2015; Ayob and Freixanet, 2014); and their indirect effect on other variables (e. g. Crick and Chaudhry, 1997). Moreover, the literature also provides studies that assess EPPs' impact using different performance results (Francis and Collins-Dodd, 2004; Calderón and Fayos, 2004), and, more recently, investigates the link between network promotion role of EPPs and SMEs' export performance (e.g. Haddoud et al., 2017).

Despite all these research efforts, empirical evidence to validate the use and appraise the effectiveness of EPPs, in terms of export performance, continues to be conflicting and limited (Lages and Montgomery, 2005; Shamsuddoha et al., 2009a; 
Freixanet, 2012). Freixanet (2012, p.1.066) points out that while some studies indicate that EPPs play an important role in assisting firms to overcome export barriers,

"... other studies show that there is a mismatch between company needs and government assistance priorities, based on managers' perceptions; that there is no clear relationship between programs and export performance; or that companies have little awareness of programs altogether and do not use them."

According to the author, the reasons behind these conflicting results are related to difficulties of measuring and comparing EPPs' impact. To overcome them, he recommends the following methodological adjustments:

- The use of multidimensional performance outcomes including both objective results and managers' perceptions;

- The use of contrast groups consisting of samples stratified ex ante with the necessary number of firms representing different typologies: industry, size, or international involvement segmentation;

- The need to differentiate between EPPs and TSIs, considering the differences in content and objectives among distinct EPPs;

- The carrying out of longitudinal studies with a long enough time lag (in view of the need to consider a time lag between the start of the EPP and the materialization of its effects).

Brewer (2009) brings up some other challenges in assessing the impact of specific EPPs: (1) the fact that typically they do not present self-stated, objectively measurable performance indicators; (2) presumed EPP's objectives may not be relevant to a country's macroeconomic interests, indicating the need to observe the actual goals of EPPs' managers (e.g., usefulness for firms does not necessarily positively impacts foreign trade balance); and lastly (3) the assumption that as EPPs' managers do not wish to be related to unsuccessful ventures, trade missions, for example, will tend to be organized around already successful firms, products and markets, casting doubts about their actual effectiveness. The author concludes 
that "...there needs to be a much more closer connection between attempts at empirical measurement and actual stated EPP program objectives (p.128)."

In fact, regarding the operationalization of export performance, Tesfom and Lutz (2008, p.365) argue that "export promotion services will not automatically result in firm sales but rather in increased knowledge and competence concerning export market development".

Concerning the need to acknowledge the different types of firms, some studies propose that the stage of export involvement directly affects the relationship between EPP's use and export performance, and therefore this critical variable should be taken into consideration when designing EPPs (Freixanet, 2012). In a similar vein, some studies have investigated EPPs' impact on the performance of SMEs from developing countries (e.g. Durmusoglu et al., 2011; Martincus et al., 2012).

Finally, although not very recent, it is worth mentioning Gillespie and Riddle's (2004), which examines the role of EPOs and suggest different methodological approaches to examine the problem.

\section{4.}

\section{Trade Support Institutions (TSIs)}

Most empirical research concerning TSIs essentially investigate their ability to generate awareness and use of EPPs to increase firms' export performance (Gillespie and Riddle, 2004). Additionally, some very few studies have attempted to measure the impact of TSIs and their strategies on national exports, as the one by Lederman et al. (2010) showing a statistically significant effect on exports of 103 developing and developed countries. Their study stresses the relevance of TSIs' services in overcoming informational barriers. According to Gil-Pareja et al. (2014), investments in gathering information generate positive externalities and, therefore, justify the allocation of resources in TSIs. Nevertheless, Lederman et al. (2010) indicate that the return tends to diminish as export promotion investments significantly increase. 
Regarding organizational arrangements, strategic approaches, goals and activities performed, TSIs may differ considerably across countries. Support services can be offered by public organizations, private institutions, or a combination of both (Tesfom and Lutz, 2008). Lederman et al. (2010), for example, suggest that TSIs "...should have a large share of the executive board in the hands of the private sector, but a large share of their budget should be publicly funded.... Moreover, for them, "the proliferation of small agencies within a country leads to an overall less effective program" (p. 258).

Other research findings about the effectiveness of TSIs indicate that their services tend to be more effective in the presence of high market entry barriers (Lederman et al., 2010) and when they promote the increase of the extensive margin of exports of more differentiated goods, i.e., facilitate export diversification (Martincus et al., 2010b).

Nevertheless, empirical evidence on the effectiveness of TSIs is still scarce and considerably partial. Indeed, several factors hinder the assessment of these institutions' effectiveness. This difficulty appears to be even more prominent in the case of TSIs in developing countries (e.g. Tesfom and Lutz, 2008; Lederman et al., 2010). Tesfom and Lutz (2008) associate these obstacles to the lack of well-defined goals, the insufficiency of credible statistics, and causal ambiguity. Cavusgil and Zou (1994) and Gençtürk and Kotabe (2001), however, believe that the major problem to adequately assess TSIs performance is the variety of approaches and measures used, indicating that there is no generally accepted criteria for determining export success.

As highlighted by Gillespie and Riddle (2004), almost 15 years ago, but still remains as a gap in TSIs' research, is that

“...remarkably little research examines how EPOs [TSIs] decide which services to offer. How do EPOs [TSIs] determine which types of firms to target? Why do EPOs [TSIs] offer certain services in the first place? What motivates EPOs [TSIs] to adjust these services over time? Why are some EPOs [TSIs] more efficient and/or more effective than others in matching services to client needs or in increasing awareness and use of their services? (p.462)" 


\section{5. \\ Export Promotion Conceptual Framework}

Similarly to export barriers research, the literature on export promotion is more often phenomena-based than rooted on a theoretical perspective. One perspective used by export promotion researchers in the field of IB has been the Uppsala model (Johanson and Vahlne, 1977), especially when taking into consideration "the different needs of exporters at different stages of the internationalization process", as noted by Faroque and Takahashi (2012 p. 18).

However, some authors have suggested a variety of theoretical perspectives that could increase the theoretical and practical usefulness of research findings. For example, Shamsuddoha et al. (2009a) suggest that, besides the Uppsala model, the Resource-Based View (RBV) (Barney, 1991) could be useful to the extent that this theory "proposes that competencies in the form of knowledge and expertise are critical to superior organizational performance." Since EPPs are designed to support the acquisition of knowledge and the development of competencies, RBV could provide a useful framework. A similar argument is presented by Sousa and Bradley, (2009), Shamsuddoha et al. (2009b), and Bannò et al. (2014).

Institutional theory, combined with $\mathrm{RBV}$, is a suggestion for further improvement of the theoretical foundations of export promotion research (Miocevic, 2013). While RBV could be useful to examine internal barriers and export promotion actions, institutional theory could guide the understanding of how to overcome external barriers. Ngo et al. (2016) also suggests the use of institutional theory in the specific context of TSIs from emerging countries.

Haddoud et al. (2017, p.70) add that institutional theory can also be helpful by explaining "the enhancing role of institutional interactions on firms' internationalization" and, specifically on the development of relational ties between firms, which would help them to access partners' resources "in the form of intangible resources such as market knowledge, skills and expertise, and tangible resources including raw materials, machinery and equipment." Institutional theory 
could be combined with network theory, because the latter emphasizes the development of business relationships in an international context.

\title{
2.6.
}

\section{Gaps in the Export Promotion Literature}

The analysis of the export promotion literature unveils its main strengths and weaknesses. In this section, the most relevant gaps in the extant literature are emphasized. Despite the considerable body of knowledge on export promotion, results are mixed, and therefore not entirely convincing.

To begin with, regardless of the increasing number of Born Globals and International New Ventures since the 1990s, the bulk of research is devoted to traditional internationalizing firms (Faroque and Takahashi, 2012), indicating the need to carry on more analysis of the specific export promotion needs of BGs and INVs. Indeed, entrepreneurship also has implications for export promotion researchers. As suggested by Faroque and Takahashi (2012, p.18),

\begin{abstract}
"It is not enough to investigate only the impact of export assistance on export performance of firm or venture because it has simultaneous impact on entrepreneurial orientation (EO) (proactiveness, risk taking, and innovativeness) of the firm (Mill Figure Xer 1983) as well as on the entrepreneurial process involving opportunity search, recognition, and subsequent exploitation of international markets."
\end{abstract}

In addition, in spite of some recent significant efforts, most of the studies conducted to date focuses on developed countries, calling for more research on developing countries (Martincus and Carballo, 2008). At the same time, Ngo et al. (2016) suggest the urge to explore the facilitating or inhibiting role of domestic institutional environments on export performance. Another important recommendation to enlarge the export promotion body of knowledge is the development of studies by industries, including the service sector.

On the other hand, Miocevic (2013) advocates the need to test the effectiveness of EPPs from a societal perspective, that is, whether or not these programs are effectively allocated. According to him, "at their very root, EP 
programs should be treated as instruments of economic policy through which policy makers distribute economic benefits according to the principles of justice (p. 6)."

Methodological limitations are among the most relevant challenges for scholars interested in export promotion research. Most studies are cross-sectional; export performance is typically measured only in terms of financial goals, disregarding its unequivocal multidimensionality; EPPs are examined mainly individually, setting aside their collective impact; and lack of qualitative studies to offer in-depth knowledge to enable the buildup of specific explanatory theories.

\section{7.}

\section{Summary of the Export Promotion Literature}

Figure 3 thematically categorizes the export promotion literature reviewed. As expected, the bulk of the literature produced during the period analyzed searched to appraise EPPs or TSIs effectiveness from several different perspectives/impact dimensions. Performance was the keyword for most researchers, who exhaustively tried to demonstrate the relationship between program use and export performance. Indeed, return on investments made on export promotion is of utmost relevance for all stakeholders involved, particularly to taxpayers themselves. 


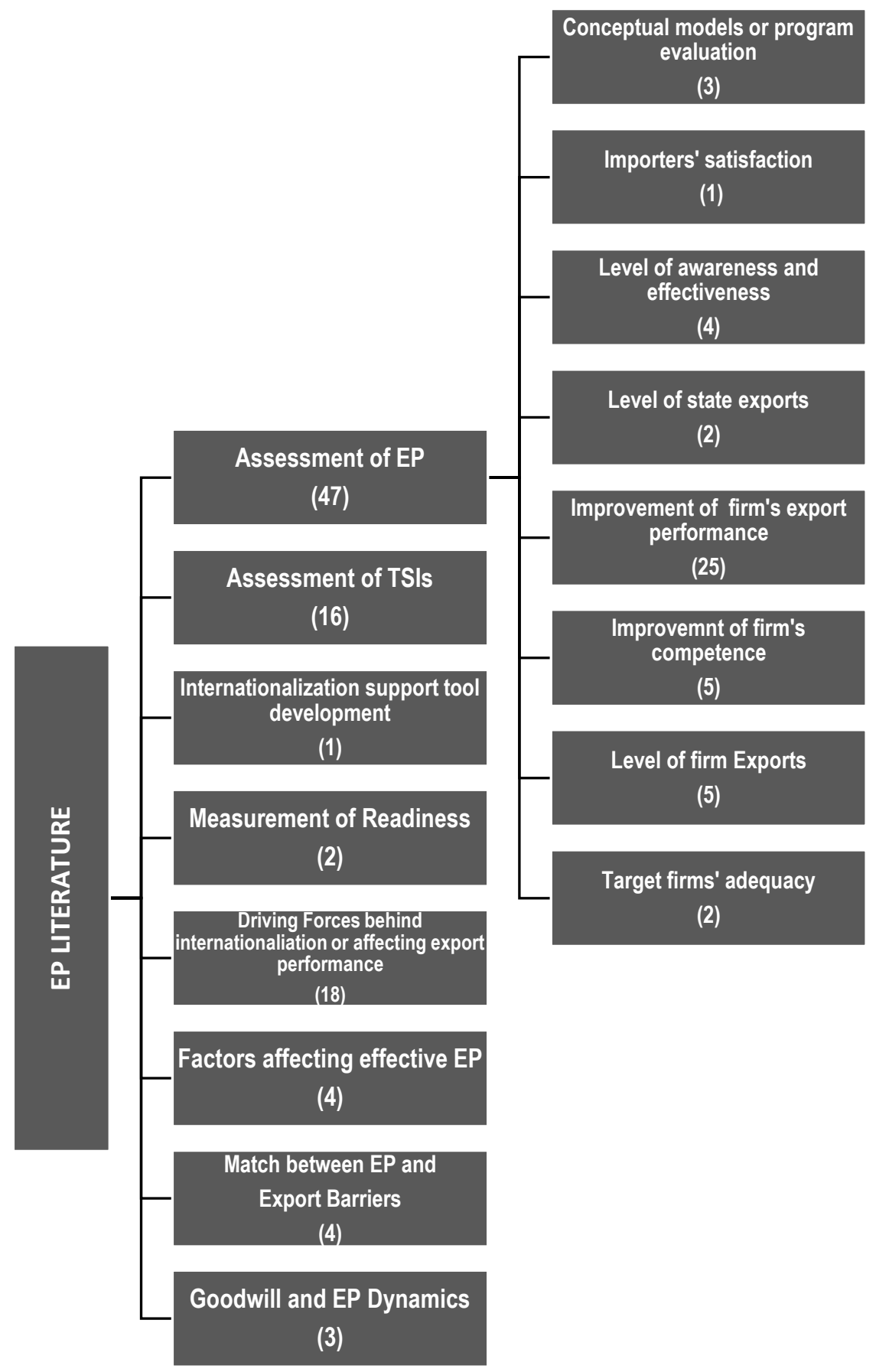

Figure 3 - A thematic overview of export promotion research

Source: elaborated by the author

Obs.: Numbers in parenthesis correspond to the quantity of articles related to each theme. Some articles treat more than one theme and were classified in more than one box

\section{8.}

\section{Conclusions}

The analysis of the two streams of literature - Export Promotion and Export Barriers - based on the works reviewed, shows that the number of studies directly 
matching export promotion programs and export barriers is extremely low, considering all the exporting literature produced in the last almost thirty years. In fact, it was only possible to identify four studies adopting this rationale, as shown in Figure 3. Moreover, only one of them, published 25 years ago, tested empirically export barriers vis-à-vis export promotion (Kotabe and Czinkota, 1992). Nevertheless, it is important to state that although not always adopting the direct relationship between EPPs and export barriers to empirically measure the effectiveness of export promotion, this logic is often implicit in most studies, since the EPPs being evaluated can be theoretically correlated to export barriers to be removed, and are indeed. In any case, recognition of the connection between the two sides of export promotion (firms' needs and TSIs' offer) does not guarantee an objective assessment of the relationship between EPPs and the exports barriers they are supposed to withdraw.

Additionally, this assessment of the literature indicates a greater interest on researching export barriers than export promotion. Indeed, during this period, 97 studies were developed to deepen the knowledge about export barriers, contrasting to 82 associated to export promotion issues. This does not mean necessarily less interesting findings or insights about one subject in detriment to the other, but it can be considered at least an intriguing evidence. Another intriguing finding is that, with little exception, researchers studying export barriers are not the same studying export promotion, as evidenced by Appendix 2 and 3. The literature strongly agrees with the fact that export promotion is directly associated to the removal of export barriers, therefore one would expect that both research fields would be intertwined. 


\section{Chapter 3 - Essay 2 - Export Promotion Initiatives in a Cluster}

This essay analyzes the trajectory of the Cabo Frio beachwear cluster in Brazil. Departing from the extant literature on clusters, the study describes the stages of birth, take-off, growth, and maturity of the cluster, focusing specifically on the attempts to promote exports by several institutions, private and public. The results suggest that coordination failures are the major reason behind the inability to internationalize, although one cannot dismiss the negative effects of the overvalued Brazilian currency, as well as aspects internal to the firms. Change agents have tried to introduce new practices and attitudes toward cooperation in exporting, but failed to do so. The key issue, therefore, is why the firms in the cluster failed to develop their export activities, despite several initiatives and investments to promote collective actions. The paper advances some possible explanations, with implications to other Brazilian clusters.

\subsection{Introduction}

Clusters, or industrial districts, can be described as concentrations of economic activity in a specific geographic location that show a certain level of specialization. Industrial clusters are characterized by a set of firms typically operating in the same or related industries, together with an array of suppliers of raw materials and parts, equipment manufacturers, as well as all types of public and private supporting institutions. Several authors have pointed out the relevance of industrial clusters. For example, Porter (1998, p.77) claims that location has become even more important in a globalized world and sees clusters as "critical masses [...] of unusual competitive success in particular fields". Scott (1996, p.391) suggests that clusters are the "regional motors of the global economy", a result of the emergence of global value chains and changes in world capitalism.

A substantial body of the literature on clusters has addressed the question of their evolution over time. According to a literature review by Martínez-Fernández, Capó-Vicedo, and Vallet-Bellmunt (2012), studies on cluster lifecycle are the 
second most frequent type of research on the subject. Also, a bibliometric study by Hervas-Oliver, Gonzalez, Caja and Sempere-Ripoll (2015, p.1842) consider the topic as part of the "evolutionary economic geography" segment of the literature on cluster and industrial districts.

However, fewer studies have looked specifically at the issue of a cluster's crisis and (even temporary) decline. Bergman (2008, p.114) advocates the need for additional research to examine the process by which clusters may prosper initially, "yet at the end exhibit fatal vulnerabilities." Zucchella (2006, p.26) also indicates that the birth and growth of clusters have received substantial attention in the literature, but there are few studies on "their decline, crisis, and eventual renewal".

In addition, the literature on clusters has given scant attention to the role of Trade Support Institutions (TSIs) in cluster development, and, specifically, to their export promotion activities to support the cluster's internationalization. Few studies have addressed in detail the role played by government-related organizations to help these agglomerations of firms in the process of entering foreign markets. In fact, some authors are not enthusiastic about the role of these institutions, as stressed by Fisher and Reuber (2000, p.18):

"It is possible to develop sectors [clusters] through public policy initiatives, although it remains an open question as to how sustainable these sectors are, and whether particular success stories can be replicated elsewhere. Moreover, different sectors face different challenges, because of their different histories, socio-cultural underpinnings, and sectoral bases."

Other authors, however, are more optimistic about the interference of government-related institutions in clusters. For example, Parrilli and Sacchetti (2008, p.396) suggest that "public stimuli instigated by such institutions may create a number of local dynamic enterprises", and Maffioli, Pietrobelli and Stucchi (2016) claim that, despite the lack of evidence on the effectiveness of governmentsponsored cluster development programs, these programs can be necessary when coordination mechanisms internal to the cluster fail.

This study aims, therefore, at examining the lifecycle of a relatively small beachwear cluster of Cabo Frio, a seaside resort located in the Northern coast of the state of Rio de Janeiro, Brazil, which has received substantial support from 
government agencies and, particularly, government-related institutions. In spite of this, the cluster has not succeeded in its internationalization efforts. The following research question guided the study: Why the beachwear cluster of Cabo Frio failed to serve international markets despite private and public efforts to develop the export activity? The contribution of the study relies on the in-depth and longitudinal analysis of a cluster, permitting to get a better understanding of a failure in export development initiatives, as well as of the related dynamics of the cluster.

This essay is organized as follows. After this introduction, the literature review focuses on three topics: first, the evolution process of clusters, as theorized by different scholars; and second, the literature on cluster internationalization, focusing specifically on the different public and private actors involved. The following section presents the methodology adopted, the case method of investigation, identifies the criteria for case selection, and describes data collection and data analysis methods. Then the essay presents the case selected and discusses the main findings of the study. The final section brings the conclusions, limitations and opportunities for future research.

\subsection{Literature Review}

Beccattini (1990, p.39) defines a cluster (or industrial district) as "a socioterritorial entity $[\ldots]$ characterized by the active presence of both a community of people and a population of firms" in a given geographic location. The relevance of the community comes from social ties between individuals and families, as well as a common system of values and beliefs, leading to trust and cooperation. The firms in a cluster can be of various sizes, although a cluster typically encompasses a large number of small firms and, in some cases, one or a few larger firms. System interactions between actors in a cluster stimulate cooperation. In addition to the advantages associated to location of suppliers and institutions and the ability of a cluster to attract highly qualified customers, firms in a cluster cooperate because the advantages of cooperation outweigh the costs of coordination (Lorenzen, 2002). Vertical cooperation is a fundamental feature of an industrial cluster, as well as horizontal competition (Beccattini, 1990; Paniccia, 1998; Tomlinson; Jackson, 2013). 


\subsubsection{Cluster evolution}

Although the study of cluster lifecycle is not new in the extant literature, scholars have not yet reached an agreement as to which phases one should consider when examining a cluster lifecycle. In fact, several proposals appear in the literature (Table 3). The examination of the proposed stages suggests that there are four possible phases: 1. Birth; 2. Take-off; 3. Growth; 4. Maturity; 5. Stagnation, or Decline. Certainly, a specific cluster does not have to follow all these stages.

\section{Table 3 - Cluster Lifecycle Stages}

\begin{tabular}{|l|l|l|l|l|}
\hline Studies & Stage 1 & Stage 2 & Stage 3 & Stage 4 \\
\hline Tichy (1998) & Creation & Growth & Maturity & Petrification \\
\hline Swann (2002) & Critical Mass & Take-off & Peak entry & Saturation \\
\hline Fornahl; Menzel (2003) & Emerging & Growing & Sustaining & Stagnating \\
\hline Wolter (2003) & Set-up & Growth & Change & Adaptation \\
\hline Maskell; Kebir (2005) & Existence & Expansion & & Exhaustion \\
\hline Lorenzen (2005) & Arise & Decline & Shift & \\
\hline Maggioni (2005) & Birth/take-off & Golden age & Maturity & \\
\hline Bergman (2006) & Formative & Growth & Maturity & Petrification \\
\hline Press (2006) & Emergence & & Endurance & Exhaustion \\
\hline Bergman (2008) & Existence & Expansion & & Exhaustion \\
\hline Menzel; Fornahl (2010) & Emergence & Growth & Sustainment & Decline \\
\hline Shin; Hassink (2011) & genesis & Development & Change & \\
\hline Source: Adaptod
\end{tabular}

Source: Adapted and enlarged from Bergman (2008, p.116); Press (2006); Menzel; Fornahl (2010); Shin; Hassink (2011).

Birth - A cluster can start spontaneously (e.g. in a location with given natural resources, or close to a port), or it can be induced (e.g. as a result of government actions, as in the case of most technology parks). In any case, for a cluster to emerge, several conditions seem to be necessary, including the formation of a local community that favours cooperation and sharing. Without this, there would not be a real cluster but merely a geographic agglomeration of firms. According to Scott and Garofoli (2007, p.5), the emergence of a cluster does not necessarily rely on existing comparative locational advantages, but more often "on the basis of endogenously built competitive advantages". They are "social creations".

Take-off - The next stage is characterized by a fast period of expansion. Some authors consider take-off an independent phase (e.g. Swann, 2002), but Bergman (2008) suggests it is part of the growth stage. This stage can happen just after the birth of a cluster, or the cluster can hibernate for a substantial period of 
time before expansion. Take-off can result from the opening of national or international markets to the cluster's products.

Growth - The growth of a cluster can be the result of traditional factors, such as favorable local conditions, diffusion of knowledge and innovation, attractiveness to investors, etc. (Iammarino; Sanna-Randaccio; Savona, 2006). At this point, the cluster is already very attractive and brings together all kinds of support institutions (such as government agencies, universities and research centers, venture capitalists, etc.) and firms in related industries (such as suppliers of parts, equipment manufacturers, etc.). The emergence and consolidation of a local coordination system (e.g. producers' associations) occurs in this phase. However, the growth of a cluster is associated to demand conditions. Since many clusters are internationalized, their growth can be associated to the expansion of demand for the cluster's products in international markets. It has been claimed more recently, however, that due to the phenomenon of globalization "new diversified and 'idiosyncratic' patterns of [cluster] growth have been observed" (Guerrieri; Pietrobelli, 2004, p. 899).

Maturity - Maturity is technically reached when the rate of entry/exit of firms tends to stability. It can be associated to the stagnation of demand for local products, caused by exogenous factors, or by limits to the capacity of the cluster to increase supply (which could be a result of diseconomies of scale or full use of nonsubstitutable natural resources). The costs of additional growth may not be counterbalanced by the benefits (Swann, 2002; Bergman, 2008). Firms may face congestion costs, and new firms may not add to the competitive advantages of the cluster. It is also possible that the leading firms in the cluster do not show a desire to expand and rely on the advantages previously built, instead of continuously searching for new advantages (Bergman, 2008). Clusters can remain for a long period in the maturity stage, or they can stagnate, or even decline.

Stagnation or Decline - Several endogenous and exogenous forces may cause a cluster to fail. Costs may rise substantially due to competition among firms for limited resources, such as the costs of specialized labor, or logistics. Even when a cluster is extremely successful, success itself may stimulate the emergence of new 
clusters, offering locational advantages compared to the old cluster. Another major reason for the decline of clusters is technological obsolescence (Trippl; Tödtling, 2008). Changes in global supply chains may also have a strong impact on a cluster's development. In fact, risks and vulnerabilities are inherent to a cluster. Also, clusters may stagnate or decline due to changes in their industry. Yet Valdaliso, Elola and Franco (2016) have shown that clusters can deviate from the trajectory of their industries. Trippl and Tödtling (2008, p.213) argue that scholars have frequently ignored that clusters can be both "a blessing and a curse" to their regions. If the cluster fails, there is general impoverishment and unemployment, and diminishing returns for the region (Potter; Watts, 2011).

Renaissance - Bergman (2008) claims that there may be another phase in a cluster's evolution - "renaissance" - in which readjustments and restructuring may take place, in such a way that the cluster creates new competitive advantages and reinvents itself. Martin (2010) also suggests that clusters can have periods of stagnation followed by recovery; they can also evolve continuously, in permanent adjustment to technological or other environmental changes. In fact, the author identifies several possible trajectories for a cluster, of which only one portrays the traditional lifecycle model (Figure 4).

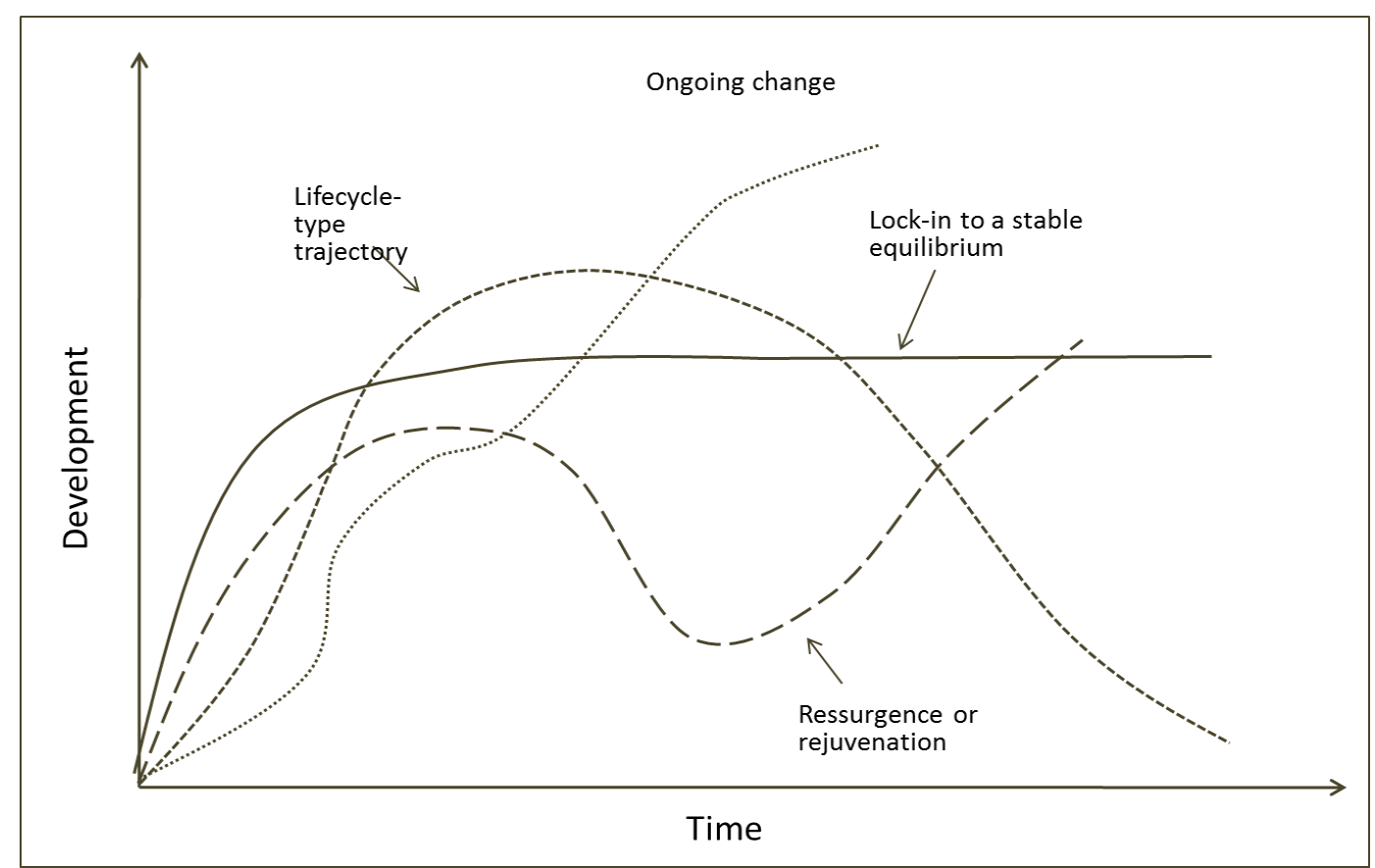

Figure 4 - Alternative Paths for a Cluster

Source: Adapted from Martin (2010, p. 10) 
One of the risks faced by a cluster is path dependence (Dobusch; Schüssle, 2013). Path dependence is generally understood as a factor that limits the potential strategic choices of firms, industries, or clusters. The mechanism of path dependence works as a chain of causal mechanisms that reinforce each other over a period of time. Vergne and Durand (2010, p.737) define path dependence as "a property of a stochastic process which obtains under two conditions (contingency and self-reinforcement) and causes lock-in in the absence of external shock." The often used term 'history matters' indicates that previous knowledge influences future knowledge, present investments limit the alternatives for future investments, and organizational cultures shape future decisions. Lock-in is a potential outcome of path dependence. Sydow, Schreyogg, and Koch (2009) suggest a process leading to path dependence. Yet several authors caution against the supposed inevitability of the lock-in effect (e.g. North, 1990; Greener, 2002; Drahokoupil, 2012), claiming that firms may reorient their paths by using experiences or knowledge that were not initially followed (Noda; Collis, 2001; Schneiberg, 2006).

Another potential threat to a cluster success is isomorphic behavior (DiMaggio; Powell, 1991), which is the tendency of the firms in a cluster to behave similarly, imitating the more successful ones. More heterogeneous clusters may find it easier to escape the lock-in effect (Martin, 2010), since firms have followed alternative paths or alternative strategies in their history. In addition, governments may intervene by making available new resources (training, resources to invest in new technologies, legal mechanisms, etc.).

\subsubsection{Cluster Internationalization}

Globalization may pose both threats and opportunities to a cluster development. In fact, a number of studies have documented the impact of globalization on the clusters' lifecycle, including relocation and reconfiguration (e.g. Bertolini; Giovannetti, 2006; Sammarra; Belussi, 2006; Bettiol; Burlina; Chiarvesio; Di Maria, 2017;). The literature on clusters has been less concerned with the process by which a cluster internationalizes, focusing more on the impact of globalization. Other studies looked at whether the location in industrial districts create locational advantages that boost internationalization (Catalan; Ramon- 
Muñoz, 2013). Guerrieri and Petrobelli (2004) argue that to become internationalized, a cluster needs to develop and integrate local and global linkages and networks. Specifically, the authors point out to the need to participate in global production networks and other global "systemic forms of integration" (p.912). In the same line, Zucchella (2006) claims that internationalization may play a relevant role in mature clusters.

Several actors may support the internationalization process of a cluster. Focal firms or key players, typically large domestic firms or multinational corporations, may have international experience and act as gatekeepers, identifying potential threats and opportunities, and connecting the other firms with global supply chains and networks (Ferreira; Tavares; Hesterly, 2006; Mariotti; Mutinelli; Piscitello, 2008; Bacchiocchi; Florio; Giunta, 2014). Also, international intermediaries may play a relevant role in connecting firms in a cluster, particularly SMEs, to global value chains (Ellis, 2003). In fact, the most recent literature of export promotion stresses the importance of export promotion programs conceived to promote networking (Haddoud et al., 2017; Chabowski et al., 2018). This type of export support is extremely relevant in the case of clusters intending to expand overseas, since it helps the firms within the clusters to overcome informational barriers. The establishment of international linkages, however, may have a deleterious effect on local linkages (DeMartino et al., 2006).

Private institutions may also be of paramount importance to start the internationalization process. For example, a study by Cannatelli and Antoldi (2012) shows that a manufacturers' association was able to promote joint export cooperative groups among SMEs in an Italian furniture cluster. The facilitator was responsible for identifying the opportunity and for inviting the firms to participate. But its main role in the process was to act as a guarantor, in the absence of trust among the entrepreneurs, who had been fiercely competing with each other for decades. The authors indicate that network facilitators can play different roles during the process of establishing an export group. During the creation of the group, the facilitator can act as "pivot of the alliance". As the alliance progresses, facilitators can then act as mediators, to assure that relationships between alliance 
members are built. Finally, the facilitator becomes an advisor, at the same time the group is capable of choosing an internal leader.

Government agencies and other public organizations (e.g. universities, research centers) are potential relevant actors in a cluster. The role of government and government-related organizations is, however, largely controversial. For example, Schmitz (1999a) found that the development of alliances between key firms in the Sinos Valley footwear cluster in Brazil and global suppliers have weakened local cooperation among manufacturers. The author suggests that market failures faced by clusters might be better solved by joint private action, rather than government action (Schmitz, 1999b). However, Parrilli and Sacchetti (2008) point out that often public policy mechanisms are needed to stimulate economic activity in a cluster, and that an active public policy should target the development of competencies, in collaboration with the private sector. The authors emphasize that these mechanisms work better when the firms' main activities are not directed towards the domestic market, where they act as competitors, but target international markets, where they often have to act as partners.

Maffioli, Pietrobelli and Stucchi (2016, p.4) pose an interesting question: "If agglomeration and coordination are beneficial for firm performance, why is public intervention needed?" The authors list several reasons, related to externalities and coordination failures. They advocate that linkages among clusters' firms are not always adequately structured, asking for proper intervention for their potential to be fully exploited. Coordination failures are especially damaging to clusters, and responsible for neutralizing their positive externalities. Clearing up coordination failures is then paramount to foster clusters' development, and this can not always be done by the clusters' members themselves, but rather by public interventions that "...create formal and informal institutional frameworks to facilitate private-private, public-private, and public-public collaboration" p. 5), potentializing the beneficial effects of geographical concentration. Concretely, as stated by the authors, these interventions seek to promote strong firms' linkages, disseminate information, elaborate a joint problem diagnosis, coordinate the efforts of all actors, identify and, when necessary, provide the crucial inputs to enhance clusters' performance. 
The international business (IB) literature and the management literature, in general, offer little insights on the internationalization of clusters. It is generally assumed in the IB literature that firms internationalize as sole actors, and joint action is largely ignored (Bonaccorsi, 1992). Even network theory, although recognizing that firms are embedded in social networks and that internationalization happens in the context of these networks, still looks at the individual firm as the unit of analysis, and not at the network (e.g. Johanson; Mattson, 1988; Chetty; Holm, 2000; Sharma; Blomstermo, 2003; Johanson; Vahlne, 2009, 2011). This stream of research recognizes, however, that firms use networks to enter foreign markets, that the nature of ties and interactions among members of the network is relevant to internationalization, and that belonging to networks allows SMEs to advance faster in the global arena. As to the general management literature, HervasOliver, Gonzalez, Caja and Sempere-Ripoll (2015, p.1843) point out that there are two topics in the extant literature on clusters and industrial districts that have been to a large extent covered from a "managerial perspective": "inter-firm networks, social capital and flows of knowledge within networks and clusters" and "innovation and firm analysis". Both topics tend to be approached by the management literature from the individual firm's perspective.

\section{3. \\ Methodology}

This research uses the case study method of investigation to examine a Brazilian cluster and answer the "why"-type research question, typical of a qualitative study related to a contemporary situation that needs to be thoroughly understood for theoretical development (Yin, 2014).

\subsection{1.}

\section{The case method}

The choice of the case study method relies on its adequacy to reveal findings and perceptions about complex phenomena that lack theoretical basis or empirical evidence and that quantitative methods fail to unveil. The method is characterized by the intensive investigation of one or a relatively small number of cases, prioritizing the thorough understanding of the relationship between the several 
factors related to the situation investigated (Yin, 2014; Ghauri, 2004). Moreover, the case method is considered the most appropriate when the context is significantly relevant to the phenomenon under examination. In other words, it is a method capable of apprehending the holistic and significant characteristics of real life situations (Dubois; Gadde, 2002; Piekkari et al., 2009). Additionally, the case method considers a wide variety of data sources, allowing to capture a broader view of the research subject, as well as the collection of more accurate and compelling evidence (Yin, 2014). Finally, the case method is considered particularly appropriate in view of the fact that research findings are unstable over time.

Among the reasons raised by several authors to justify the use of the case method (Eisenhardt, 1989; Ghauri, 2004; Gibbert et al., 2008; Yin, 2014), the following are particularly suitable to validate its adoption in this research:

- The need to comprehensively examine, in a thorough manner, why the beachwear cluster of Cabo Frio failed to develop international activities in spite of private and public efforts to foster the export activity;

- The fact that quantitative research on export promotion does not provide a deep understanding of the role of TSIs in cluster development and internationalization;

- The need to carry out an in-depth longitudinal analysis to adequately answer the research question proposed.

Case studies respond for approximately $7 \%$ of the studies on industrial clusters (Martínez-Fernández et al., 2012), and are predominant in cluster lifecycle studies. Case studies are often used in the international business literature to describe and analyze processes, and their use has been considered useful to foster the understanding of such processes (e.g. Jones; Khanna, 2006). 


\subsection{2.}

\section{Unit of analysis and case selection}

Following the tradition in the study of industrial clusters, the unit of analysis selected was the cluster. Indeed, since Becattini's (1979) seminal work defended the use of industrial districts as an essential unit of analysis, several authors (e.g. ; Schmitz, 1999b; Bertollini; Giovannetti, 2006) have studied industrial clusters as an entity in itself. Specifically, this research adopted a longitudinal approach, aiming to investigate the trajectory of the selected cluster - the beachwear cluster of Cabo Frio, a seaside resort located in the Northern coast of the State of Rio de Janeiro, Brazil - following the recommendation of Jones and Khanna (2006), in their article published in the Journal of International Business Studies, where they stressed the need to research the historical trajectory in the IB field using qualitative studies, thus validating the choice of this perspective as the most appropriate for carrying out the present study.

The selection of the beachwear cluster of Cabo Frio to answer the study research question was based upon two main premises: (1) the international reputation of the Brazilian beachwear products, recognized for their good quality, fit, and design, which, at least theoretically, should facilitate the industry's internationalization (even though export volumes have never been particularly large); and (2) the unfruitful several attempts and huge investments made by TSIs to develop the cluster's international activities.

\subsection{3.}

\section{Data Collection}

Data sources were both secondary and primary. Secondary sources included several reports on the evolution of clusters by government and private institutions; other information available in the internet; academic studies; and articles in the business press. Primary data was gathered between 2014 and 2017, by means of (i) in-depth personal interviews conducted with three entrepreneurs of leading firms in the cluster, one of which was also the head of the local industry association, and with a consultant to Sebrae, a non-profit national organization financed by the Brazilian government dedicated to support small and medium-sized enterprises 
(SMEs); (ii) telephone interviews with government agents involved in public actions in the cluster; (iii) informal interviews in a business meeting organized by Sebrae under the auspices of the Interamerican Development Bank (IDB); and (iv) informal interviews during several visits to the cluster. These eclectic data sources permitted to get different perspectives, from different types of actors in different moments of time. They also made possible to have access to internal documents that helped to understand the cluster's historical trajectory. Specifically, the participation in a large business meeting, in which the future of the cluster was being discussed, helped to understand the dynamics of social interaction among local actors, the efforts by institutions, and the problems faced by the firms to cooperate. The data collected was therefore both retrospective and real-time: most of the data related to the cluster historical trajectory and several TSIs' initiatives were collected retrospectively, that is, after the facts, whereas some other evidence concerning the effects of TSIs' initiatives on cluster dynamics were collected in real-time, i.e., during their occurrence. In-depth interviews were taped, and transcripts made. In addition, the researchers took notes during or after telephone interviews and informal conversations. The use of several sources was important to ensure the necessary triangulation to achieve construct validity. Several other tactics were also employed, aiming to improve the study's validity and reliability, such as establishment of a chain of evidence, use of a case study protocol, and the development of a case study database.

\section{4.}

\section{Case Analysis and Research Limitations}

Data analysis was done in two steps. First, a detailed descriptive account of the cluster's trajectory was developed, confronting secondary and primary data collected for the study. This descriptive account was very important to put together the series of events and interventions that shaped the trajectory of the cluster over time. The historical description was a critical step because of the large amount of different types of data gathered during the period of the study, and the need "to present an 'authentic' understanding of people's experience" (Ghauri, 2004, p.117). This is one of the most serious challenges faced by qualitative researchers. The historical analysis was not done at the end of data collection; rather, it happened 
along the data collection process. This was necessary because historical data was not easily available, and events that happened a long time before were already reinterpreted, and even their time limits changed from one interviewee to another.

The second step in data analysis was to organize the data in categories. The challenge here was to sort the great amount of data collected, identifying categories and linkages, disclosing themes, and elaborating sensible reflective conclusions, aiming to answer the study's research question. This consisted on a process of destructing and reconstructing conceptual connections through a selected lens to unveil an interpretation, while cautiously documenting the whole process to improve the credibility of the findings. The categories emerged from the data rather than being imposed prior to data collection and analysis, and were then confronted with the literature as the analysis progressed (Pauwels and Mathyssens, 2004).

Qualitative research developed through case studies presents some limitations, one of which is related to its very nature, i.e., results cannot be generalized to the population. The subjectivity of the researcher's judgment can also be pointed out as a disadvantage of the method, as well as the occurrence of biases during the interviews (ex-post facto, affinity and others). The use of data triangulation aimed at mitigating these limitations.

\section{5.}

\section{The Cabo Frio Beachwear Cluster}

\subsection{1.}

\section{The Context}

The beachwear industry developed in Brazil to serve the country's large domestic market for these products. Three major factors explain the domestic demand for beachwear: a tropical climate, a long coastal line of beaches, and a culture of sensuality. By 2014, it was estimated that the beachwear industry annual revenue was around US\$ 2 billion dollars, of which only a very small portion (US\$ 10.7 million) was exported. The main markets for Brazilian exports of beachwear were the U.S., Portugal, France, Israel, and Paraguay (Simões, 2015). Exports of beachwear have peaked in 2005, but then declined in the following years (Figure 
5). The reduction in the volume exported by the industry was to a large extent due to the overvalued Brazilian currency, a situation that became more acute after 2005. Nevertheless, with the substantial devaluation of the Real in 2015, it was expected that the industry would be more price competitive in the near future.

The industry comprises more than 1,300 firms, of which around $70 \%$ are small firms. There are also a large number of micro firms operating informally. A few large-sized firms, mostly located in the state of São Paulo, were responsible for a large percentage of exports in 2005, but this situation changed since then. Firms that competed only on price were unable to meet the prices offered by Asian competitors, and therefore ceased to export. In fact, by 2015 firms that continued to export were located mostly in the cities of Rio de Janeiro (56\% of Brazilian exports of beachwear) and São Paulo. These firms, typically middle-sized, had established brand names and were able to export their products based on design and exclusivity, adopting a differentiation strategy. Nevertheless, they could only export small volumes, because of their size. As a result, the average unit price of exported beachwear products more than doubled during the last decade. More than $40 \%$ of Brazilian beachwear exports go to the U.S. market.

The recent history of the industry also shows that imports have risen steadily, at the same time exports decreased, suggesting that the local industry lost price competitiveness both in the domestic and in the international markets. Indeed, by 2014, imports of beachwear products have far exceeded exports. More than $90 \%$ of the imports of beachwear products came from China (Moiseichyk et al., 2012). 


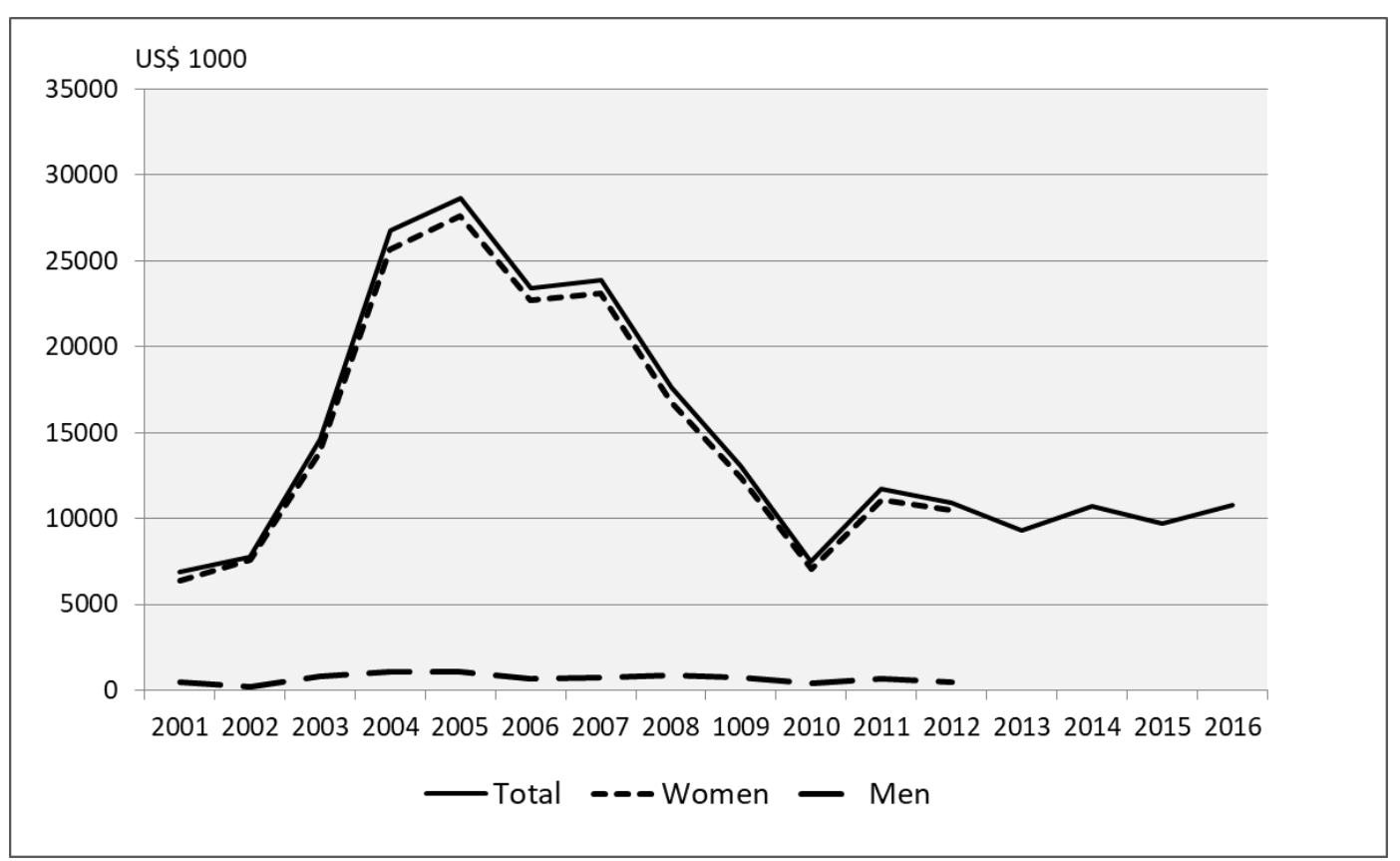

Figure 5 - Evolution of Beachwear Exports - Brazil

Note: Data on women and men beachwear were only available until 2012.

\subsection{2.}

\section{The cluster lifecycle}

The Cabo Frio beachwear cluster was responsible, in 2014, for $2 \%$ of the Brazilian production of beachwear products and employed 3,000 people the whole year, and 10,000 during the summer season. The cluster can be classified as a Marshallian district, formed by small firms. It is estimated that presently between 150-200 firms are located in the cluster. The cluster followed the typical path predicted in the cluster lifecycle literature: birth, take-off, growth, and maturity.

Birth - The Cabo Frio beachwear cluster has its origins in the 1950s, when a local entrepreneur started a business to serve the beach resort areas in the region. The business grew rapidly and was soon imitated by other entrepreneurs. Until 1970, however, almost all producers operated informally, and copied products of established brand name manufacturers and designers located in the city of Rio de Janeiro. Stores were typically established in the entrepreneur's home.

Take-off - It was only in the 1980s that the cluster started to grow, with the inflow of entrepreneurs from the city of Rio de Janeiro, who recognized an opportunity to establish manufacturing units or brand name stores in the region 
(Cassiolato; Peixoto, 2004; Peixoto, 2005; Cardoso, 2006). International sales started as tourists carried beachwear products to their countries of origin to resell, or to offer as gifts. Nevertheless, local firms did not adopt any specific strategy to increase foreign sales, but remained passive. Instead, they were contacted by foreign buyers and only served unsolicited foreign orders.

Crisis and Growth - Local firms faced high seasonality, because a large percentage of their sales was associated to school vacations. However, an increase in the number of days in school in the second half of the 1990s caused a reduction of around $30 \%$ on the cluster's sales. The crisis prompted local government assistance programs to increase the cluster's competitiveness. Local government actions included to provide better infrastructure to the area where the stores were located (known as the "Bikini Street"), and the establishment of a ferry service to serve the area, thus increasing the attractiveness and facilitating the access. These changes, in turn, helped to increase the flow of information and knowledge among local firms, attracted new firms to the cluster, and increased the cluster's size and influence. Innovation spread not only in relation to products, processes, and the adoption of new machinery, but also in the design of producers' local stores (Cardoso, 2006; Pereira; Reis, 2008). As the cluster developed, several institutions joined or were established in the region, including banks, a local college, as well as a manufacturers' association (ACIRB). Efforts were made during the first half of the 2000s to develop export activities, especially the creation of an export consortium.

Maturity - Due to the emergence of a "new" middle class in Brazil, and the attractiveness of Cabo Frio as a beach resort, the cluster was able to grow and mature. Although there are no consolidated data available concerning the number of firms that entered and exited the cluster, or the evolution of cluster's sales (domestic or international), one can assume (based on the data collected) that, by 2016, the cluster had reached maturity, with a steady number of firms operating in the region. Sales were basically domestic with an insignificant volume being occasionally sold to other countries. 


\subsection{3.}

\section{The Pau-Brasil Export Consortium (2003 - 2004)}

Sebrae, a non-profit national organization financed by the Brazilian government and dedicated to support small and medium-sized firms, had an important role in developing the cluster. In spite of an initial and unsuccessful attempt to create a joint export marketing group, Sebrae's actions were directed towards changing the local mindset of the entrepreneurs, stimulating them to sell their products in other states of the country, as well as entering international markets. In addition, the institution also advised local entrepreneurs to diversify their product lines to other types of products that could be sold during the whole year. The aim was to reduce the high seasonality of the cluster's sales, a major obstacle to retain qualified labour and keep high standards of quality.

Sebrae agents kept insisting with local entrepreneurs that joint efforts were the best path to overcome the problems faced by the cluster and to create a new development path. Specifically, exporting to countries in the Northern Hemisphere would permit to counterbalance seasonality effects. There was, however, substantial resistance of local entrepreneurs to associative movements largely due to "the corporate culture of the region $[\ldots]$ : generally very individualistic, distrustful, with little strategic orientation, and unable to realize the competitive advantages that could come from cooperation" (Pereira; Reis, 2008, p.42). Moreover, the previous unsuccessful experience with an export consortium had negatively impacted any new initiative of cooperation.

In spite of the obstacles, an opportunity triggered the internationalization of the cluster. In 2003, Sebrae, the Federation of Industries of the State of Rio de Janeiro (FIRJAN), and several other organizations launched the Rio Fashion Business, an event parallel to the Rio Fashion Week, aiming at creating an opportunity for the Rio de Janeiro entrepreneurs to meet foreign buyers. Efforts were made by the organizers to stimulate all the fashion clusters located in the state to participate. To prepare for the event, Sebrae decided to establish and support a new export marketing group, named "Consórcio de Exportação Pau Brasil" (The Pau Brazil Export Consortium). 
The choice of firms to participate in the group was unilaterally made by Sebrae, causing several local entrepreneurs that were not invited to complain (Cardoso 2006; Pereira; Reis, 2008). Eight firms were selected to enter the consortium, most of them with international experience. Sebrae also hired a designer to develop a beachwear collection for the consortium, as well as a historian, to search for local cultural design elements. Accordingly, the new collection, named Tupinambás, recovered elements of the culture of Indian tribes that had lived in the region (Pereira; Reis, 2008). There was, however, some criticism regarding the absence of elements typically used by local beachwear manufacturers, such as shells and beads (Cardoso, 2006).

The initiative did generate some sales, but there is substantial controversy regarding the results. The firms were able to get in contact with several potential buyers from Spain, Italy, and France; most of the sales were to Spain. According to the president of ACIRB, the firms were unable to cooperate "a [foreign] buyer came, and one firm got the order; another buyer came, and another firm got the second order. The orders were not shared. And then the consortium started to collapse." In addition, four out of the eight firms that participated in the consortium went bankrupt. Having developed a product line to serve international markets, but not adequate to the preferences and tastes of the domestic market, they were unable to sell their production internally, and could not export all their output. The other four firms were larger and were able to keep two product lines, one aiming the domestic market and the other the international market (Cardoso, 2006).

Several other issues contributed to the failure in exporting. Insufficient or inadequate financing was another obstacle. In fact, most of the financing came from Banco do Brasil, the largest state bank in the country. Banco do Brasil had developed a special line of credit for small firms established in clusters, but due to its highly centralized structure and national coverage, the Cabo Frio branch was unable to offer customized support to local firms (Villela; Soares, 2009). This inability to offer specialized services to the cluster was more critical when it came to finance export activities. In addition, local firms had made limited use of marketing to promote their products either to the domestic or to the international market. According to Magnavita et al. (2010), only 13\% of the firms used the 
Internet to display and promote their products. In spite of this, some businessmen were aware of the potential advantages of marketing efforts, but there had been no joint efforts to promote the cluster.

At a certain point, Sebrae admitted that the strategy used to develop the cluster and to promote exporting had been unsuccessful. Technicians concluded that instead of promoting export cooperation, it would be better to help individual firms to export. Nevertheless, the consortium was not terminated, but remained as a symbol of the cluster's export activities, mostly for public relations purposes. It was also decided that Sebrae would focus on supporting any local firm interested in exporting. The president of ACIRB explained: “After the consortium ended, there were still some international sales. But slowly the volume went down, and finally came to zero. One firm withdraw [from exporting], then another, and then exports were not interesting anymore, and basically everybody discontinued exporting."

\subsection{4. The Strategic Plan (2005-2008)}

A management consulting firm was hired by a pool of government and private nonprofit associations, under the leadership of Sebrae, to develop a strategic plan for the cluster, covering the period from 2005 to 2008. The plan aimed at developing a culture of cooperation within the cluster, increasing firm competitiveness in global markets, and improving firm profitability (Sebrae, 2005). There were eight programs designed to improve the development of competencies, to facilitate market access, to strengthen the cluster's institutional image, to improve customer relationship management, to improve the products, to stimulate social and environmental responsibility, to develop a local service center, and to manage information and knowledge. Within each program, several actions were envisaged to be initially carried out by the supporting institutions - such as Banco do Brasil (a state bank), Senac (a non-profit organization dedicated to the training of workers), Correios (the post office service), and a local university, among others but with the intention to transfer later the responsibility of implementation to the local firms. Yet the entrepreneurs claimed that they did not have the time to perform these activities (Cardoso, 2006). As time passed, the results came out to be quite 
modest and the initiative ended. In fact, a study conducted by Sebrae (2008) during 2008 with 55 local firms showed that cooperative efforts were still embryonic. International activities were limited, the attitude was reactive (25\% gave as the main reason not to export the lack of foreign orders), most firms (72\%) had no quality control activities, and the availability of information systems was still quite limited.

\subsection{5.}

\section{The IDB Project $(2011$ - 2017)}

In spite of the experiences and the problems faced, efforts to develop the cluster by supporting institutions were not discontinued. By 2011, the Interamerican Development Bank, Sebrae, the Secretary of Economic Development (SEDEIS) of the State of Rio de Janeiro, in partnership with the federal government and other institutions, signed a project to develop two clusters in the state of Rio de Janeiro, one of which was the Cabo Frio beachwear cluster. The final purpose was to transfer to the state government a methodology to develop clusters located in the state of Rio de Janeiro. The project did not intend specifically to develop international activities, but internationalization was still seen as a major strategy to reduce seasonality, and to face the serious downturn in the domestic market since 2015 .

The project recognized as the two main problems faced by the Cabo Frio cluster (i) the lack of an effective structure of collective governance, and (ii) "an enormous skepticism among company owners towards the effectiveness of collective actions" (IDB, 2015, p.2). To a large extent, this skepticism was the result of failed previous experiences, but also an obstacle to the implementation of new actions. Apparently, the emphasis on developing new governance mechanisms was not fully appreciated by entrepreneurs, and the IDB report mentioned the need to offer shorter-term benefits to maintain firms' interest and support to the project. In addition, according to state government agent interviewed for the present study, the lack of local leaders or of a flagship firm capable of mobilizing and providing direction to the cluster was one of the most serious problems encountered. In addition, there was a major concern regarding the end of the project in the beginning of 2017, and its impact on the cluster. If until then the cluster was unable to overcome resistance to cooperation and to establish new mechanisms of 
governance, there were substantial doubts as to whether the results would be enduring. In order to help deal with these problems, Sebrae hired two outside consultants to work in the project, with the purpose of sensitizing the entrepreneurs to the need of cooperation, and organizing work groups in order to develop and implement short- and long-term actions. A major understanding among support institutions, at this point, was that they should in fact only provide support, but that the firms in the cluster had to lead the process.

A meeting organized by Sebrae in 2016 gathered a large group of local entrepreneurs to discuss the actions implemented to support the cluster, and the need to organize for the future, after the end of the project ("what will happen when the IDB grant ends?"). Interestingly, the most revealing aspects of the interaction within the cluster became apparent during the debates in this business meeting. In this occasion, representatives of the institutions involved with the cluster urged the entrepreneurs to cooperate in order to take advantage of the substantial grant made available by the IDB ("no other cluster in Brazil received as much money"). The participants seemed to be roughly divided into two groups, based on old and new leaderships that appeared to be emerging. There was also a third group in the cluster, comprising entrepreneurs that did not participate in the meeting, albeit being invited. The climate of the meeting could be well described as somewhat aggressive, in some cases bitter, in others indifferent. A major issue openly discussed was the difficulty faced by the cluster to implement collective actions. One entrepreneur mentioned the lack of firm participation in the local association, "because they [the entrepreneurs] do not understand what it means to act collectively." Other entrepreneurs mentioned also the lack of support by the city government in implementing actions that could improve the local infrastructure. Representatives of institutions repeatedly pointed out the importance of collective action: "you need to believe in your potential and in the collectivity"; "crises serve to show that together we are stronger"; "it is more satisfying and feels better to act together than independently." In addition, the representatives of the support institutions presented specific actions that were underway, such as the development of an internet portal for the cluster, a printed catalog of the firms, and an exhibition during the Olympic Games in Rio de Janeiro. One of the actions included to bring foreign buyers to visit the cluster during the Olympic Games. 


\subsection{6.}

\section{Barriers Identified by Local Entrepreneurs}

The barriers faced by the cluster to export were openly discussed during the interviews. Table 4 presents the barriers identified limiting international activities faced by firms in the cluster. Although the exchange rate was a serious obstacle to exporting, the data suggests that support institutions failed in terms of preparing the firms to export. In fact, it seems that local firms have not acquired the necessary knowledge to start and remain exporting.

\section{Table 4 - Barriers Associated to International Activities Reported by the Entrepreneurs ${ }^{6}$}

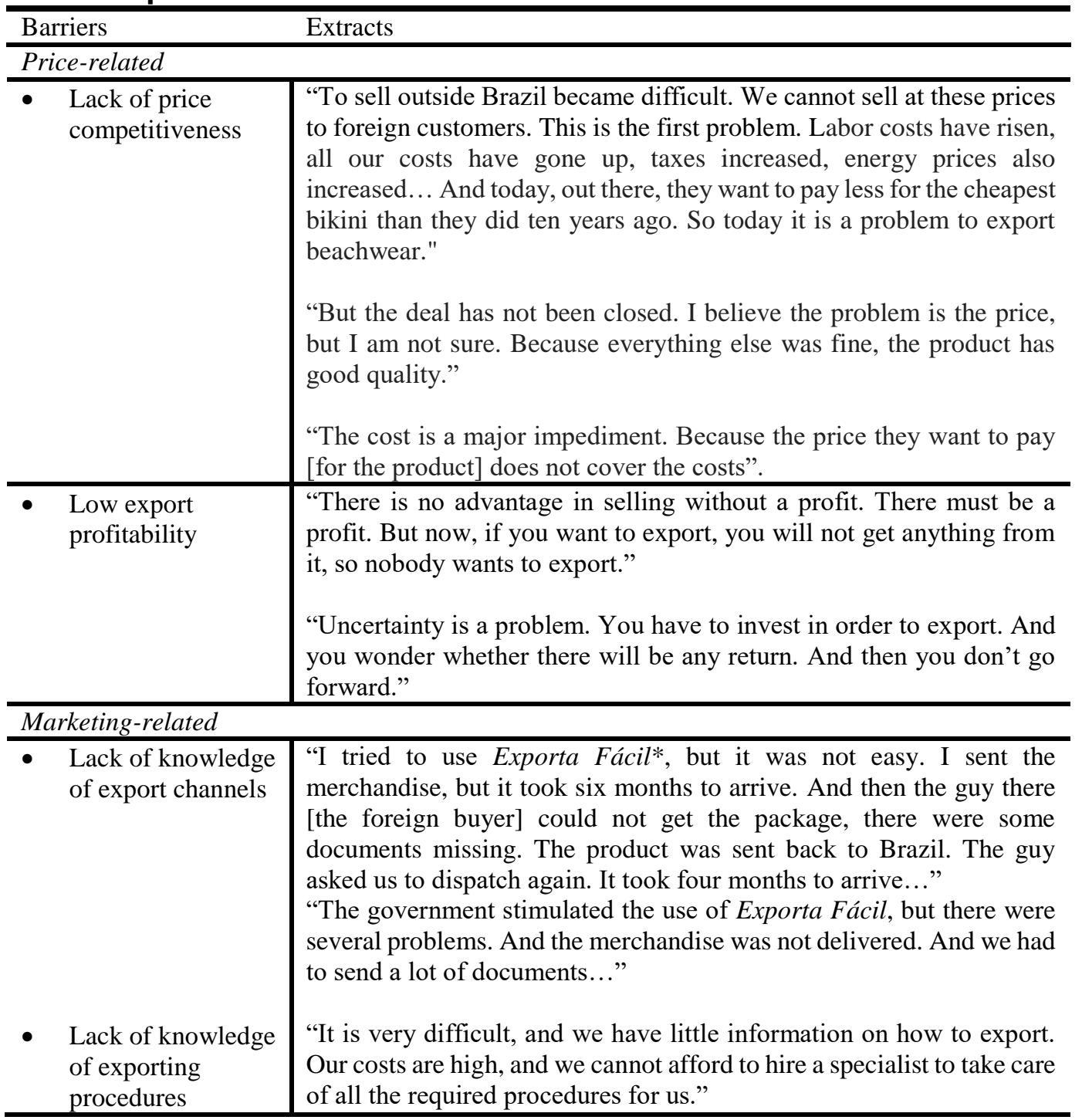

\footnotetext{
${ }^{6}$ Marketing-related barriers, among others, consist of informational barriers, which were identified in Essay 1, through the works of Leonidou (2004) and Arteaga-Ortiz and Fernández-Ortiz (2010).
} 


\begin{tabular}{|c|c|}
\hline Barriers & Extracts \\
\hline $\begin{array}{l}\text { Lack of market } \\
\text { knowledge }\end{array}$ & $\begin{array}{l}\text { "We really need a study to understand how export markets work, what } \\
\text { are the benefits, what do we need to do". } \\
\text { "There are places where they use the Brazilian bikini, but not in others. } \\
\text { For example, they use the Brazilian bikini in Portugal, France, Spain, } \\
\text { Greece. Now, I have sold to the U.S., to California. But their } \\
\text { requirements are different". }\end{array}$ \\
\hline $\begin{array}{l}\text { - Need of product } \\
\text { adaptation }\end{array}$ & $\begin{array}{l}\text { "Some foreign buyers contact us to ask whether we would be interested } \\
\text { in exporting. We say yes, but only if they do not require changes in our } \\
\text { products." }\end{array}$ \\
\hline $\begin{array}{l}\text { Lack of } \\
\text { conformity to } \\
\text { international } \\
\text { market standards }\end{array}$ & $\begin{array}{l}\text { "We do have quality products in Brazil. We try to make our products } \\
\text { with high standards of quality, the best way possible, but the } \\
\text { requirements there are much more. Not only concerning how to make } \\
\text { the product, but also regarding issues such as labels." } \\
\text { "We need to know what type of information should come in the } \\
\text { product, labels, sizes." }\end{array}$ \\
\hline \multicolumn{2}{|l|}{ Behavioral } \\
\hline $\begin{array}{l}\text { Attractiveness of } \\
\text { the domestic } \\
\text { market /Lack of } \\
\text { interest in } \\
\text { exporting }\end{array}$ & $\begin{array}{l}\text { "It is much easier to sell to the cities nearby, or other states, then to } \\
\text { foreign markets." } \\
\text { "We have invested here, in the domestic market." } \\
\text { "We prefer to supply the stores here, even to serve a wholesaler in } \\
\text { Brazil. We sell to other states of Brazil, to other stores that carry our } \\
\text { brand. [...] Exporting is not a target, but I am not saying it is not an } \\
\text { option." }\end{array}$ \\
\hline $\begin{array}{l}\text { Lack of a } \\
\text { cooperative } \\
\text { orientation }\end{array}$ & $\begin{array}{l}\text { "We have an association, but the problem here is that people are } \\
\text { disunited. Businessmen do not participate in meetings, do not act } \\
\text { together..." } \\
\text { "The entrepreneurs here are still not united." } \\
\text { "The association does not receive any support from the local } \\
\text { businessmen. Only a few seemed interested in cooperating. I do not } \\
\text { understand why they do not cooperate. I guess they get too involved } \\
\text { with their own business and forget the collective." }\end{array}$ \\
\hline
\end{tabular}

\section{6.}

Discussion

The results of this study show how local firms and supporting institutions failed to take advantage of the typical benefits of being located in a cluster, due to the inability to cooperate. As mentioned by Wolfe and Gertler (2004, p.1074), "the key assets that determine the viability of a cluster are firm-based." Undoubtedly, the potential to cooperate is one of the key competitive advantages of small firms located in the same region, and operating in the same industry, since they can 
overcome liabilities of smallness and gain joint economies of scale. Therefore, the lack of cooperation among local firms in the Cabo Frio beachwear cluster severely impacts the cluster's ability to expand its sales volume.

The failure to develop international activities is clearly connected to the fact that firms in the cluster have not learned to cooperate in order to achieve a common goal. Although one cannot dismiss the deleterious effects of the overvalued Brazilian currency on the cluster's foreign trade, the history of the cluster clearly points out to a lack of cooperative action from the beginning, even at the time when the exchange rate was favorable to exporting. Indeed, to escape price competition coming from the Chinese and other Asian competitors, the only strategic choice available later available was differentiation, a path that can only be pursued by small firms acting together, because of the marketing costs that need to be incurred (such as branding, development of channels of distribution, promotion, etc.). In fact, middle-sized firms in the city of Rio de Janeiro have successfully followed this path.

Interestingly, there was substantial consensus among the participants of the Cabo Frio cluster (entrepreneurs, consultants, and representatives of support institutions) that the main problem was the lack of cooperation among cluster members. This difficulty to cooperate has already been identified in certain Brazilian industrial clusters, where "an extremely non cooperative business culture emerged" (e.g. Meyer-Stamer, 1998, p.1495). Similar results were obtained in a recent study (Deboçã; Martins, 2015, p.1025) of two furniture clusters located in different states of Brazil, in which "the behavior of entrepreneurs ... tends strongly towards individualism." Furthermore, the main relational benefits associated to belonging to a cluster identified by firms were only "location (proximity to large consumer centers) and access to roads" (p.1040). In an early study on the formation of export consortia in Brazil, Da Rocha (1988) indicates that these organizations rarely succeeded, for several reasons, including lack of trust among members, lack of a governance structure, and resistance to cooperate.

The lack of cooperation negatively impacts learning, one of the main benefits of being located in a cluster. The entrepreneurs report a lack of knowledge 
of export methods and practices, and of export markets, which is quite unexpected considering the cluster's previous export experience and the efforts of several agencies to promote export activities in the cluster for so many years. It seems that local firms did not develop exporting capabilities and there was little experiential learning.

This coordination failure in the Cabo Frio cluster is associated to the lack of a governance structure. The local association failed to gather member firms under a single umbrella. There is no beachwear producer in the cluster that could become a flagship firm. Institutions, such as Sebrae and Banco do Brasil, are seen as outsiders and thus unable to lead the cluster.

The intriguing question is then: why Brazilian firms located in clusters have not learned to cooperate? Meyer-Stamer (1998) suggests that the roots of this lack of cooperation were three-fold: (i) a long-term tradition of market protection, and, as a result, a lack of international competition in the domestic market; (ii) inability to plan for the long-term, probably due to decades of chronic high inflation rates, or hyperinflation; and, (iii) as a consequence, internalization of activities within each firm, leading to excessive vertical integration. In spite of this, the author pointed out that, faced with severe threats in the 1990s, certain Brazilian clusters had undergone substantial change in firms' behavior towards "competition and internal efficiency" (p. 1496). Change, however, could only happen as certain preconditions emerged, particularly the existence of change agents and role models within the clusters. Deboçã; Martins (2015) explain the failure to cooperate in Brazilian furniture clusters as a result of "lack of coordination", leading to the offer of competitive, and not complementary, products, which in turn stimulates competition, rather than cooperation. As pointed out in a study of a Costa Rican ICT cluster, product similarity might stimulate "extreme rivalry and unwillingness to coordinate their [entrepreneurs'] actions in collaborative networks" (Ciravegna, 2012, p.87). Finally, Parrilli and Sacchetti (2008) suggest that cluster development mechanisms are more effective when firms are oriented towards the international, not the domestic market, which is not the case of the beachwear Cabo Frio cluster. 
Change agents, particularly Sebrae, have tried to introduce new practices and attitudes toward cooperation in the cluster, but failed to do so, in opposition to the experience reported by Cannatelli and Antoldi (2012) in a furniture industrial district in Italy. In addition, the absence of flagship or focal firms in the cluster (Zucchella, 2006) did not provide a local role model that could potentially serve to show new alternative paths. Another reason might be the fact that firms essentially offer similar products, therefore having little incentive to cooperate and adopting a competitive attitude vis-à-vis the other firms, as reported in other studies. Furthermore, the fact that several experiences of internationalization and cooperation in the cluster have failed created resentment and distrust among members and between members and export promotion institutions.

\section{7.}

\section{Conclusions}

The Cabo Frio beachwear cluster has followed the traditional stages in a cluster's lifecycle, having reached maturity in the late 2000s. However, the cluster is currently at a crossroads, as the Brazilian economy suffers a severe downturn. The cluster faces a combination of the weakening of demand for the cluster's products in the domestic market and the failure to enter international markets, a situation that has been envisaged in the literature as leading to decline (De Propris; Lazzeretti, 2009). The cluster seems to be following a path-dependent trajectory, and it faces the risk of lock-in. Most firms are not interested in exporting, or, worse even, see exporting as a non-alternative, because of perceived uncertainty. In addition, failed experiences of internationalization have the potential of haltering future initiatives in export cooperation, due to resistance and disbelief in positive results.

As domestic sales fall, and since the cluster has failed to develop international markets, will it change its path and promote a new cycle of innovation or will it face stagnation or decline? As proposed by Martin (2010), clusters have essentially two alternative paths: one leads to a stable state (and potentially, but not necessarily, to decline), and the other consists of a dynamic process of change and adaptation. Will the Cabo Frio beachwear cluster be able to face the present 
challenges and follow a new path, or "renaissance" (Bergman, 2008), or will it be locked-in?

These challenges will have to be faced by TSIs in order to support a cluster renewal. Several recommendations can be presented. First, following Fisher and Reuber (2000, p.25), government-related institutions need to serve these firms in a different way, both as clients and as responsible partners, and not to treat them as "recipients of charitable assistance." Accordingly, TSIs should monitor and evaluate the results of their interventions on a continuous basis, whether these interventions target a cluster, an industry or any specific group of firms. From its conception, EPPs should be based on clear and measurable goals, capable of generating relevant feedback to nurture the implementation processes.

Second, promoting exporting activities must take into account the structural differences and distinguished characteristics among industry sectors, which ask for different support for internationalization activities. In fact, tailor-made support must be relevant to the cluster's development strategy. Third, support must be flexible to adapt to environmental changes and be offered in a long-term basis.

Third, the provision of services to clusters' firms is a crucial tool to their development. It is responsible for deepening firms' interaction, and promoting cost reduction and time saving by offering high-quality standard solutions to shared problems. Export development services should focus important firms' needs, such as lack of market knowledge and lack of knowledge of export methods and techniques. Interestingly, the literature on export barriers converges in indicating that informational barriers are the main deterrent to SMEs' exporting initiation and growth.

Fourth, TSIs should give the greatest relevance to the development of relational ties among firms in the cluster, among the relevant actors in TSIs and other support institutions, and between firms in the cluster and foreign networks. Because Brazil has a relational culture, the focus on relationships among different stakeholders can be extremely helpful in disseminating trust and cooperation, which are crucial to develop SMEs export activities. 
Fifth, to promote exporting to these entrepreneurs is not an easy task, given the negative experiences of the cluster. Perhaps the most effective approach is to select a few firms with the highest export potential and invest in these firms to create successful role models to be followed in the future by other firms in the cluster.

Last, but not least, any solution should consider the governance issues and coordination failures, knowing that the improvement of coordination of TSIs' efforts in general, and EPPs in particular, must be sought regularly and continuously. Corroborating these recommendations, a simultaneous benchmarking of more than 260 cluster organizations and of cluster policies from 23 European countries, suggested that

"...an adequate level of governance and the provision of services are key characteristics of excellent cluster management organizations that yield effects on cluster development, particularly in regard to the development of business, R\&D and international activities of SMEs (Müller et al., 2012, p.36)."

This study presents some limitations. First, it examines only one beachwear cluster. Other clusters may show different paths than the one here examined. Second, the cluster studied suffered several interventions from government and non-government support agencies that have had an impact on the behavior of local entrepreneurs. Third, the study relies mostly on secondary sources mainly to describe the cluster's history. More longitudinal research is needed to explore the reasons for this lack of cooperation among firms in Brazilian clusters. 


\section{4. Chapter 4 - Essay 3 - The Coordination of Export Promotion Networks for the Creative Industries}

This essay investigates the different approaches used by three countries that are successfully supporting the internationalization of their creative industries. The study departs from several contributions in the areas of export promotion and public networks and adopts an interorganizational perspective, focusing on network coordination. The research was based on three case studies. The results show that the three countries have adopted markedly different coordination systems to ensure cooperation among a number of public and private entities that offer export promotion services and support. In addition, it appears that both the centralization of export promotion activities and the coordination of a network of institutions may work satisfactorily. However, each approach serves different purposes, given each country's cultural and economic context.

\section{1. Introduction}

Export promotion programmes (EPPs) are defined as public or publicprivate partnerships to encourage firms to internationalize, reduce or eliminate export barriers, assist firms in planning and preparation for exporting through both financial and non-financial support. EPPs are operated by Trade Support Institutions (TSIs), which include a broad set of organisations that offer support to exporters, including export promotion, financing, quality, standards and legal advice. These organisations can be public, private, non-profit or a combination of these. Among the TSIs, the most commonly studied is the trade promotion organisation, or export promotion agency.

The first export promotion agency appeared in Finland in 1919, and approximately 45 years later they turn out to be a broadly adopted tool to expand national exports and reduce countries' trade deficits. Still, almost 50 years later, in 2014, the International Trade Centre (ITC), a UNCTAD-GATT multilateral organizational, affirmed in its "Policy Road Map for Export Success" that trade promotion organizations "play a pivotal role within the domestic business 
environment, as the interlocutor between government and business, but also as an interface with foreign markets, and their establishment is an important step in achieving export success" (ITC, 2014, p. 31).

In fact, according to Lederman et al. (2009, 2010), there was a substantial increase in the number of export promotion agencies in the previous two decades to respond to the need of helping firms to overcome their liability of foreignness when expanding operations abroad. Moreover, their weight in governments' budget has also increased during that period (Freixanet, 2012). The explanation for such increase is twofold, according to Belloc and Di Maio (2011)

First, changes in the regulatory environment (especially in the WTO rules) have led, in the last decades, to substantial restrictions in the export promotion activities (subsidies and similar trade policies) and have, as a consequence, induced the governments to look for new measures to circumvent such restrictions. Second, other dramatic changes in the international trade environment are occurring, such as increasing liberalization of goods, services and factor markets, redesign of regional agreements and rebalance of power, advances in information, communication and transportation technologies. These changes, on the one side, have created new profitable opportunities for exporters and investors worldwide. But, on the other side, they have also increased uncertainty in the globalized international arena. From this it follows that potentially successful opportunities could remain unexploited because of limited information and lack of proper evaluation of the associated risks. The aim of the TPO is to help domestic and foreign entities internationally involved to match potential opportunities with profitable experiences. (p 14-15).

In fact, the ITC Trade Promotion Organizations Directory 2015 (ITC, 2015) lists 113 members (see Appendix 1 of Chapter 1), and their importance seems to be due to the current concerns with restrictions to international trade, as well as the need of further development of firms' exporting capabilities to face unpredictable changes (Geldres-Weiss et al., 2017).

The increase in the number and importance of these institutions have raised questions about their effectiveness, particularly in developing countries. There are important reasons supporting the development of a comprehensive and accurate evaluation of TSIs performance. Among these, one can list the need to maximize TSIs' economic and social impact, and to increase their credibility with stakeholders and funders (governments, firms and citizens). In addition, firms' managers need to be aware about how their firms can profit from EPPs to enhance 
export performance (Freixanet, 2012). Accordingly, several studies have addressed the issue of EPPs and TSIs performance (Schmidt and Silva, 2015), but the resulting empirical evidence is controversial.

To evaluate the contribution of TSIs to export performance improvement at the firm and at the macro level seems to be a very complex task (ITC 2016b). The reasons for these inconclusive results at the firm level are the following (Freixanet, 2012): (1) the great number of other factors affecting export performance other than EPPs; (2) differences in the operationalization of export performance; (3) differences in EPPs' content and objectives making it difficult to achieve an adequate overall evaluation; and (4) the need to take into consideration a time lag between the introduction of EPPs and their impact. On the other hand, some explanations to justify difficulties in measuring EPPs performance at the macro level are the unavailability of adequate national trade statistics and differences in environmental factors affecting each TSI's country (e.g. Gillespie and Riddle, 2004).

Recent studies have determined that EPPs have a positive and significant effect on exports (e.g. ITC, 2016a; ITC, 2016b; Hayakawa et al., 2014b; Kang, 2011; Ledermann et al., 2009). Indeed, a study developed by the University of Geneva, using data from three rounds of surveys performed in 2005, 2010 and 2014, encompassing 94 countries, confirmed previous literature results, and concluded that a $1 \%$ increase in export promotion budgets increases overall exports by $0.074 \%$, and GDP per capita by $0.065 \%$, besides generating indirect positive effects on the productivity and competitiveness of non-exporting sectors (ITC, 2016b). In a recent work, Coudounaris (2018) reaffirmed EPPs' catalytic role in exports growth and that the mechanism of awareness and use of EPPs do accelerate firms' export performance.

Furthermore, Leonidou et al. (2011) find a positive relationship between EPPs and the improvement of firms' export-related capabilities. The effect is stronger on smaller firms and less experienced ones. Similarly, Olarreaga et al. (2015) observe that more effective export promotion agencies tend to focus on new exporters and medium-sized (rather than larger-sized) firms. In addition, Martincus 
and Carballo (2010a), verify that EPPs tend to favour the increase and diversification of export markets of differentiated goods.

Other researchers focused on investigating the impact on export performance of different types of EPPs. A study from Geldres-Weiss et al. (2017), examining specifically the impact of trade fairs and trade missions on Chilean firms' export competitiveness, points out that trade fairs promote firms' export sales growth, and trade missions are advantageous to non-experienced exporters. Further, Quaye et al. (2017) revealed that not only trade fairs, but also foreign offices, tax and financial incentives have a strong positive relationship with export performance of Ghanaian manufacturing firms. Moreover, investigating the network promotion role of EPPs in driving UK SMEs' export performance, Haddoud et al. (2017) disclosed that both informational and experiential EPPs enhanced all forms of SMEs' relationships, but only the experiential ones had an indirect effect on export performance. Finally, scholars have also looked at other issues related to the successful usage of EPPs (e.g. Coudounaris, 2012; Dominguez, 2017; Marzouk, 2017; Wang et al., 2017).

Whatever their results, research has not covered the whole spectrum of issues (Freixanet, 2012) and many relevant aspects remain under-investigated. Tesfom and Lutz (2008), discussing the effectiveness of export support services in developing countries, observed:

"...while the concept and role of such export support is similar across these countries, organisational set-up and strategic approaches may differ considerably. Often public organisations, private institutions or both, undertake the export support activities... (p 365.)"

An export promotion agency seldom carries out all the export promotion activities alone. In fact, EPPs usually are not organised and implemented by one single organisation, but are rather the result of a joint effort. Being so, the need to develop alliances and partnerships with several organizations having different and complementary capabilities appears as a logical consequence:

"Private operators alone cannot achieve optimal allocation of resources and state actors may not be able to address market failures on their own. Effective publicprivate dialogue can address failures in government policy designed to overcome market failures... When the state and business interact effectively, they can promote more efficient allocation of scarce resources, conduct more appropriate 
trade policies and regulations, remove the biggest obstacles to trade and create wealth more efficiently (ITC, 2011 p.3-4).”

Already in the early 2000s, Lefebvre et al. (2003) indicated that “...external agents were found to play an influential role in the internationalisation process, creating and maintaining business networks that enable potential partners to meet and communicate... (p. 464)". Exploring the role of industrial business associations, Costa et al. (2017) confirmed that institutional networks have a positive impact on SMEs' international strategies by reducing risks and consequently encouraging their internationalization process, highlighting the need for further research on the impact of different export promotion actors.

The organisational efficiency of TSIs is of major concern for national governments and international organisations, such as the International Trade Centre (ITC). Yet, EPPs are difficult to analyse, since they often involve several public and private organisations. This situation appears more frequently in service industries, and particularly in the creative industries. The reason is that, while manufacturing and traditional industries follow a well-defined value chain (from input sourcing to output selling), which can be served by standardized programs, the service industries and the creative industries show substantial heterogeneity, making it more difficult to implement standardized programs to stimulate exporting (outward or inward) activities.

In this paper the following research question is addressed: How are different networks of TSIs organised to serve the needs of firms in the creative industries in different countries? To answer this question, this essay examines cases of export promotion networks targeting segments of the creative industries in three different countries: United Kingdom, South Korea and Colombia. The fact that the three countries experience different levels of economic and social development could provide interesting insights to increase the understanding of the phenomena investigated here. The contribution of the paper is both theoretical and empirical. Theoretically, the paper identifies different types of EPP networks and how these networks are coordinated. To the author's knowledge, no other study has addressed this issue. Empirically, the research results can be useful to policymakers and to the managerial team of TSIs. 
The paper proceeds as follows. After this introduction, the theoretical background is discussed, followed by the research methodology adopted in the study and its limitations, as well as the rationale for case selection, the data sources and the data analysis method used. A general description of the three cases is followed by a cross-case analysis and a discussion of the findings. Lastly, conclusions and implications are drawn.

\section{2.}

\section{Theoretical Background}

Different countries have organised their export promotion efforts differently (Seringhaus and Rosson, 1990). In some cases, the government is the dominant player, controlling the organisations in charge of EPPs. This is the case of Canada and Australia, which have developed a coordination mechanism to organise the efforts of various agencies at different levels of government. Other countries combine government and the private sector to render export promotion services. This is the case of the UK, which has adopted "an organised partnership approach with extensive sharing and cooperation" (p. 15). Finally, other countries, such as Germany, rely mainly on the private sector (e.g. chambers of commerce, industry associations) to carry on these activities. Seringhaus and Rosson (1990, p.15) suggest that "planned and strategic export promotion programs will probably outperform those that are more loosely coordinated". Comparing two models of export promotion from the user's perspective, one private or quasi-private and based on strategic planning (Austria), and the other public and loosely coordinated (Canada), Seringhaus and Botschen (1991) discovered that Austrian firms considered the export promotion services provided by the Austrian system more useful and also used them more often than their counterparts in Canada, thus suggesting that coordination and integration may help to design, implement and control export promotion activities.

In a survey of export promotion agencies around the world, Lederman et al. (2009) found that $85 \%$ were government-related (62\% semi-autonomous and $23 \%$ part of a ministry), $10 \%$ were fully private, and $5 \%$ were public-private. However, even when there was a dominant agency in a country, there were several "public 
and private agencies working in closely related areas" (p.5). Interestingly, Martincus and Carballo (2010d), examining the case of Colombia, found that "bundled services work better," that is, when services are integrated and combined they tend to be more effective in promoting exports. There is also some evidence that market-oriented export promotion agencies are more effective (Ferreira and Teixeira, 2011) and that "a larger share of board's seats in the hands of the private sector" increases the effectiveness of export promotion agencies (Olarreaga et al., 2015, p.12).

The issue of how different national TSIs work together to promote exporting has recently received substantial attention. For example, the ITC states that there is an increasing concern "about the lack of impact that trade related technical assistance is producing due to the duplication of services by TSIs and other development agencies." As a result, "TSIs are pooling their resources, skills and knowledge to form networks which together provide a complete and relevant range of service offers" (ITC, 2016a).

The rationale behind the effort to coordinate the services and support offered by numerous TSIs in a given country rests on the understanding that it is difficult for a single TSI to have the full range of resources and capabilities required to efficiently and effectively serve domestic firms in their expansion abroad, and that networking provides several advantages. In addition, lack of coordination among TSIs leads to problems such as an insufficient number of qualified participants in each EPP (GAO, 2001; Williamson et al., 2011), competition among TSIs to attract clients, and confusion. Czinkota (2012, p.15) points out that "coordination is crucial" to the performance of EPPs, since TSIs must organize their efforts to make them easily accessible, “without making it the firm's task to identify possible support offices." Therefore, cooperation among public and private TSIs is considered pivotal for EPPs' success (ITC, 2014). Nevertheless, there is still a lack of research on how to organise the collaborative efforts of TSIs to develop effective and efficient EPPs.

Networks are conceptualized as "a social system of interconnected relationships" (Campbell and Wilson, 1996, p.129). There are three main types of 
networks, according to the lead actors, sometimes named differently by different authors: societal or civic; business or private; and public or government-related (e.g. Dal Molin and Masella, 2016; Scott and Thomas, 2015). However, Oparaocha (2015, p.864) combines NGOs and government networks in one category, institutional networks, and defines the focus of institutional networks as "the interaction between institutions and organizations in order to support market opportunity recognition and the connection of the organization with other resources."

Some networks develop spontaneously, while others are planned. The literature on networks often calls these two types "emergent networks" and “orchestrated networks" (Dagnino et al., 2016). Orchestrated networks are usually associated to a lead organization that provides legitimacy, coordinates the process of value creation and organizes the operating environment for the network (Paquin and Howard-Grenville, 2013). Network dynamics are also relevant. Some networks expand over time, until they reach a saturation point, while others are constrained in their growth. In the last case, coordination of the network is more difficult when the number of members (and nodes) expand exponentially (Dagnino et al., 2016).

Ties among network members can be strong or weak, formal or informal. Granovetter (1973) suggests that strong ties are less productive than weak ties, because weak ties have the potential to bring new resources and capabilities to the network. Accordingly, strong ties typically mean redundancy in the knowledge and resource base of network members (Sharma and Blomstermo, 2003). Dagnino et al. (2016) present a comparison of networks based on formal and informal ties. According to the authors, formal ties impose higher costs of cooperation and commitment. Formal tie drivers are interorganizational projects that are "deliberately programmed and implemented", while informal tie drivers are more "spontaneous" and based on "serendipity" (p.360). Networks of formal ties are also characterized by "sharing of complex and highly contextual knowledge", while networks of informal ties by "heterogeneity and breadth" in their knowledgesharing processes (p. 360). 
One of the basic assumptions of network theory is that "the comparative analysis of organizations must take into account their network characteristics (Nohria and Eccles, 1992, p.7). Thus, network theory - particularly one of its theoretical approaches, interorganizational theory (Araujo and Easton, 1996; Neghandi, 1980) - can be used to analyse how different TSIs interact. This theoretical approach holds that independent organisations can benefit by coordinating their activities.

Interorganizational theory has looked more often to the interaction of government agencies and non-profit organisations (e.g. Provan, 1984; Provan and Milward, 1995), although several researchers have applied it to for-profit organisations and even to multinational corporations (e.g. Ghoshal and Bartlett, 1990; Lechner et al., 2010).

Authors that have adopted this approach quite early (e.g. Van de Ven, 1976) have been concerned with how different social and public agencies can maximize their effectiveness by purposefully working together and "coordinating a range of disparate resources to deliver particular types of services targeted at specific social problems" (Araujo and Easton, 1996, p. 76). Interorganizational coordination has received multiple definitions, varying from a "voluntary adjustment" to "systematic control," depending on the theoretical perspective adopted (Alexander, 2013, p.21). Such coordination can be carried out using informal (e.g. informal networks) or formal structures. Coordination of government programs should be seen as a political process of "mutual adjustment" between the members. In the author's view, many government programs, such as "a loan guarantee program for selected exporters, $[\ldots]$ is less the result of a rationally coordinated process of interaction between relevant actors" and more often "the result of self-interested bargaining and mutual adjustment in a political market" (Alexander, 2013, p.5).

Alexander (2013, p. xvi) claims that the complexity and scope associated with delivering most public services "cannot be addressed without deploying multiple agencies and a host of other organisations and institutions." Resources can include physical facilities, financial resources, personnel, or even the moreintangible capabilities that each entity possesses. The configuration of resources 
and activities of public agencies and non-profit organisations needs to be cautiously planned and implemented to be effective.

Rietjens et al. (2007) identify three types of coordination problems that could potentially threaten the success of interorganizational networks: task vagueness, dissimilarity of routines, and lack of local understanding. Fountain (2013) mentions regulatory ambiguity, unclear accountability, and limitations of the budget process to share resources as being restraints on effective coordination by independent government agencies.

Networks are classified according to their level of horizontal integration (Mandell and Keast, 2009). The present study focuses on "coordination networks," that is, when several entities have to coordinate their efforts to attain certain results that could not be achieved otherwise. Lecy et al. (2014) call these same entities "governance networks", while other authors (e.g. Emerson et al., 2012; Scott and Thomas, 2015) refer to "collaborative governance." Newig et al. (2010) claim that, because of the complexity involved in the coordination of government activities (and often non-governmental actors), network governance is now a critical issue. In the same token, Dal Molin and Masella (2016), recognizing the importance of coordination and integration in networks that combine public, private and societal institutions, observe that the knowledge on the governance of these networks is still fragmented.

Provan and Kenis (2008) and Kenis and Provan (2009) proposed three types of network governance: shared governance (organisations that collaborate without formal coordination), lead organisation governance (one organisation leads the network) and network administrative organisation governance (i.e. a separate organisation leads the network). Herranz $(2008$, 2010) describes three possible orientations for network coordination: bureaucratic, entrepreneurial, and community-oriented. Bureaucratic orientation works well at serving legal, regulatory and administrative requirements. It is also more interested in maintaining a stable flow of services, and accountability. An entrepreneurial orientation includes both a concern with financial issues (and greater financial performance) and an innovative approach to decision-making. Lastly, a community-oriented 
approach to network coordination focuses on building trust and promoting reciprocity among network members. Isett et al. (2011, p. i158) suggest that networks "may be formal and orchestrated by a public manager or they may be emergent, self-organising, and ad hoc, with many variants in between."

The number and the heterogeneity of network members affect governance; complexity increases with diversity (Dagnino et al., 2015; Dal Molin and Masella, 2016; Røiseland, 2011). In the case of networks comprising actors from public, private and not for profit organizations, the issue is even more relevant due to the differences in purpose, goals, routines, etc. Rietjens et al. (2007) identify three types of coordination problems that could potentially threaten the success of interorganizational networks: task vagueness, dissimilarity of routines, and lack of local understanding. Fountain (2013) mentions regulatory ambiguity, unclear accountability, and limitations of the budget process to share resources as being restraints on effective coordination by independent government agencies.

A review of the literature thus suggests that coordination issues are crucial to the effectiveness of export promotion networks, whatever their nature. Table 5 synthesizes the main issues concerning export promotion networks examined in this study.

Table 5 - Issues Concerning the Coordination of Export Promotion Networks

\begin{tabular}{|l|l|l|}
\hline Characteristic & Author(s) & Type \\
\hline Leading actor & Seringhaus and Rosson (1991) & public or government-related \\
\cline { 3 - 3 } & Lederman et al. (2009) & Private \\
\cline { 3 - 3 } & $\begin{array}{l}\text { Scott and Thomas (2015) } \\
\text { Dal Molin and Masella (2016) }\end{array}$ & public-private \\
\cline { 2 - 3 } & Scott and Thomas (2015) \\
& Dal Molin and Masella (2016) & Third sector, societal \\
\hline Intentionality & Paquin and Howard-Grenville (2013) & Emergent \\
\cline { 3 - 3 } & Dagnino et al. (2016) & Orchestrated \\
\hline Orientation & Herranz (2008, 2010) & Bureaucratic \\
\cline { 3 - 3 } & Dagnino et al. (2016) & Entrepreneurial \\
\cline { 3 - 3 } & & community-oriented \\
\hline Organization & Isett et al. (2011) & Formal \\
\hline
\end{tabular}




\begin{tabular}{|l|l|l|}
\hline Characteristic & Author(s) & Type \\
\hline & Dagnino et al. (2016) & Informal \\
\hline $\begin{array}{l}\text { Member } \\
\text { diversity }\end{array}$ & Røiseland (2011) & Homogeneous \\
\cline { 3 - 3 } & Dal Molin and Masella (2016) & Heterogeneous \\
\hline Governance & Provan and Kenis (2008) & shared \\
\cline { 3 - 3 } & Kenis and Provan (2009) & lead organization \\
\cline { 3 - 3 } & Dagnino et al. (2015) & network administrative organization \\
& Dal Molin and Masella (2016) & \\
\hline Coordination \\
mechanisms
\end{tabular}

\section{3.}

\section{Methodology}

The study uses the case method of investigation to examine three export promotion networks and answer the research question.

The nature of the research question guides the choice of the method to be used, as well as the nature of the events investigated and the level of control over them (Ghauri, 2004; Yin, 2014). The question to be answered in this study is of the "how" type and relates to a contemporary situation, on which detailed understanding is sought for theoretical development. This type of question is adequate to a qualitative study using the case method of investigation.

\subsection{1.}

\section{The case method}

The origins of the case method of investigation go back to the Chicago School of Sociology in the USA and the 19th century Frédéric Le Play's fieldwork in France (Hamel et al., 1993). In fact, the method has been shown to be more appropriate to address a number of issues that are relevant not only to the field of Management, but also to other social sciences such as Sociology, Psychology and Law, as well as other fields of science, like Medicine. 
Piekkari and Welch (2011) point out that case studies regained a leading role in management research, with the publication of special editions dedicated to qualitative research by leading scientific journals, and the inclusion of sessions on qualitative methods in the annual conferences of important academic associations such as the Academy of International Business - AIB and the European International Business Academy - EIBA. In the specific case of International Business, Brannen and Doz (2010) argue that the theories have moved too far from the phenomena they intended to explain, urging field researchers to take a closer look at their objects of study.

In fact, case studies serve to understand, from a holistic perspective, important and complex social phenomena that lack theoretical foundation or empirical evidence, and which cannot be fully understood by quantitative methods (Ghauri, 2004; Yin, 2014). Another important characteristic of the case method is its adequacy to investigate phenomena that cannot be dissociated from their context (Dubois; Gadde, 2002; Ghauri, 2004, Yin, 2014,). Piekkari et al. (2009, p.569) defined the case study as "... a research strategy that examines, through the use of a variety of data sources, a phenomenon in its naturalistic context, with the purpose of 'confronting' theory with the empirical world ".

The reasons to use the case method were raised by several authors (Eisenhardt, 1989; Ghauri, 2004; Gibbert et al., 2008; Yin, 2014), such as (i) when existing theory is inadequate, incomplete or empirical tests have generated conflicting or ambiguous results; (ii) to give a new perspective on a phenomenon already studied; (iii) to study the phenomenon in its context; and (iv) to study situations in which there is a large number of actors, variables, and interrelationships among them. Accordingly, the following aspects justify the adoption of the method in this research:

- The need to deeply analyze, in a detailed manner, the way in which different networks of TSIs are organized to serve the needs of firms in the creative industries, knowing that their use can vary according to different economic and cultural contexts; 
- The fact that quantitative research on export promotion does not provide a deep understanding of the processes and strategies pursued by TSIs to assist the internationalization of creative services firms;

- The scarcity of qualitative studies on TSIs and the recommendations to use them.

\subsection{2. \\ Unit of analysis and case selection}

To answer the research question, the unit of analysis selected was the export promotion network.

The selection of multiple cases follows the logic of replication. The purpose is to generate contrasting results for predictable reasons (Ghauri, 2004; Gibbert et al., 2008; Yin, 2014). Purposive theoretical sampling was used to identify ideal typical cases. The choice of cases had the support of specialists from the Brazilian Export Promotion Agency - Apex-Brasil.

Based on a list of eight potential TSIs, the researcher relied on her judgment to choose the final networks to be studied. This method is effective when only a limited number of cases can serve as primary data sources due to the nature of the research design as well as to its aims and objectives (Pauwels and Matthyssens, 2004). Finally, the process of case selection considered pragmatic issues such as ease of access and availability of secondary data.

Three cases were finally selected: United Kingdom, Colombia and South Korea export promotion networks. The first case deals with the promotion of UK design abroad. The second case looks at the promotion of filmmaking services in Colombia. The third case examines another approach to the export promotion of creative services: South Korea's experience in developing a specific agency to support its creative economy. 
The three countries, despite experiencing different stages of economic development, have been quite successful in their export promotion efforts. The choice of divergent cases purposefully aimed at examining different approaches used by different countries to deal with the issue of promoting the international activities of their creative industries.

The selection of industries was due to the importance given to specific creative industries by UK and Colombia. In the case of South Korea, the fact that the country has a centralized TSI to deal with export promotion of virtually all creative industries suggested it would be preferable to examine the South Korean TSIs as a whole.

The three cases selected should provide the means to investigate the diversity of contexts necessary to answer the research question.

\subsection{3. Industry selection}

The service sector has been considered the power engine of global economy and economic development, being responsible, since 2008, for more than half of the wealth generated by less developed countries. Concurrently, the creative industries, particularly, have grown at an extremely high pace in terms of job creation, and income and exports' expansion (Oliveira, Araujo and Silva, 2013).

The definition of the creative industries used by each country differs significantly, making it difficult to assess their economic value. Nevertheless, consistent evidence has been produced to demonstrate their relevance to the world economy. A $2015 \mathrm{EY}^{7}$ study revealed that the cultural and creative industries ${ }^{8}$

\footnotetext{
${ }^{7}$ Formerly Ernst \& Young, EY is one of the world's largest professional services firms.

${ }^{8}$ For the purposes of the study Cultural and Creative Industries - CCI - encompass industries producing creative goods and services, defined by UNESCO during its 2005 Convention on the Protection and Promotion of the Diversity of Cultural Expressions as "activities, goods and services which... embody or convey cultural expressions, irrespective of the commercial value they may have." Appendix 1 presents the 11 sectors composing cultural and creative industries for the purpose of the research.
} 
generated revenues of US $\$ 2,250$ billion in $2013^{9}$, being responsible for the creation of approximately 30 million jobs worldwide (EY, 2015). Regarding global trade, according to UNCTAD (2015), in 2012, the creative industries generated around US\$547 billion in exports.

\subsection{4.}

\section{Country selection}

United Kingdom, South Korea and Colombia experience different stages of economic development, but for all three countries the service sector plays a relevant role in their economic performance as shown in Table 6.

Table 6 - Main social and economic indicators for the three countries

\begin{tabular}{|l|c|c|c|c|c|c|}
\hline \multirow{2}{*}{ Indicators } & \multicolumn{2}{|c|}{ United Kingdom (1) } & \multicolumn{2}{|c|}{ South Korea (2) } & \multicolumn{2}{c|}{ Colombia (3) } \\
\cline { 2 - 7 } & Value & $\begin{array}{c}\text { Position } \\
\text { in the } \\
\text { World } \\
\text { Ranking }\end{array}$ & Value & $\begin{array}{c}\text { Position in } \\
\text { the World } \\
\text { Ranking }\end{array}$ & Value & $\begin{array}{c}\text { Position in } \\
\text { the World } \\
\text { Ranking }\end{array}$ \\
\hline Population (millions) & 64.8 & 22 & 51.2 & 27 & 47.7 & 29 \\
\hline $\begin{array}{l}\text { Service sector labor } \\
\text { force (\%) }\end{array}$ & 83.5 & - & 59.1 & - & 62 & - \\
\hline $\begin{array}{l}\text { GDP (official } \\
\text { exchange rate) } \\
\text { [US\$] }\end{array}$ & 2.57 & - & $\begin{array}{c}1.53 \\
\text { trillion }\end{array}$ & - & $\begin{array}{c}307.5 \\
\text { billion }\end{array}$ & - \\
\hline $\begin{array}{l}\text { GDP per capita } \\
\text { (Purchasing Power } \\
\text { Parity) [US\$] }\end{array}$ & 43,600 & 40 & 39,400 & 45 & 14,500 & 113 \\
\hline $\begin{array}{l}\text { GDP - real annual } \\
\text { growth rate (\%) }\end{array}$ & 1.7 & 169 & 3 & 114 & 1.7 & 165 \\
\hline $\begin{array}{l}\% \text { of GDP } \\
\text { generated by } \\
\text { Service Sector }\end{array}$ & 80.4 & - & 59.1 & - & 61.4 & - \\
\hline $\begin{array}{l}\text { Total Exports (US\$ } \\
\text { billions) }\end{array}$ & 436.5 & 11 & 552.3 & 6 & 36.8 & 57 \\
\hline $\begin{array}{l}\text { Exports' share of } \\
\text { GDP (\%) }\end{array}$ & 30.1 & - & 43.9 & - & 14.2 & - \\
\hline $\begin{array}{l}\text { Human } \\
\text { Development Index }\end{array}$ & 0.909 & 16 & 0.901 & 18 & 0.727 & 95 \\
\hline
\end{tabular}

Sources: CIA World Factbook and UNDP - United Nations Development Programme 2016 Human Development Reports

(1) All data refer to 2017 estimates except for the percentage of services sector labor force, which refers to 2014; GDP (Official Exchange Rate) and Human Development Index attributed to 2016.

(2) All data refer to 2017 estimates except for GDB (Official Exchange Rate) and Human Development Index which are attributed to 2016.

\footnotetext{
${ }^{9}$ To measure revenues, the study adopts an approach based on final consumer and business markets (B2C and B2B), primarily at retail prices (without indirect taxes). Informal sales, defined as cultural goods and services sold through unofficial distribution channels by producers and retailers, are included in the estimates, as well as public license fees for the audiovisual sector (TV and radio).
} 
(3) All data refer to 2017 estimates except for the percentage of services sector labor force, which refers to 2011; GDP (Official Exchange Rate) and Human Development Index attributed to 2016.

\section{The United Kingdom}

Ranked the third largest economy in Europe, the United Kingdom is considered a mature economy and highly developed nation, as well as a leading trading force and financial center, generating GDP annual growth rates of around $2 \%$ during the last five years - 2013 to 2017 - with a peak of $3.1 \%$ in 201410 . Considering the country's GDP per capita (Purchasing Power Parity), the UK was in the 40th place in the world ranking. As of 2016, the country was listed 16th in the Human Development Index world ranking.

The economy relies heavily on services, considered key drivers of the country's GDP growth. In 2017, around $80 \%$ of UK's GDP was generated by the service sector. At the same time, the creative industries, in particular, constituted a thriving sector of the British economy, worth in 2016 around US\$123,3 billion, with an increase of $7.6 \%$ over the previous year and of $44.8 \%$ from 2010 to $2016^{11}$ (Department for Digital, Culture, Media \& Sport, 2017; Easton et al., 2018).

Exports are also a significant driver of the British economy growth. In 2017, exports' share of GDP was $30.1 \%$; the country was the 11th world exporter. Moreover, in 2012, the country was ranked the third creative goods exporting country among the top 10 developed economies, led by the Design sector (UNCTAD, 2015).

\section{$\underline{\text { South Korea }}$}

South Korea came out as one of the $20^{\text {th }}$ century's most impressive economic successes, evolving within decades into a fast developing, globally connected, high-technology, service-based economy.

\footnotetext{
10 Data retrieved on March 2018 from the statistics portal Statista https://www.statista.com/statistics/281734/gdp-growth-in-the-united-kingdom-uk/.

${ }^{11}$ Corresponding to 92 billion British pounds converted in US\$ with the exchange rate of November 292017 (1 GBP = US\$1,3402). The sector contribution is measured in terms of Gross Value Added, i.e., the value of goods and services produced without associated costs.
} 
As the world evolved to knowledge and creative economies, South Korea's government acted to switch the country's economic growth model to one based on creativity and innovation, launching in 2013 and implementing since then, the 'Creative Economy Action Plan and Measures to Establish a Creative Economic Ecosystem' (UNCTAD, 2015).

The country's GDP grew consistently over the past decade, apart from 2008 and 2009 due to the global financial crisis. Considered one of the world's most booming countries, South Korea is one of the G-20 major economies as well as one of the Next Eleven countries, a term coined by Goldman Sachs in late 2005 to indicate eleven countries which have the potential to become the world's largest economies in the $21^{\text {st }}$ century. The country showed GDP annual growth rates of around 3\% during the last five years - 2013 to 2017. As to the GDP per capita (Purchasing Power Parity), South Korea was placed $45^{\text {th }}$ in the 2017 world ranking. The nation has shown steady growth and poverty reduction since the 1960s, being listed 18th in the 2016 Human Development Index world ranking.

Just like in the United Kingdom, South Korea's service sector is considered an important driver of the country's economic growth, with almost $60 \%$ of its GDP originating in the service sector in 2017. Indeed, since 1960s resources have been directed to export-oriented industries, what allowed the country to become the world's sixth-largest exporter in 2017, with exports representing a 43.1 share of its GDP in the same year. Moreover, in 2012, the country was ranked the fourth world exporter of creative goods among the top five developing countries, showing an increase of more than $150 \%$ over the previous decade (UNCTAD, 2015).

\section{$\underline{\text { Colombia }}$}

Colombia is a developing country, located in the Northwest corner of South America, which became independent from Spain in the early $19^{\text {th }}$ century. Despite several internal conflicts, the country has enjoyed a remarkable political and economic turnaround over the 2000s, standing out among South American countries for its relatively successful social and economic development process. 
Colombia's economy, like many South American countries, is still considerably based in agriculture and commodity-driven industries. However, many service sectors are becoming ore important in the economy. According to 2017 estimates, $62 \%$ of Colombian GDP was generated by the service sector. The country showed an average GDP annual growth rate of $3.2 \%$ for the last five years - 2013 to 2017 - with a peak of $4.87 \%$ in $2013^{12}$. Considering the GDP per capita (Purchasing Power Parity), Colombia was listed $113^{\text {th }}$ in the 2017 world ranking and $95^{\text {th }}$ in the 2016 Human Development Index ranking ${ }^{13}$.

In 2017 , Colombia was the $57^{\text {th }}$ world exporter, with exports' share of its GDP amounting to $14.2 \%{ }^{14}$. Despite its still modest position in the world's international trade ranking, Colombia has made important efforts to expand and promote exports in some specific goods and service sectors. At the late-2000s the country's government concluded that, to achieve sustainable economic development, it was necessary to focus on improving the competitiveness of some particular business sectors. The Productive Transformation Program (PTP), launched in 2009, can be considered the central axis of the country's export promotion policy. Inspired by the experiences of the East Asian economies that emerged from underdevelopment to achieve high growth rates, the program is a public-private partnership, created by Colombia's Ministry of Commerce, Industry and Tourism, and administered by Colombia's Foreign Trade Bank - Bancóldex engaging several industry sectors, considered strategic and of high export potential, with the aim of accelerating their growth and competitiveness.

The country that showed an increase of almost a 100\% from 2003 to 2012 in creative industries exports, maintaining a platform for the circulation and exchange of creative products and services in 6 key sectors: design, performing arts, audiovisuals, music, publishing and videos games. (UNCTAD, 2015). In 2013,

\footnotetext{
${ }^{12}$ Data retrieved on March 2018 from the statistics portal Statista https://www.statista.com/statistics/369076/gross-domestic-product-gdp-growth-in-colombia/ ${ }^{13}$ Idem previous footnote.

${ }^{14}$ Idem previous footnote.
} 
over $57 \%$ of Colombian digital content companies (videogames, animation, mobile apps and audiovisual) exported their products and services (Procolombia, 2013).

\subsection{5. \\ Data collection}

The study is based on secondary data. The secondary data were obtained from multiple sources, including organisations' sites, published documents, previous studies on the specific countries and export promotion agencies, journal articles, etc. The use of a number of sources enabled to reconstruct the cases and permitted triangulation, supporting construct validity (Yin, 2014). Appendix 4 presents the most important secondary data sources for each case and the main type of documents provided by them.

\section{4. \\ Case analysis}

Individual case reports and cross-case analysis were used.

The cases were developed sequentially, that is, each case study was completed (in terms of data collection and analysis) before starting the next case. Accordingly, a detailed descriptive report for each case was prepared and preliminary data analysis performed before proceeding to the next case. Although this process takes more time, it is considered preferable to a simultaneous collection of data followed by an analysis of all the cases because it gives the researcher the opportunity to refine the research question, and even to select cases that are more suitable to the originally envisaged purpose (Ghauri, 2004; Dubois and Gadde, 2002).

The data analysis used within-case and cross-case analysis (Pauwels and Matthyssens, 2004; Yin, 2014). After a preliminary analysis of each case, a detailed within-case analysis was performed using chronologies and tables (Ghauri, 2004), followed by a comparison of the three cases (cross-case analysis), aiming at identifying similarities and differences. At the end of the analysis, an effort was made to theorize the different types of export promotion networks identified. 
Several tactics were applied throughout the investigation, with the purpose of increasing the validity and reliability of the research based on Yin's (2014) recommendations (Table 7).

\begin{tabular}{|c|c|c|}
\hline Tests & Tactics & $\begin{array}{l}\text { Research phase when they } \\
\text { were applied }\end{array}$ \\
\hline $\begin{array}{l}\text { Construct } \\
\text { validity }\end{array}$ & $\begin{array}{ll}- & \text { Use of multiple sources of evidence } \\
\text { (triangulation) } \\
\text { - } & \text { Establishment of chain of evidence } \\
\text { - } & \text { Review of case study reports by } \\
& \text { specialists in export promotion }\end{array}$ & $\begin{array}{ll} & \text { Data collection } \\
\text { - } & \text { Data collection } \\
\text { - } & \text { Reports } \\
\end{array}$ \\
\hline $\begin{array}{l}\text { Internal } \\
\text { Validity }\end{array}$ & - Use of cross-case analysis & - Data analysis \\
\hline $\begin{array}{l}\text { External } \\
\text { Validity }\end{array}$ & $\begin{array}{l}\text { - Use of multiple cases } \\
\text { - Use of replication logic }\end{array}$ & $\begin{array}{ll}\text { - } & \text { Research design } \\
\text { - } & \text { Research Design } \\
\end{array}$ \\
\hline Reliability & $\begin{array}{l}\text { - Use of case study protocol } \\
\text { - } \quad \text { Development of case study database }\end{array}$ & $\begin{array}{ll}\text { - } & \text { Data collection } \\
\text { - } & \text { Data collection } \\
\end{array}$ \\
\hline
\end{tabular}

\section{5.}

\section{Research Limitations}

There are limitations inherent to qualitative research based on case studies. The first one stems from the very nature of the method, that is, the fact that case studies do not allow statistical generalizations: the behavior of a specific unit of analysis may or may not reflect the behavior of the population. Nevertheless, it is possible to use the findings of case studies to arrive to analytical generalizations. Another limitation commonly attributed to case studies is associated to the subjectivity of the researcher's judgment. In fact, subjectivity is typical of qualitative methods, but can be mitigated by the use of triangulation (Yin, 2014), a procedure adopted in this research.

Additionally, this study analyzes only three cases, all representing successful experiences. The examination of other cases, including some describing failed experiences, could offer other important insights, enriching the understanding of the phenomenon being studied. Indeed, the unavailability of information on the networks of various countries restrained the prior identification of successful and unsuccessful representative cases. Furthermore, researching TSIs' efforts to 
promote exports of other industries could also imply different findings, revealing other important probable patterns.

Also noteworthy is the fact that this type of data is considered by many TSIs and their managers as strategic, and therefore confidential, what obstructed the process of primary data collection.

\section{6.}

\section{Case Description}

This section briefly describes the three cases selected for the study: design in the UK; filmmaking in Colombia, and the creative industries in South Korea.

\subsection{1.}

\section{Design in the United Kingdom}

The UK is one of the leading countries in the world in terms of design; the country has been consistently ranked among the top six in design over the past few years, according to several world rankings. Furthermore, exports of products in which design was a key characteristic were responsible for more than $7 \%$ of total UK exports in 2013, and UK design exports rank fifth in the world (Design Council, 2015). Accordingly, the design industry has received substantial governmental support, as well as support from non-government entities, and it is considered a strategic industry by the UK.

Some of the institutions that promote UK design internationally are: the Design Council, the British Design and Art Direction, the Design Business Association, the British European Design Group, the Department of Architecture, Design, and Fashion (DADF) of the British Council, the British Design Initiative, and the Design Museum. Table 8 presents some characteristics of these organisations. 


\section{Table 8 - UK Organisations and the Promotion of the Internationalization of Design}

\begin{tabular}{|c|c|c|}
\hline Organization & $\begin{array}{l}\text { Date of } \\
\text { inception }\end{array}$ & $\begin{array}{l}\text { Goals and activities related to the promotion of } \\
\text { the internationalization of UK design }\end{array}$ \\
\hline $\begin{array}{l}\text { Design Council (non-profit } \\
\text { organisation) }\end{array}$ & 1944 & $\begin{array}{l}\text { Increase the competitiveness of UK design; } \\
\text { encourage UK firms to use design to reach new } \\
\text { markets via training and coaching. }\end{array}$ \\
\hline $\begin{array}{l}\text { British Design and Art } \\
\text { Direction (professional } \\
\text { association) }\end{array}$ & 1962 & $\begin{array}{l}\text { Establish standards of excellence for UK design; } \\
\text { promote UK design internationally. }\end{array}$ \\
\hline $\begin{array}{l}\text { Design Business } \\
\text { Association (industry } \\
\text { association) }\end{array}$ & 1986 & Offer export advice and market information. \\
\hline $\begin{array}{l}\text { British European Design } \\
\text { Group (trade organization) }\end{array}$ & 1991 & $\begin{array}{l}\text { Promote the internationalization of European and } \\
\text { British design overseas (from Asia to the Americas) } \\
\text { by organising trade fairs and exhibitions, and by } \\
\text { offering coaching and consulting services. }\end{array}$ \\
\hline $\begin{array}{l}\text { British Council (Dept. of } \\
\text { Architecture, Design and } \\
\text { Fashion) }\end{array}$ & n.a. & $\begin{array}{l}\text { Promote British design through international } \\
\text { exchange programmes, international and national } \\
\text { events, foreign missions, student grants, etc. }\end{array}$ \\
\hline $\begin{array}{l}\text { British Design Initiative } \\
\text { (dissolved on January } \\
\text { 2016) }\end{array}$ & 1993 & $\begin{array}{l}\text { Offer counseling to foreign firms interested in UK } \\
\text { design services; participate in foreign missions and } \\
\text { exhibitions; register export design activities, etc. }\end{array}$ \\
\hline $\begin{array}{l}\text { Design } \\
\text { profit) }\end{array}$ & 1989 & Organise touring exhibitions of UK design abroad \\
\hline $\begin{array}{l}\text { Dept. for International } \\
\text { Trade (previously UK } \\
\text { Trade and Investment) }\end{array}$ & 1999 & $\begin{array}{l}\text { Enhance the competitiveness of UK firms in } \\
\text { international business by offering a broad range of } \\
\text { services to firms in general. }\end{array}$ \\
\hline
\end{tabular}

Source: sites of the organisations.

Each of these organisations has a variety of programs aimed at strengthening national capabilities in design, supporting firms and promoting the UK as a leading country in design. In spite of the number of institutions and initiatives, there is strong cooperation between public and private entities and a common understanding that the development of the UK design industry is associated with the expansion of its international business activities.

The Department for International Trade (DIT) (previous UK Trade and Investment - UKTI) is the United Kingdom's trade and investment promotion organisation. It has 227 foreign offices, serving around 48,000 client firms. The creative industries are among the five key sectors targeted by the DIT (ITC, 2015). There is evidence that the organisation's actions to support UK firms in foreign countries are well-conceived and effectively conducted. The large number of offices permits the development of a network of contacts within specific foreign 
markets, connecting UK companies with local business and government (Coelho and Rocha, 2013). The DIT is also recognized for "one of the most advanced results-measurement systems" among TSIs worldwide (Prunello, 2014, p.15). The DIT does not exercise a formal role of coordination; however, because the other institutions are smaller and focused on one sector - in this case, design - without a broad range of foreign offices, the DIT's role is critical for networking and for local business services, thus playing an important coordination role. According to Alexander and Warwick (2007, p.182), to provide "intermediation service is one of the main roles" of the DIT because of the government's "wide range of contacts." The authors report the results of a study that evaluates the performance of the DIT positively.

\subsection{2.}

\section{Filmmaking in Colombia}

The second case study is the filmmaking services industry in Colombia. Colombia presently ranks fourth in Latin America in the production of movies. The government's main strategic goals for the industry include: promote Colombia as one of the leading destinations for the production of movies; attract foreign investment; and promote co-productions and international partnerships. The main competitive advantages for Colombia to develop this industry are believed to be its geographic diversity (such as tropical forest, high mountains, and ocean coastline), rich colonial heritage (such as historical sites, mansions, and villas), low-cost services (compared to the US and Europe), skilled professionals and technical staff, and a favourable regulatory environment (CONPES, 2007).

The following government agencies are involved in the promotion of filmmaking in Colombia: the Colombian Ministry of Culture's Film Office, the National Council for Film Arts and Culture (CNACC), Proimágenes Colombia, and Procolombia. In addition, private entities also have a say in this process. To coordinate these efforts among the agencies and with the private sector, the Colombian Film Promotion Committee (CFPC) was created in 2012. 
The Committee is composed of the Secretary of Commerce, Industry and Tourism, the Secretary of Culture, the director of the Ministry of Culture's Film Office, the director of Proimágenes Colombia, the president of Procolombia (the Colombian export promotion agency), a representative of the filmmakers in the CNACC, and two other representatives with a broad background in the film industry. The CFPC administers the Colombian Film Fund, created in 2012, which reimburses part of the expenses (up to 40\%) to foreign filmmakers for film services delivered in Colombia by local firms, and is responsible for promoting the country as a film location. The CFPC offers an additional list of services to foreign filmmakers, such as: information regarding incentives and services available locally, legal assistance, networking with local organisations, etc. Table 9 presents some additional information on these organisations.

\section{Table 9 - Colombian Organisations and the International Promotion of the Filmmaking Industry}

\begin{tabular}{|l|c|l|}
\hline Organization & $\begin{array}{c}\text { Date of } \\
\text { inception }\end{array}$ & $\begin{array}{l}\text { Goals related to the promotion of Colombia as a } \\
\text { filmmaking location }\end{array}$ \\
\hline $\begin{array}{l}\text { National Council for Film } \\
\text { Arts and Culture (CNACC) } \\
\text { (government agency) }\end{array}$ & n.a. & $\begin{array}{l}\text { Strengthen and promote the Colombian film industry } \\
\text { in cooperation with Proimágenes }\end{array}$ \\
\hline $\begin{array}{l}\text { Proimágenes Colombia } \\
\text { (not for profit) }\end{array}$ & 1997 & $\begin{array}{l}\text { Organise and coordinate events, exhibitions, and } \\
\text { festivals; facilitate international co-productions and } \\
\text { joint projects; provide detailed information on sites } \\
\text { and services available in Colombia for foreign } \\
\text { filmmakers. }\end{array}$ \\
\hline $\begin{array}{l}\text { Procolombia (export } \\
\text { promotion agency) }\end{array}$ & 1992 & $\begin{array}{l}\text { Promote Colombian exports, by offering a broad } \\
\text { range of services to firms in general. }\end{array}$ \\
\hline $\begin{array}{l}\text { Colombian Film Promotion } \\
\text { Committee (CFPC) }\end{array}$ & 2012 & $\begin{array}{l}\text { Offer information, support, and advice to foreign } \\
\text { filmmakers interested in Colombia; manage the } \\
\text { Colombian Film Fund; organise missions of foreign } \\
\text { filmmakers to Colombia. }\end{array}$ \\
\hline
\end{tabular}

Source: sites of the organisations; n.a. = not available

Procolombia (formerly Proexport Colombia) is an export promotion agency with 26 foreign offices, serving around 7,000 domestic companies. Like many other developing countries' export promotion agencies, Procolombia does not target specific key industries, but serves firms from every industry in the agribusiness, manufacturing and services sector (ITC, 2015). Nevertheless, Procolombia has a limited number of offices abroad and most of its budget is spent on activities within the country, which is explained by the fact that firms need to overcome internal obstacles or competitive disadvantages (González, 2009) before they are ready to 
export. Analyzing an EPP conducted by Procolombia in the early 2000s, González (2009) mentioned the lack of coordination between operators and the TPO as one of the key criticisms of participant members. However, Procolombia has made substantial efforts to overcome many of these problems. In fact, in 2014 Procolombia received the ITC award for the best export promotion agency in a developing country for its methodology for developing textiles and apparel exports to the US, focusing particularly on Colombian firms' ability to meet US buyers' expectations.

In this case, the Colombian government created a specific entity (CFPC) to carry out the coordination and leadership of the export promotion efforts for the audiovisual sector in the country. Because of its specificities, the audiovisual industry needs extensive coordination due to the different goals and purposes of government institutions, filmmakers, distributors, and other organisations and individuals: whereas some focus on the cultural value of the activity, others emphasize the business side. Therefore, coordination is not only a matter of organising export assistance in an efficient and effective manner, but also getting the commitment and ensuring the cooperation of different stakeholders.

\subsection{3.}

\section{Creative Industries in South Korea}

The third case examined herein is the exporting of creative services from South Korea. In fact, South Korea has promoted a major change in its support to the creative industries. Until 2009, there were several agencies in charge of developing specific sectors of the creative industry, including the Korea Broadcasting Institute, the Korea Culture and Content Agency, the Korea Game Industry Agency, the Cultural Content Center, and the business group for digital content of the Korea IT Industry Promotion Agency. In 2009 these organisations merged into a single new agency, the Korea Creative Content Agency (KOCCA), under the supervision of the Ministry of Culture, Sports and Tourism (MCST). The purpose was to promote the development and growth of South Korea's creative industries in order for the country to become one of the five leading content 
providers in the world. The agencies responsible for design and information technology have been kept separate.

KOCCA presently has offices in seven countries: the US, Japan, China, the UK, Indonesia, the UAE and Brazil. The main functions of KOCCA are: providing support to content development and production; support to start-ups, including incubating; support to the localization of content (such as translation, dubbing, and marketing); organising and hosting international trade shows, fairs, exhibitions and other events; providing general overseas services; offering human resource development and education; and developing cutting-edge technology. KOCCA presently provides support to the following segments of the creative industries: games, broadcasting, cartoons and comics, animation, character licensing, music and fashion. In addition, the organisation runs a laboratory, a training center and an incubator.

KOCCA works in close connection with the Korea Trade-Investment Promotion Agency (KOTRA), created in 1962 to support the internationalization of the Korean economy. Presently, KOTRA has 126 trade offices in 86 countries, with around 14,000 client companies (ITC, 2015). In 2011 KOTRA launched the Service Mundus Programme, aimed at the internationalization of South Korea's service industries, including a small group of promising exporters from several service industries: animation, design, character licensing, music, smart concept/ games and mobile; e-learning, franchising, health services, and engineering services. The initiative was meant to support small and medium-sized world-class firms in their foreign expansion, in order to reduce the typical trial-and-error approach to internationalization used by entrepreneurial firms in their internationalization process. The program offers the following services, in addition to other services delivered by KOTRA: a roadmap for the international expansion of SMEs; the development of partnerships and strategic alliances required to enter international markets; customer and partner identification in international markets; customised market research; consulting and coaching for planning and budgeting; legal advice in terms of copyright and brand protection in foreign countries. 
KOTRA's major contribution to the export expansion of South Korea's creative industries probably has to do with its large network of foreign offices, whereas KOCCA only administers seven offices abroad. As past research has revealed (Kang, 2011), KOTRA'S offices in foreign countries have had a positive and significant impact on the growth of the country's exports.

KOCCA has developed close partnerships with other government agencies, such as the Korean Culture and Information Service (KOCIS) and the Korean Film Council (KOFIC), both supervised by the MCST. Other partners are the Ministry of Foreign Affairs and the Ministry of Tourism (Tuk, 2012). In addition, KOCCA works in cooperation with the Korea Invention Promotion Agency (KIPA) to support inventiveness in the creative industries.

Interestingly, there is only an informal coordination among the various agencies involved in the promotion (domestically and internationally) of South Korea's creative industries. Although Tijan (2009, p.181) claims that "all these efforts work collectively," Kim and Nam (2016) point out that there is "a lack of systematic integration between the MCST and key national agencies of the tourism and creative industries sector" (p.110), and they suggest that there is a need for "a systematic communication channel to facilitate effective collaboration and cooperation between relevant government organizations" (p.112).

Table 10 presents South Korean organisations involved with the internationalization of Korean firms in the creative industries. Although some organisations serve multiple industries, the table only includes those activities that directly or indirectly promote the international activities of the firms.

Table 10 - South Korean Organisations and the International Promotion of the Creative Industries

\begin{tabular}{|l|c|l|}
\hline Organization & $\begin{array}{c}\text { Date of } \\
\text { inception }\end{array}$ & $\begin{array}{l}\text { Goals related to the promotion of South Korea's } \\
\text { creative industries }\end{array}$ \\
\hline $\begin{array}{l}\text { Korea Creative Content } \\
\text { Agency (KOCCA) } \\
\text { government agency) }\end{array}$ & 2009 & $\begin{array}{l}\text { Promote the growth of South Korea's creative } \\
\text { industries in order to turn the country into one of the } \\
\text { world's leading producers of content. }\end{array}$ \\
\hline $\begin{array}{l}\text { Korea Trade-Investment } \\
\text { Promotion Agency (KOTRA) } \\
\text { (government agency) }\end{array}$ & 1962 & $\begin{array}{l}\text { Promote South Korea's image, as well as its } \\
\text { products and services abroad. }\end{array}$ \\
\hline
\end{tabular}




\begin{tabular}{|l|c|l|}
\hline Organization & $\begin{array}{c}\text { Date of } \\
\text { inception }\end{array}$ & $\begin{array}{l}\text { Goals related to the promotion of South Korea's } \\
\text { creative industries }\end{array}$ \\
\hline $\begin{array}{l}\text { Ministry of Culture, Sports } \\
\text { and Tourism (MCST) } \\
\text { (government agency) }\end{array}$ & 1968 & $\begin{array}{l}\text { Support the development of South Korea's creative } \\
\text { industries and to improve its cultural reputation } \\
\text { globally }\end{array}$ \\
\hline $\begin{array}{l}\text { Korean Culture and } \\
\text { Information Service (KOCIS) } \\
\text { (government agency) }\end{array}$ & 1971 & $\begin{array}{l}\text { Promote South Korea overseas. Operates 29 } \\
\text { cultural centers outside the country. }\end{array}$ \\
\hline $\begin{array}{l}\text { Korean Film Council } \\
\text { (KOFIC) (state-supported) }\end{array}$ & 1973 & $\begin{array}{l}\text { Support and promote Korean filmmakers in the } \\
\text { domestic and international markets. }\end{array}$ \\
\hline $\begin{array}{l}\text { Korea Invention Promotion } \\
\text { Agency (KIPA) } \\
\text { (government agency) }\end{array}$ & 1973 & $\begin{array}{l}\text { Promote the international competitiveness of } \\
\text { Korean inventiveness by offering assistance, } \\
\text { training, and patent management support. }\end{array}$ \\
\hline
\end{tabular}

Source: sites of the organisations.

\section{7.}

\section{Cross-Case Comparison}

The descriptive account of how each country organised its export promotion network to promote the creative industries' exports led to a classification of the three approaches according to four previously identified dimensions (leading actor, intentionality, orientation, organisation, member diversity, governance and coordination mechanisms). Table 11 presents a comparison of the different approaches used.

\section{Table 11 - A Comparison of the Three Export Promotion Networks}

\begin{tabular}{|l|l|l|l|}
\hline $\begin{array}{l}\text { Characteristic of export } \\
\text { promotion networks }\end{array}$ & $\begin{array}{l}\text { UK } \\
\text { (design) }\end{array}$ & $\begin{array}{l}\text { Colombia } \\
\text { (filmmaking) }\end{array}$ & $\begin{array}{l}\text { South Korea } \\
\text { (creative } \\
\text { industries) }\end{array}$ \\
\hline Leading actor & public-private & public & Public \\
\hline Intentionality & orchestrated & orchestrated & orchestrated \\
\hline Orientation & entrepreneurial & bureaucratic & $\begin{array}{l}\text { entrepreneurial and } \\
\text { bureaucratic }\end{array}$ \\
\hline Organization & informal & formal & Informal \\
\hline Member diversity & heterogeneous & heterogeneous & heterogeneous \\
\hline Governance & $\begin{array}{l}\text { lead organization } \\
\text { (DIT) }\end{array}$ & $\begin{array}{l}\text { network } \\
\text { administrative } \\
\text { organization (CFPC) }\end{array}$ & Shared \\
\hline Coordination mechanisms & loose & tight & tight/loose \\
\hline
\end{tabular}

The lead actors in UK's export promotion network are private-public export promotion network, while both Colombia and South Korea are public. The three networks show a considerable amount of member heterogeneity (Dal Molin and Masella, 2016; Røiseland 2011). The UK's network presents a combination of 
public, not for profit and private organizations, while Colombia's has public and not-for-profit members, and South Korea's is essentially public, although with several different types of agencies. Interestingly, the literature has only recently emphasized the presence of not-for-profit organizations as part of interorganizational networks (e.g. Scott and Thomas, 2015; Dal Molin and Masella, 2016). In Colombia, the participation of the private sector is limited to seats in a national state-sponsored film council. The three networks can be characterized as orchestrated (Dagnino et al., 2016), because they were intentionally created to promote these industries' internationalization. This characteristic is expected in publicly-sponsored programs.

In terms of orientation and organisation, the Korean system more closely resembles the UK's. In both countries the coordination of export promotion networks is informal, and they seem to adopt a more entrepreneurial approach than Colombia's. However, the UK system has a clear lead organization - the DIT, the UK's trade and investment promotion organisation - while the Korean system does not have a well-defined leadership. This specific characteristic might explain why there has been some concern about improving the coordination mechanisms of the export promotion network in charge of the promotion of South Korea's creative industries abroad (Kim and Nam, 2016). As for Colombia's approach, it shows a more bureaucratic focus (Herranz, 2008, 2010) and is more formal (Isett et al., 2011; Dagnino et al., 2016). It is organized under the direction of a network administrative organization - the CFPC - designed to bring efforts together and promote cooperation among different stakeholders.

\section{8. \\ Discussion}

The comparison between different approaches to export promotion in the creative industries shows that both centralization (as in South Korea) and decentralization (as in the UK) of activities may work satisfactorily. Defining an ideal set up is not feasible when dealing with different institutional environments (e.g. Belloc and Di Maio, 2011, Gillespie and Riddle, 2004). Whatever the degree of centralization, countries have adopted a loose, tight (Seringhaus and Rosson, 
1991), or loose-tight coordination system, each with advantages and disadvantages. However, regardless of the set up adopted, this study's results supports the understanding that interorganizational networks generate organizational effectiveness by enhancing organizational capacity building and leading to positive effects on EPPs and TSIs (e.g. Jones et al., 2017; Oparaocha, 2015; Paarlberg \& Varda, 2009).

Figure 6 offers a pictorial representation of the UK and the Colombian cases analysed in this paper.

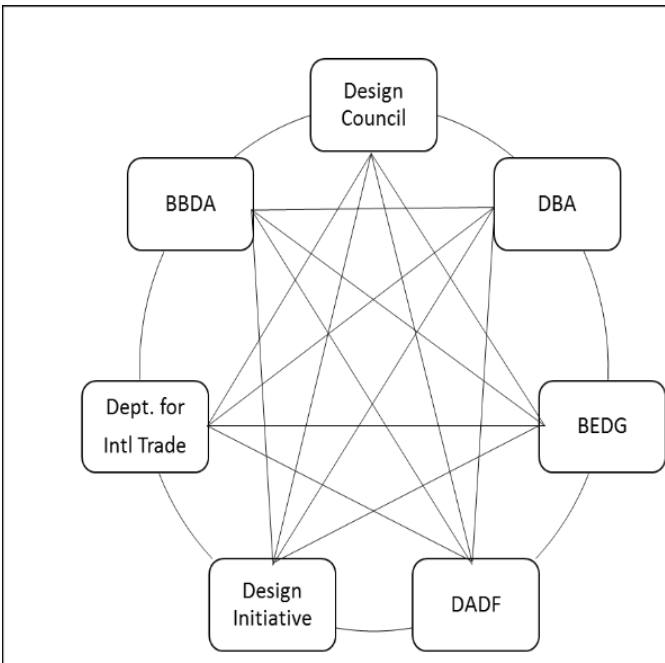

Loose Coordination - U.K. design EPP

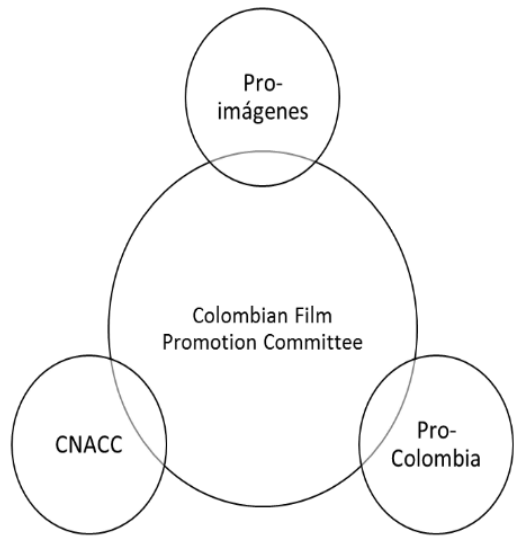

Tight Coordination - Colombia filmmaking EPP

Figure 6 - Comparison of the UK and Colombian approaches

The UK's approach to the promotion of the design industry can be conceptualized as a loose coordination system. This approach seems to work quite well in this case, but the model may not be easily copied by other countries. It is possible that one reason for the smooth functioning of these different institutions' activities is the fact that the UK has a mature design industry and consistently ranks among the leading countries in design. Therefore, efforts are rather incremental and do not require substantial change. However, the loose coordination approach is not the most effective way of dealing with export promotion networks. As depicted in Figure 6 , the number of potential linkages between the organisations involved is very high, increasing the risk of duplication of efforts, lack of coordination, 
problems of communication, etc. (e.g. Czinkota, 2012; GAO, 2001; Rietjens et al., 2007; Williamson et al., 2011; Dagnino et al., 2016).

The Colombian approach addresses the problem of coordination by creating a specific institution to coordinate the export promotion network for filmmaking services. All relevant entities associated with the public or private filmmaking industry have a seat on the Committee, thus permitting easy communication and coordination of efforts and activities. Unlike the UK, Colombia is developing a nascent industry, and the country is not a traditional supplier of pre- and postproduction services to the global filmmaking industry. Therefore, the approach used - which I call tight coordination - potentially allows for a better use of the country's resources and avoids duplication of efforts and conflicts. Nevertheless, the creation of a central committee is not enough for a tight coordination; its success depends on effective and efficient implementation (e.g. Belloc and Di Maio, 2011; Alexander, 2013).

Lastly, South Korea has adopted a centralized approach by combining most of its creative industries into one single agency, after having used a decentralized system for many years. Although potentially it can allow for better coordination and control, there are also potential risks of not giving enough attention to different activities and trying to 'fit all into one.' The cooperation between the agency responsible for the creative industries and the Korean trade promotion organisation is enhanced by the fact that the latter has recently launched a programme to internationalize South Korea's services industries, with particular emphasis on the creative industries. Goal congruence appears to be a critical factor in promoting cooperation among Korean TSIs. In spite of this, there has been some criticism regarding the coordination of activities between different entities (Kim and Nam, 2016). Therefore, the study's results indicate that South Korea has adopted a tight approach, by combining several agencies into one, but also keeps a loose approach in the relationships between the creative industries agency and the export promotion organization (Figure 7). 

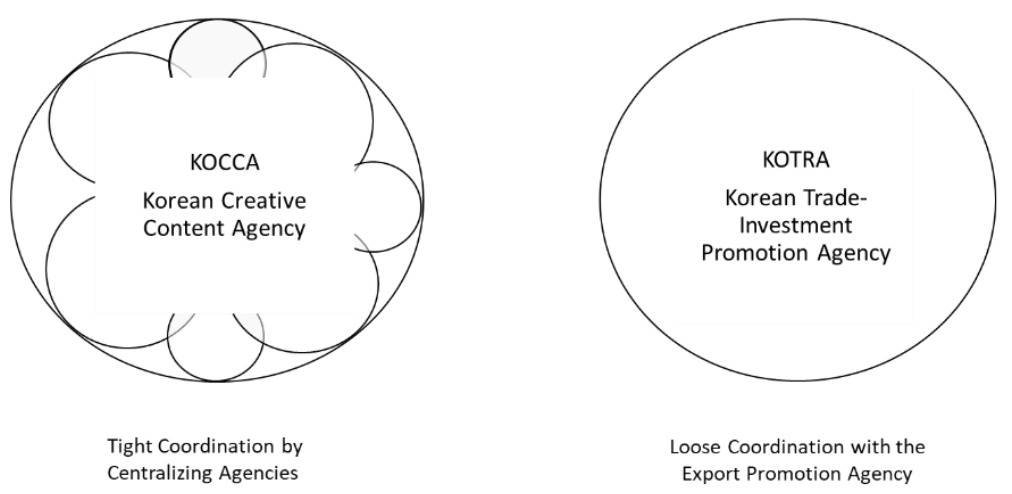

Figure 7 - Korea's tight/loose coordination

The examination of these three types of export promotion networks and their coordination choices suggests that there are different options that can be followed by different countries. No one model fits any one country specifically. Four factors seem to have an impact on the coordination of export promotion networks: the level of economic development of each country; the level of development of the target industry; the country's export intensity; and cultural and historical factors.

As to level of economic development, one can hypothesize that less resources (typical of a less developed country) invite a tighter coordination system, which tends also to be more bureaucratic. It is noteworthy, in the case of Colombia, the limited participation of private sector actors, contradicting the prescription in the literature that strategic collaboration of the private sector is paramount for attaining success with export promotion efforts (e.g. Belloc and Di Maio, 2011). Yet, this limitation seems to be offset by the presence of the private sector in the executive board of the Colombian state-sponsored film council. Indeed, the literature points out that private sector participation in boards are related to greater TSIs' efficiency (ITC, 2016b).

The stage of development of the industry targeted by the export promotion network, whether nascent, growing, or mature, also seems to have an impact. The UK adopts loose coordination mechanisms probably because the country's design 
industry is already mature, while Colombia chooses a tighter coordination of the export promotion network to develop a nascent industry. South Korea, on the other side, is an export-oriented economy, with almost $44 \%$ of its GDP coming from exports (compared with Colombia, with around 14\%), and thus invests much more in the development of exports. The Korean export promotion network for the creative industries is characterized by a combination of pre-existing government agencies into one, which interacts with other agencies, particularly the powerful national export promotion agency. Moreover, in the case of South Korea, cultural and historical factors seem to also interfere; in a collectivist culture, the congruence of interorganizational with national goals is easier to achieve (Hofstede, 1980), and therefore do not require tight coordination between different agencies.

In addition to the four factors cited as determinants of the type of coordination adopted by export promotion networks, we second the extant literature that argues that each specific situation calls for the right combination of partners, participation structures, and coordination mechanisms, and that the network's leading actor must be able to detect and implement the adequate mix (Russell et al., 2015; Oparaocha, 2015). Indeed, size, governance structure, funding partners and activities of TSIs basically will vary according to the strategic needs of each country (ITC, 2016b). Finally, the study leads us to believe that systematically monitoring the TSIs' performance is critical to assessing the eventual need to promote changes in their governance structure.

\section{9.}

\section{Conclusions}

Networks of organisations are today an undeniable trend in almost every field of human activity, such as export promotion. While these networks simultaneously allow for the combination of resources and capabilities of different entities, they also challenge the ability to coordinate these efforts in an effective and efficient way. Coordination thus has turned into a critical issue in export promotion activities. 
The aim of this research was thus to explore the issue of how different countries have successfully designed and implemented the coordination of TSIs' activities to assist their creative industries. The study provides empirical evidence of how different approaches, from the centralization of an export promotion network to decentralization, and from loose coordination to tight, may be used to promote the exports of firms in the creative industries.

The results also suggest that each context may require a different approach to the coordination of TSI's activities. The degree of economic development of each country, the maturity of the target industry, the resources dedicated to export promotion, as well as cultural and historical issues, may play a role in determining which approach would be a better fit for each country and sector.

Although the study has not covered the issue of network framing, that is, the extension to which these networks are subject to political goals and resource allocation restraints, future studies should examine this issue. The effectiveness of these export promotion networks was also not considered in this study, although their choice was based on the understanding of specialists that they have been quite successful.

This study has its limitations. Firstly, the use of the case method of investigation does not permit the generalization of the findings to the population of TSIs and export programs directed to the creative industries. The method, however, allows for analytical generalizations. Secondly, the research examined only three cases; other cases could provide additional perspectives to enrich the understanding of the phenomena under study. Thirdly, the three cases portray successful experiences. It is possible that unsuccessful experiences provide additional insights into the matter. Also noteworthy is that the data required for the research is considered by many TSIs and their managers as strategic, and therefore confidential, thus limiting the access to primary data. Attempts to schedule personal interviews were frustrated, and the only personal interview conducted did not add relevant information beyond that already obtained from secondary sources. Further research is needed to examine this issue in more depth. 


\section{5. \\ Chapter 5 - Conclusions and Avenues for Future Research}

This chapter presents the overall conclusions reached by the study, the contributions to the theory and practice of export promotion, and some avenues for future research.

\section{1.}

\section{Conclusions}

The conclusions reached by this $\mathrm{PhD}$ thesis are limited by the qualitative methods used, which do not allow statistical generalizations of the findings, but only analytical generalization.

My first concern was to understand the fit between the export promotion literature and the literature on export barriers. Since barriers limit the firm's ability to export, and the main purpose of export promotion is to address the problems that inhibit export activities, one should expect a perfect match. Nevertheless, the examination of the literature shows only limited dialogue between the two sides. Although the export promotion literature acknowledges the existence of export barriers, in general the authors do not go beyond this recognition. This situation becomes even more obvious when examining the list of authors from each literature, which is surprisingly different. Therefore, one can conclude that both literatures present serious shortcomings that need to be addressed, and do not at this point offers a broad and consistent enough view of the match between firms' needs and TSIs' offer.

An important issue that should be taken into consideration to allow a better match between export promotion and export barriers literatures and guide research on these fields is the fact that despite the existence of market failures and barriers to entry in international markets, this does not automatically imply that export assistance is adequate. The correct appraisal of the need for this type of intervention demands an evaluation of the cost-effectiveness of government actions. Export promotion must bring benefits not only to firms individually, but also to society as 
a whole (meaning citizens/taxpayers), balancing issues associated to equity and fairness.

The difficulty in defining and empirically measuring the main constructs export barriers, export promotion and export performance - surrounding these research fields are probably at the heart of the flaws in terms of consistency and comparability of the research results. Moreover, the phenomena-based nature of the export barriers domain, that is, the unavailability of sound theoretical perspectives to lead researchers towards building a more consistent and reliable body of knowledge, adds another obstacle to the dialogue of both streams of literature. Another part of the problem comes from measuring the benefits of export promotion only from an economic perspective. The use of other measures, both at the macro and micro level, would permit a more comprehensive evaluation of the impact of export promotion. The standardization of data collection instruments would also add to the quality of research. Also, more longitudinal studies are required, both quantitative and qualitative, in order to evaluate the long-term impact of export promotion.

Also, the literature on export promotion ignores, to a large extent, the role of private sector and non-profit TSIs. Questions that remain are: Are private and non-profit TSIs effective? When is it desirable and convenient to involve private and non-profit TSIs and how should they act? How to foster cooperation between different kinds of TSIs? What type of organizational set-up could better serve export promotion systems?

Therefore, the first essay presented leads to the conclusion that substantial effort is needed to combine these two literatures and integrate their findings into one more solid body of knowledge.

The second essay has adopted a more empirical approach, examining to what extent firms' needs are served by export promotion programs. This situation was examined in a longitudinal study of a fashion cluster, formed by smaller-sized firms. Again, there is a lack of dialogue between the two sides of export promotion. Moreover, the most serious barrier to exporting faced by the firms was not due to 
market failures, but to coordination failures. Moreover, despite substantial investment by several TSIs along the cluster's lifecycle, it seems that basic firm needs, such as knowledge of the market and of export methods and practices, were not well served by these programs.

The findings reported in the second essay show a typical case of misallocation of resources, since they were rather abundant along the cluster's trajectory. Financial investments, investments in design, human capital development and attempts to transfer knowledge did not, at the end, benefit firms in the cluster, or the cluster as a social and economic entity. The failure of such efforts can be credited to the TSIs involved in the export promotion efforts, but also to the individual firms, suggesting that the model used to transfer benefits to the cluster has not been successful.

One issue that I have not raised in the study, but that seems to some extent to be behind more apparent problems, has to do with the absorptive capacity of individual firms. The transfer of knowledge is not one-sided; it requires certain capabilities on the side of the firm. It is definitely surprising that several entrepreneurs mentioned their lack of skills to perform even the simplest exporting methods and practices, as well as their ignorance about foreign markets. Since informational barriers are the most crucial and the most common market failures, and there was substantial investment in export promotion in the cluster, why these firms still seem so unprepared? I believe that the issue of absorptive capacity needs to be addressed by future research.

Therefore, both the literature and the practice of export promotion suggest that the two sides - Trade Support Institutions and exporting firms - still need to improve their dialogue. In fact, the crucial issue revealed by the empirical study coordination failures - is barely addressed in the two streams of literature examined. In the cluster studied, the lack of inter-organizational relationships are a deterrent to the establishment of trust and commitment. As pointed out by Chabowski et al. (2018, p.136), "the role of networking and developing relationships is critical for sustained interaction with others." 
The third essay shows, however, that successful export promotion programs combine different types of TSIs (public, private, and non-profit) and use different coordination models depending on the specific characteristics of the countries. This means that it is possible to develop an indigenous model to organize and coordinate export promotion efforts that can better serve each country's specificities. Different models can serve different purposes, and one must be aware of the specific needs served, considering that flexibility is a key aspect of EPPs.

As an overall conclusion the study points out to the potential mismatch between firms' needs and TSIs offers. It also points out the important role of interorganizational relationships among firms, among firms and TSIs, and among TSIs for the success of SMEs' export activities.

\section{2.}

\section{Additional Considerations}

At the end of this research process, I present some thoughts from my own experience preparing small and medium-sized firms to export at a governmentsponsored program, PEIEX. Most firms that I mentored were in the pre-export phase, and a few were already involved in exporting, but in a preliminary stage.

In the close contact with these entrepreneurs and managers, I realized how difficult it was the process of acquisition of knowledge about export methods and practices and foreign markets. Because the only experience these entrepreneurs and managers have had was in the domestic market, they cannot conceive different ways of doing business, and tend to accept only models that are akin with their own experience. Their ability to absorb new knowledge is thus limited by the lack of international experience and contacts.

On the other side, export assistance is often too theoretical, especially when making use of short-term training programs. In my view, it is necessary to change their mind-set, and this can be done through experiential learning, as predicated by Johanson and Vahlne (1977), following the seminal work of Edith Penrose (2009). Objective knowledge, as these authors have claimed, cannot by itself change the 
mind-set of the individual. How can experiential learning opportunities be created? Participation in trade fairs and trade missions are important, but require some promptness to export, which is usually not the case.

A possible answer is networking. Export assistance should focus on the development of relationships with foreign buyers and firms, very much in line with the revised Uppsala model (Johanson and Vahlne, 2009, 2013). The link between companies and potential partners in the foreign market would help to develop competencies that the future exporter needs to acquire, in such a way that part of the export promotion efforts would be more towards accelerating networking, and thus promoting experiential knowledge, than to transfer objective knowledge.

My experience as a researcher and as a consultant also suggests that substantial misallocation of resources may occur due to the lack of coordination between various TSIs, due to duplication of offers, redundant activities, or communication problems, despite the individual competence of managers and technical staff of public, private and non-profit TSIs. Only now, some efforts are being made to coordinate these different institutions, in order to achieve more effectiveness in the allocation of resources.

\section{3.}

\section{Avenues for Future Research}

Research findings point to some interesting future research areas, as follows:

- The study of the interrelationship between export promotion and export barriers' literatures could be amplified by aggregating the thorough analysis of the literature of export stimuli and driving forces of internationalization;

- Given the current methodological limitations reported by both literatures, the suggestion to adopt mixed-methods to generate additional insights on the themes could be welcome; 
- While Born Globals (BGs) and International New Ventures (INVs) have attracted considerable research interest recently, few studies have examined the eventual need of these firms of some type of export promotion and the impact of such assistance on their performance. In fact, their outwardoriented nature could also turn them into counterfactuals to provide useful explanatory insights to the export promotion theory development;

- Given the rising importance of the service sector, export promotion research as well as export barriers studies should include service companies to investigate differences in assistance needs and their impact. Moreover, knowing the diverse nature of service industry's sub-sectors, studies should consider the development of specific analysis of barriers and export promotion impact for each sub-sector of the service industry. This research recommendation is also valid as a path for future research considering other industries than the service sector.

- Geographic and cultural dimensions are other aspects to be considered in developing studies on export promotion and export barriers. Despite the reasonable amount of research produced lately encompassing developing countries, there is still little evidence related to important emergent countries such as BRICS;

- Network-related drivers are amplifying their role in facilitating SMEs' exports expansion. Organizations such as business associations, government agencies, non-governmental institutions, and consultancies, composing networks of TSIs, should currently redesign their roles confronted with limited resources at hand. A more in-depth analysis of these relational configurations and patterns might help in achieving a more thorough understanding of prospects for SMEs' export orientation;

- Other TSIs' cases, including unsuccessful experiences, could provide additional perspectives to enhance the understanding of inter-organizational relationships and their ability to impact SME's exports expansion. 


\section{6. \\ Bibliographic References}

AABY, N.-E.; SLATER, S. F. Management Influences on Export Performance: A Review of the Empirical Literature 1978-1988. International Marketing Review, v. 6, n. 4, p. 7-26, 1989.

ADU-GYAMFI, N.; KORNELIUSSEN, T. Antecedents of export performance: the case of an emerging market. International Journal of Emerging Markets, v. 8, n. 4, p. 354-372, 2013.

AHMED, Z. U.; MOHAMED, O. JOHNSON, J. P.; MENG, L. Y. Export promotion programs of Malaysian firms: an international marketing perspective. Journal of Business Research, v. 55, n. 10, p. 831-843, 2002.

; JULIAN, C. C.; JUMAAT MAHAJAR, A. Export Barriers and Firm Internationalisation from an Emerging Market Perspective. Journal of Asia Business Studies, v. 3, n. 1, p. 33-41, 2008.

AL-AALI, A. Obstacles facing Saudi Arabian food and chemical exporters. International Journal of Commerce and Management, v. 5, n. 3, p. 17-31, 1995.

ALBAUM, G. Effectiveness of government export assistance for US smaller-sized manufacturers: some further evidence. International Marketing Review, v. 1, n. 1, p. 68-75, 1983.

ALEXANDER, E.R. How Organizations Act Together: Interorganizational Coordination in Theory and Practice, 2nd ed., New York: Routledge, 2013, 353p.

ALEXANDER, C., WARWICK, K. Governments, exports and growth: Responding to the Challenges and Opportunities of Globalisation, The World Economy, v. 30, n. 1, p. 177-194, 2007.

ALEXANDRIDES, G.C. How the major obstacles to exporting can be overcome. Atlantic Economic Review, v. 1, n. 1, p. 12-15, 1971.

AL-HYARI, K.; AL-WESHAH， G.; ALNSOUR, M. Barriers to internationalisation in SMEs: evidence from Jordan. Marketing Intelligence \& Planning, v. 30, n. 2, p. 188-211, 2012.

ALTINTAS, M.H., TOKOL, T.; HARCAR, T. The effects of export barriers on perceived export performance: an empirical research on SMEs in Turkey. EuroMed Journal of Business, v. 2, n. 1, p. 36-56, 2007.

ALVAREZ, R. Sources of export success in small- and medium-sized enterprises: The impact of public programs. International Business Review, v. 13, n. 3, p. 383400, 2004. 
ANDERSON, J. E.; MARCOUILLER, D. Insecurity and the Pattern of Trade: An Empirical Investigation. Review of Economics and Statistics, v. 84, n. 2, p. 342352, 2002.

ARAUJO, L.; EASTON, G. Networks in socioeconomic systems: a critical review. In Iacobucci, D. (Ed.): Networks in Marketing. Thousand Oaks: Sage, 1996, p. 63-107.

ARENARO E MELlO DIAS, A. C.; ROCHA, A. M. C. da; SILVA, J. F. da. Foreign Direct Investment Entry Modes: A Study of Empirical Literature. RAC Revista de Administração Contemporânea, v.18, n.4, p. 416-445, 2014.

ARRANZ, N; ARROYABE, J. C. F. De. Internationalization Process of Spanish Small Firms - Strategies, Transactions and Barriers. International Small Business Journal, v. 27, n. 4, p. 420-441, 2009.

ARTEAGA-ORTIZ, J.; FERNÁNDEZ-ORTIZ, R. Why Don't We Use the Same Export Barrier Measurement Scale? An Empirical Analysis in Small and MediumSized Enterprises. Journal of Small Business Management, v. 48, n. 3, p. 395420, 2010.

AWAN, M. A. The Relationship Between Internet Use and Perceptions of Barriers Facing Small Business Exporters in Developing Countries. Journal of Internet Commerce, v. 10, n. 2, p. 144-161, 2011.

AYOB, A. H.; FREIXANET, J. Insights into public export promotion programs in an emerging economy: The case of Malaysian SMEs. Evaluation and Program Planning, v. 46, p. 38-46, 2014.

BACCHIOCCHI, E.; FLORIO, M.; GIUNTA, A. Internationalization and industrial districts: evidence from the Italian automotive supply chain. International Review of Applied Economics, v. 28, n. 1, p. 1-21, 2014.

BAGCHI-SEN, S. The small and medium sized exporters' problems: an empirical analysis of Canadian manufacturers. Regional Studies, v. 33, n. 3, p. 231-245, 1999.

BANNÒ, M.; PISCITELLO, L.; AMORIM VARUM, C. The Impact of Public Support on SMEs' Outward FDI: Evidence from Italy. Journal of Small Business Management, v. 52, n. 1, p. 22-38, 2014.

; SGOBBI, F. Firm participation in financial incentive programmes: The case of subsidies for outward internationalisation. Journal of Policy Modeling, v. 32, n. 6, p. 792-803, 2010.

BARISAN, L.; BOATTO, V.; ROSSETTO, L.; SALMASO, L. The knowledge of Italian wines on export markets: A nonparametric methodology to analyze promotional actions. British Food Journal, v. 117, n. 1, p. 117-138, 2015. 
BARKER, A.T.; KAYNAK, E. An Empirical Investigation of the Differences between Initiating and Continuing Exporters. European Journal of Marketing, v. 26, n. 3, p. 27-36, 1992.

BARNES, B. R.; CHAKRABARTI, R.; PALIHAWADANA, D. Investigating the export marketing activity of SMEs operating in international healthcare markets. Journal of Medical Marketing, v. 6, n. 3, p. 209-221, 2006.

BARNEY, J. Firm Resources and Sustained Competitive Advantage. Journal of Management, v, 17, n. 1, p. 99-120, 1991.

BARRETT, N.J.; WILKINSON, I.F. Export stimulation: a segmentation study of the exporting problems of Australian manufacturing firm. European Journal of Marketing, v. 19, n. 2, p. 53-72, 1985.

BAUERSCHMIDT, A.; SULLIVAN, D.; GILlESPIE, K. Common factors underlying barriers to export: studies in the US paper industry. Journal of International Business Studies, v. 16, n. 3, p. 111-123, 1985.

BAUM, M.; SCHWENS, C.; KABST, R. International as opposed to domestic new venturing: The moderating role of perceived barriers to internationalization. International Small Business Journal, v. 31, n. 5, p. 536-562, 2013.

BEAMISH, P. W.; LUPTON, N. C. Cooperative strategies in international business and management: Reflections on the past 50 years and future directions. Journal of World Business, v. 51, n. 1, p. 163-175, 2016.

BECATTINI, G. Dal settore industriale al distretto industriale: Alcune considerazioni sull'unita' di indagine dell'economia industrial. Rivista di Economia e Politica Industriale, n. 1, p. 7-21, 1979.

The Marshallian industrial districts as a socio-economic notion. In: Pyke, F., Beccattini, G.; Sengenberger, W. (Eds.) Industrial Districts and Inter-Firm Cooperation in Italy. Geneva: International Institute for Labour Studies, 1990, p. 37-51.

BELL, J. A Comparative Study of the Export Problems of Small Computer Software Exporters in Finland, Ireland and Norway. International Business Review, v. 6, n. 6, p. 585-604, 1997.

BELLOC, M; Di MAIO, M. Survey of the literature on successful strategies and practices for export promotion by developing countries, IGC - International Growth Centre Working Paper. 2011. Available at: https://www.google.com/url?q=https\%3A\%2F\%2Fwww.theigc.org\%2Fwpcontent\%2Fuploads\%2F2011\%2F06\%2FBelloc-Di-Maio-2011-WorkingPaper.pdf. Accessed 09 March 2018.

BELWAL, R.; CHALA, M. Catalysts and barriers to cut flower export. International Journal of Emerging Markets, v. 3, n. 2, p. 216-235, 2008. 
BENNETT, R. Export marketing and the Internet experiences of website use and perceptions of export barriers among UK businesses. International Marketing Review, v. 14, n. 5, p. 1-11, 1997.

BERGMAN, E.M. Cluster life-cycles: an emerging synthesis. In: Karlsson, C. (Ed.) Handbook of Research on Cluster Theory. Cheltenham: Edward Elgar, 2008 p. 114-132.

Sustainability of Clusters and Regions at Austria's Accession Edge. In: Bochniarz, Z. and Cohen, G. B. (Eds.) The Environment and Sustainable Development in the New Central Europe, New York: Berghahn Books, 2006, p. 59-77.

BERTOLINI, P.; GIOVANNETTI, E. Industrial districts and internationalization: The case of the agri-food industry in Modena, Italy. Entrepreneurship \& Regional Development, v.18, n. 4, p. 279-304, 2006.

BETTIOL, M.; BURLINA, C.; CHIARVESIO, M.; Di MARIA, E. From delocalisation to backshoring? Evidence from Italian industrial districts. Investigaciones Regionales, n. 39, p. 137-154, 2017.

BIANCHI, C.; WICKRAMASEKERA, R. An Exploratory Study of the Factors Enhancing and Inhibiting Export Growth in the Chilean Wine Industry. Journal of International Food \& Agribusiness Marketing, v. 25, n. 2, p. 85-102, 2013.

BILKEY, W. J. An Attempted Integration of the Literature on the Export Behavior of Firms. Journal of International Business Studies, v. 9, n. 1, p. 33-46, 1978.

; TESAR, G. The export behavior of smaller-sized Wisconsin manufacturing firms. Journal of International Business Studies, v. 8, n. 1, p. 9398, 1977.

BJARNASON, A.; MARSHALL, D.; EYJÓLFSSON, E. B. Export Barriers and Problems Associated with Exporting Icelandic Marine Products Under Conditions of Export or Die. Journal of International Food \& Agribusiness Marketing, v. 27, n. 4, p. 290-310, 2015.

BONACCORSI, A. On the relationship between firm size and export intensity. Journal of International Business Studies, v. 23, n. 4, p. 605-635, 1992.

BRANNEN, M. Y.; DOZ, Y. L. From a distance and detached to up close and personal: Bridging strategic and cross-cultural perspectives in international management research and practice. Scandinavian Journal of Management, v. 26, n. 3, p. 236-247, 2010.

BREWER, P. Australia's Export Promotion Program: Is It Effective? Australian Journal of Management, v. 34, n. 1, p. 125-142, 2009.

BROOKS, M. R.; FRANCES, A. Barriers to Exporting: An Exploratory Study of Latin American Companies. In: Seringhaus, F.H.R. and Rosson, P.J. (Eds.) Export 
Development and Promotion: The Role of Public Organizations, Boston: Springer, 1991, p. 95-118.

BODUR, M. A study on the nature and intensity of problems experienced by Turkish exporting firms. In: Cavusgil, S. T. (Ed.) Advances in International Marketing, v. 1, Greenwich: JAI Press, 1986, p. 205-232.

BURGESS, S. M.; OLDENBOOM, N. South African and Singaporean exporters: their attitudes, information sources and export problems. South African Journal of Business Management, v. 28, n. 2, p. 53-62, 1997.

BURTON, F. N.; B. B. SCHLEGELMILCH, B. B. Profile Analyses of NonExporters versus Exporters Grouped by Export Involvement. Management International Review, v. 27, n. 1, p. 38-49, 1987.

CAHEN, F.R.; LAHIRI, S.; BORINI, F.M. Managerial perceptions of barriers to internationalization: an examination of Brazil's new technology-based firms. Journal of Business Research, v. 69, n. 6, p. 1973-1979, 2016.

CALDERÓN, H.; FAYOS, T. Factores Empresariales que Influyen en las Políticas de Promoción de las Exportaciones: Aplicación a la Comunidad Valenciana. Dirección y Organización, n. 30, p. 122-133, 2004.

CALI, M.; ELLIS, K.; Te VELDE, D. W. The contribution of services to development: The role of regulation and trade liberalization. London: Overseas Development Institute, 2008, 17p. ODI Working Paper 298.

CAMPBELL, A. J. The effects of internal firm barriers on the export behavior of small firms in a free trade environment. Journal of Small Business Management, v. 34, n. 3, p. 50-58, 1996.

CAMPBELL, A. J.; WILSON, D.T. Managed networks: creating strategic advantage. In: Iacobucci, D. (Ed.) Networks in Marketing. Thousand Oaks: Sage, 1996, p.125-143.

CANNATELLI, B.; ANTOLDI, F. The role of network facilitators in fostering strategic alliances: a longitudinal case study. Journal of Small Business and Entrepreneurship, v. 25, n. 1, p. 19-34, 2012.

CANSINO, J. M.; LOPEZ-MELENDO, J.; PABLO-ROMERO, M. del P.; SÁNCHEZ-BRAZA, A. An economic evaluation of public programs for internationalization: The case of the Diagnostic program in Spain. Evaluation and Program Planning, v. 41, p. 38-46, 2013.

CARDOSO, C, SOUKIAZIS E. Explaining the uneven economic performance of the EU cohesion countries: An export-led growth approach. The International Trade Journal, v.22, n.2, p. 156-165, 2008.

CARDOSO, F. S. A Influência da Exportação no Desenvolvimento de Arranjos Produtivos Locais de Moda no Estado do Rio de Janeiro. Rio de Janeiro, 2006. 147p. Master thesis (Public Administration) - EBAPE, Fundação Getúlio Vargas. 
CASSEY, A. J.; COHEN, S. State Export Promotion and Firm-level Employment. Public Finance Review, v. 45, n. 4, p. 538-563, 2016.

CASSIOlAtO, J. E.; PEIXOTO, F. O Pólo de Moda Praia de Cabo Frio/RJ. Rio de Janeiro: SEBRAE/UFSC/NEITEC/FEPESE, 2004, 28p. Programa de Financiamento de Bolsas de Mestrado Vinculadas à Pesquisa "Micro e Pequenas Empresas em Arranjos Produtivos Locais no Brasil” Working Paper.

CATALAN, J.; RAMON-MUÑOZ, R. Marshall in Iberia. Industrial districts and leading firms in the creation of competitive advantage in fashion products. Enterprise and Society, v. 14, n. 2, p. 327-359, 2013.

CAVUSGIL, S.T. Differences Among Exporting Firms Based on Their Degree of Internationalization. Journal of Business Research, v. 12, n. 2, p. 195-208, 1984a.

Organizational Characteristics Associated with Export Activity. Journal of Management Studies, v. 21, n. 1, p. 2-22, 1984 b.

Some Observations on the Relevance of Critical Variables for Internationalization Stages. In: Czinkota, M. R. and Tesar, G. (Eds.), Export Management, New York: Praeger, 1982, p. 276-286.

; BILKEY, W.; TESAR, G. A note on the export behavior of firms: Exporter profiles. Journal of International Business Studies, v. 10, n. 1, p. 91-97, 1979.

.; NAOR, J. Firm management characteristics as discriminators of export marketing activity, Journal of Business Research, v. 15, n. 3, p. 221-235, 1987.

.; NEVIN, J.R. A Conceptualization of the Initial Involvement in International Marketing. In: Lamb, C.W. and Dunne, P.M. (Eds.), Theoretical Developments in Marketing, Chicago: American Marketing Association, 1980, p. 68-71.

; YEOH, P.-L., Y. Public Sector Promotion of U.S. Export Activity: A Review and Directions for the Future. Journal of Public Policy \& Marketing, v. 13, n. 1, p. 76-84, 1994.

.; ZOU, S. Marketing Strategy-Performance Relationship: An Investigation of the Empirical Link in Export Market Ventures. Journal of Marketing, v. 58, n. 1, p. 1-21, 1984.

CHABOWSKI, B.; KEKEC, P.; MORGAN, N. A.; HULT, T. M.; WALKOWIAK, T.; RUNNALLS, B. An assessment of the exporting literature: using theory and data to identify future research directions. Journal of International Marketing, v. 26, n.1, p. 118-143, 2018.

CHEONG, W.K.; CHONG, K.W. Export behaviour of small firms in Singapore, International Small Business Journal, v. 6, n. 2, p. 34-41, 1988. 
CHETTY, S.; HOLM, D.B. Internationalisation of small to medium-sized manufacturing firms: a network approach. International Business Review, v. 9, n. 1, p. 77-93, 2000.

CHRISTENSEN, C.H., DA ROCHA, A.; GERTNER, R.S. An empirical investigation of the factors influencing exporting success of Brazilian firms. Journal of International Business Studies, v. 18, n. 3, p. 61-77, 1987.

CIA WORLD FACTBOOK. Available at: https://www.cia.gov/library/publications/the-worldfactbook/docs/profileguide.html. Accessed 28 January 2018.

CIRAVEGNA, L. Promoting Silicon Valleys in Latin America: Lessons from Costa Rica. London: Routledge, 2012, 159p.

CLARKE, W. M. Changing Small Firms' Attitudes to Exporting: A Case Study of Successful Intervention. Export. In: Seringhaus, F.H.R. and Rosson, P.J. (Eds.) Export Development and Promotion: The Role of Public Organizations, New York: Springer, 1990, p.275-299.

COELHO, D.B.; ROCHA, C.P. Strategy and management in export and investment promotion agencies: the UK Trade and Investment case in Brazil. Globalization, Competitiveness and Governability Journal, v.7, n. 2, p.68-84, 2013.

COLAIACOVO, J.L. Export Development in Latin America. In: Czinkota, M.R. and TESAR, G. (Eds.) Export Policy: A Global Assessment, New York: Praegar, 1982.

CONPES - Consejo Nacional de Política Económica y Social. Lineamientos para el fortalecimiento de la cinematografia en Colombia. Colombia: Vice Presidencia de la República; Ministerio de Cultura; Ministerio de Comercio Industria y Turismo; Departamento Nacional de Planeación, 2007. Conpes Document $3462 . \quad$ Available at: http://www.locationcolombia.com/docs/espanol/392_conpes_3462.pdf. Accessed 5 September 2016.

Política de transformación productiva: um modelo de desarrollo sectorial para Colombia. Colombia, Departamento Nacional de Planeación. Ministerio de Comercio, Industria y Turismo, 2010. Conpes Document 3678. Available at: https://www.dnp.gov.co/LinkClick.aspx ?fileticket=XF0faAmYJ5E\%3D\&tabid=1 063. Accessed 15 November 2017.

COSTA, E.; SOARES, A. L.; SOUZA, J. P. de. Institutional networks for supporting the internationalisation of SMEs: the case of industrial business associations. Journal of Business \& Industrial Marketing, v. 32, n. 8, p. 1182$1202,2017$. 
COUDOUNARIS, D. N. Effective targeting of national export promotion programmes for SMEs, International Journal of Globalisation and Small Business, v. 4, n. 3/4, p. 242-283, 2012.

Export promotion programmes for assisting SMEs, Review of International Business and Strategy, v. 28, v. 1, p. 77-110, 2018.

COUGHLin, C. C.; CARTWRIGHT, P. A. An Examination of State Foreign Export Promotion and Manufacturing Exports. Journal of Regional Science, v. 27, n. 3, p. 439-449, 1987.

CREUSEN, H.; LEJOUR, A. Market entry and economic diplomacy. Applied Economics Letters, n. 20, p. 37-41, 2013.

CRICK, D. An Investigation into the targeting of UK export assistance. Journal of Marketing, v. 29, n. 8, p. 76-94, 1995.

The Decision to Discontinue Exporting: SMEs in Two UK Trade Sectors. Journal of Small Business Management, v. 40, n. 1, p. 66-77, 2002.

- SMEs' Barriers Towards Internationalisation and Assistance Requirements in the UK: Differences Between Exporters and Firms Employing Multiple Modes of Market Entry. Journal of Small Business \& Entrepreneurship, v. 20, n. 3, p. 233-244, 2007.

UK SMEs' decision to discontinue exporting: an exploratory investigation into practices within the clothing industry. Journal of Business Venturing, v. 19, n. 4, p. 561-587, 2004.

.; AL OBAIDI, M.; CHAUDHRY, S. Perceived obstacles of Saudi Arabian exporters of non-oil products. Journal of Marketing Practice, v. 4, n. 7, p. 187-199, 1988.

.; CHAUDHRY, S. Export problems and Government assistance required by UK exporters: An investigation into the effect of ethnicity. International Journal of Entrepreneurial Behavior \& Research, v. 3, n. 1, p. 3-18, 1997.

; UK agricultural exporters' perceived barriers and government assistance requirements. Marketing Intelligence \& Planning, v. 18, n. 1, p. 30-38, 2000.

.; CZINKOTA, M. R. Export assistance: Another look at whether we are supporting the best programmes. International Marketing Review, v. 12, n. 3, p. 61-72, 1995.

CUYVERS, L.; PELSMACKER, P. De ; RAYP, G. ; ROOZEN, I. T. M. A decision support model for the planning and assessment of export promotion activities by government export promotion institutions - the Belgian case. International Journal of Research in Marketing, n. 12, p. 173-186, 1995 
CZINKOTA, M. R. A national export assistance policy for new and growing businesses. Journal of International Marketing, v. 2, n. 1, p. 91-101, 1994.

York: Praeger, 1982.

Export Development Strategies: US Promotion Policies. New Rationale for export promotion, Marketing Management- Insights Global, p.14-15, Spring 2012.

Services Trade: The Negotiation Agenda. In: Czinkota, M. R. et al. (Eds.). Export Promotion - The Public and Private Sector Interaction. New York: Praeger, 1983. p. 285-302.

.; SKUBA, C. Trade Policy and International Marketing. Marketing News, v. 47, n. 5, p. 22-26, 2013.

.; URSIC, M.L. Impact of export growth expectations on smaller firms. International Marketing Review, v. 1, n. 2, p. 26-33, 1983.

DA ROCHA, A. Os consórcios como alternativa para exportação. In: Rocha, A. (Ed.) Gerência de Exportação no Brasil. Rio de Janeiro: UFRJ; São Paulo: Atlas, 1990, p.181-190.

; FREITAS, Y. A.; SILVA, J. F. da. Do Perceived Export Barriers Change over Time? A Longitudinal Study of Brazilian Exporters of Manufactured Goods. Latin American Business Review, v. 9, n. 1, p. 102-128, 252008.

DA SILVA, P.; DA ROCHA, A. Perception of export barriers to Mercosur by Brazilian firms. International Marketing Review, v. 18, n. 6, p. 589-611, 2001.

DAGNINO, G. B.; LEVANTI, G.; DESTRI, A. M. L. Structural dynamics and intentional governance in strategic interorganizational network evolution: a multilevel approach, Organization Studies, v. 37, n. 3, p. 349-373, 2016.

; MINÀ, A., and PICONE, P. M. Interorganizational network and innovation: a bibliometric study and proposed research agenda, Journal of Business \& Industrial Marketing, v. 30, n. 3/4, p. 354-377, 2015.

DAL MOLIN, M.; MASELLA, C. From fragmentation to comprehensiveness in network governance, Public Organization Review, v. 16, p. 43-508, 2016.

DEAN, D.; GAN, C.; MYERS, C. An investigation of the relationship between a firm's perceived export barriers and stages of export development: an analysis of Canterbury manufacturing firms. Journal of Enterprising Culture, v. 6, n. 2, p. 199-216, 1998.

DEAN, D. L.; MENGÜÇ, B.; MYERS, C.P. Revisiting firm characteristics, strategy, and export performance relationship: a survey of the literature and an investigation of New Zealand small manufacturing firms. Industrial Marketing Management, v. 29, n. 5, p. 461-477, 2000. 
DEBOÇÃ, L.P.; MARTINS, R.S. Competitive advantages from horizontal relationships in productive agglomerations: perceptions of local agents. Revista Brasileira de Gestão de Negócios, v. 17, n. 56, p. 1025-1043, 2015.

DeMARTINO, R.; REID, D. M.; ZYGLIODOPOULOS, S. C. Balancing localization and globalization: exploring the impact of firm internationalization on a regional cluster. Entrepreneurship \& Regional Development, v. 18, n. 1, p. 113, 2006.

DEPARTMENT FOR DIGITAL, CULTURE MEDIA \& SPORT. DCMS Sectors Economic Estimates 2016: Gross Value Added. London: DCMS, 2017. 14p. DCMS Report.

DE PROPRIS, L.; LAZZERETTI, L. Measuring the decline of a Marshallian industrial district: the Birmingham Jewellery Quarter. Regional Studies, v. 43, n. 9, p. 1135-1154, 2009.

DESIGN COUNCIL. The Design Economy: The value of design to the UK. London: Design Council, 2015. 80p. Design Council Report. Available at: http://www.designcouncil.org.uk/sites/default/files/asset/document/. Accessed 10 August 2016.

DIAMANTOPOULOS, A.; SCHLEGELMILCH, B. B.; ALLPRESS, C. Export marketing research in practice: A comparison of users and non-users. Journal of Marketing Management, v. 6, n. 3, p. 257-273, 1990.

; KATY TSE, K. Y. Understanding the Role of Export Marketing Assistance: Empirical Evidence and Research Needs. European Journal of Marketing, v. 27, n. 4, p. 5-18, 1993.

DICHTL, E.; KOEGLMAYR, H.G.; MUELLER, S. International orientation as a precondition for export success. Journal of International Business Studies, v. 21, n. 1, p. 23-40, 1990.

DiMAGGIO, P. J.; POWELL, W. W. The iron cage revisited: institutional isomorphism and collective rationality in organizational fields. In: Powell, W. W. and DiMaggio, P. (Eds.) The New Institutionalism in Organizational Analysis. Chicago: The University of Chicago Press, 1991, p. 5-28.

DOBUSCH, L.; SCHÜSSLE, E. Theorizing path dependence: a review of positive feedback mechanisms in technology markets, regional clusters, and organizations. Industrial and Corporate Change, v. 22, n. 3, p. 617-629, 2013.

DOERN, R. Investigating Barriers to SME Growth and Development in Transition Environments: A Critique and Suggestions for Developing the Methodology. International Small Business Journal, v. 27, n. 3, p. 275-305, 2009.

DOMINGUEZ, N. Promotion agencies and SMEs' internationalization process: A blessing or a curse? Journal of International Entrepreneurship, v. 16, n. 1, p. 58-81, 2017. 
DOSUGLU-GUNER, B. An Exploratory Study of the Export Intention of Firms. Journal of Global Marketing, v. 12, n. 4, p.45-63, 1999.

DRAHOKOUPIL, J. Beyond lock-in versus evolution, towards punctuated coevolution: on Ron Martin's 'Rethinking regional path dependence'. International Journal of Urban and Regional Research, v. 36, n. 1, p. 166-171, 2012.

DUBOIS, A.; GADDE, L. E. Systematic combining: an abductive approach to case research, Journal of Business Research, v. 55, n. 7, p.553-560, 2002.

DUNNING, J. H.; LUNDAN, S. Multinational enterprises and the global economy, 2nd ed., Cheltenham: Edward Elgar, 2008, 919p.

DURMUŞOǦLU, S. S. et al. The effect of government-designed export promotion service use on small and medium-sized enterprise goal achievement: A multidimensional view of export performance. Industrial Marketing Management, v. 41, n. 4, p. 680-691, 2011.

EASTON, E.; YOUNG, S.; CAULDWELL-FRENCH, E. Global Trade Report. London: Creative Industries Federation, 2018. 69p. Creative Industries Federation Report.

EDMUNDS, S. E.; KHOURY, S. J. Exports: A Necessary Ingredient in the Growth of Small Business Firms. Journal of Small Business Management, v. 24, p. 54$65,1986$.

EISENHARDT, K. M. Building Theories from Case Study Research. Academy of Management Review, v.14, n. 4, p. 532-550, 1989.

ELDIK, S. VAN; VIVIERS, W. The measurement of export readiness of companies in South Africa. Southern African Business Review, v. 9, n. 2, p. 1-11, 2005.

ELLIS, P. Are international trade intermediaries catalysts in economic development? A new research agenda. Journal of International Marketing, v. 11, n. 1, p. 73-96, 2003.

EMERSON, K., NABATCHI, T., and BALOGH, S. An integrative framework for collaborative governance, Journal of Public Administration Research and Theory, v. 22, n. 1, p.1-29, 2012.

ESHGHI, A. Attitude-behavior inconsistency in exporting. International Marketing Review, v. 9, n. 3, p. 40-61, 1992.

EY. Cultural times - The first global map of cultural and creative Industries, Paris: EY France, 2015. 120p. EY France Report. Available at: www.ey.com/Publication/vwLUAssets/ey-cultural-times.../ey-cultural-times2015.pdf. Accessed 15 December 2017. 
FAROQUE, A. R.; TAKAHASHI, Y. Export Assistance: The Way Back and Forward. An Empirical Investigation into Developing Country "Born Globals". New York: Springer, 2012, 73p.

FERREIRA, M.P.; TAVARES, A.T.; HESTERLY, W. Evolution of industry clusters through spin-offs and the role of flagship firms. In: Tavares, A.T.; Teixeira, A. (Eds.) Multinationals, Clusters and Innovation: Does Public Policy Matter? New York: Palgrave, 2006, p. 87-106.

FERREIRA, M.I.V.; TEIXEIRA, A.A.C. Organizational characteristics and performance of export promotion agencies: Portugal and Ireland compared. Porto: Faculdade de Economia do Porto, Universidade do Porto, 2011. 44p. FEP Working Paper n. 424.

FIGUEIREDO, K.F.; ALMEIDA, L.F. As barreiras à exportação de calçados brasileiros", in Da Rocha, A. (Ed.). Gerência de exportação no Brasil: problemas e oportunidades, São Paulo: Atlas, Rio de Janeiro, Editora da UFRJ, 1988, p. 73-86.

FILLIS, I. Barriers to internationalisation. European Journal of Marketing, v. 36, n. 7/8, p. 912-927, 2002.

FISHER, E.; REUBER, R. Industrial clusters and SME promotion in developing countries. Commonwealth Trade and Enterprise Paper n.3. London: Commonwealth Secretariat, 2000, 36p. .$;$ Support for Rapid-Growth Firms: A Comparison of the Views of Founders, Government Policymakers, and Private Sector Resource Providers. Journal of Small Business Management, v. 41, n. 4, p. 346-365, 2003.

FORD, I. D.; LEONIDOU, L.C. Research developments in international marketing. In: Paliwoda, S.J. (Ed.), New Perspectives on International Marketing. London: Routledge, London, 1991, p. 3-32.

FORNAHL, D.; MENZEL, M-P. Co-Development of Firm Foundings and Regional Clusters. Hannover: School of Economics and Management, University of Hannover, 2003, 25p. Working Paper 284.

FOUNTAIN, J. Implementing cross-agency collaboration: a guide for federal managers. Washington: IBM Center for the Business of Government, 2013. Available at: http://www.businessofgovernment.org/report/implementing-crossagency-collaboration-guide-federal-managers. Accessed 10 December 2016.

FRANCIONI, B.; PAGANO, A.; CASTELLANI, D. Drivers of SMEs' exporting activity: a review and a research agenda. Multinational Business Review, v. 23, n. 3, p. 194-215, 2016.

FRANCIS, J.; COLLINS-DODD, C. Impact of export promotion programs on firm competencies, strategies and performance. International Marketing Review, v. 21, n. 4/5, p. 474-495, 2004. 
FREIXANET, J. Export promotion programs: Their impact on companies' internationalization performance and competitiveness. International Business Review, v. 21, n. 6, p. 1065-1086, 2012.

GAO - General Accounting Office. Export promotion: government agencies should combine export training programs. Washington: U.S. General Accounting Office, 2001, 18p. Report to congressional committees. Available at: http://www.dtic.mil/docs/citations/ADA396836. Accessed 10 December 2016.

GELDRES-WEISS, V. V.; CARRASCO-RIO, J. A. Impact evaluation of national export promotion programs on export firms using contrast groups. International Journal of Export Marketing, v. 1, n. 1, p. 77- 95, 2016.

GELDRES-WEISS, V. V.; LÓPEZ, M. S. E. Promoción de Exportaciones en el Ámbito Público: su impacto en el desempeño exportador a nivel de la firma. Revista Latinoamericana de Administración, v. 47, p. 1-17, 2011.

.; MONREAL-PÉREZ, J. The effect of export promotion programs on Chilean firms' export activity: A longitudinal study on trade shows and trade missions, Journal of Promotion Management, v. 24, n. 5, p. 1-15, 2017.

GENÇTÜRK, E. F.; KOTABE, M. The Effect of Export Assistance Program Usage on Export Performance: A Contingency Explanation. Journal of International Marketing, v. 9, n. 2, p. 51-72, 2001.

GHAURI, P. Designing and conducting case studies in international business research. In: Marschan-Piekkari, R.; Welch, C. (Eds.). Handbook of Qualitative Research Methods in International Business. Cheltenham: Edward Elgar, 2004, p.109-124.

.; KUMAR, P. An empirical investigation of factors influencing export behaviour of smaller Swedish firms. In: Avlonitis, G.; Papavasiliou, N.K. and Kouremenos, A.G. (Eds.), Marketing Thought and Practice in the 1990s, Athens: EMAC Proceedings, 1989, p. 355-372.

GHOSHAL, S.; BARTLETT, C.A. The multinational organization as an interorganizational network. Academy of Management Review, v. 15, n. 4, p. 603$625,1990$.

GIBBERT, M.; RUIGROK, W.; WICKI, B. What passes as a rigorous case study? Strategic Management Journal, v. 29, n. 13, p. 1465-1474, 2008.

GIL-PAREJA, S.; LLORCA-VIVERO, R.; MARTINEZ-SERRANO, J. A. Do nonreciprocal preferential trade agreeements increase beneficiaries' exports? Journal of Development Economics, v. 107, p. 291-304, 2014.

Regional export promotion offices and trade margins. Review of World Economics, v. 151, n. 1, p. 145-167, 2015. 
GILLESPIE, K.; RIDDLE, L. Export promotion organization emergence and development: a call to research. International Marketing Review, v. 21, n. 4/5, p. 462-473, 2004.

GONZÁLEZ, J.H. Assessing export culture in Colombian SMEs: a look at the export promotion program (EPP), Cuadernos de Administración, v. 22, n. 39, p. 99-134, 2009.

GRANOVETTER, M. S. The strength of weak ties. American Journal of Sociology, v. 78, n. 6, p. 1360-1380, 1973.

GRATER, S.; STEENKAMP, E.; VIVIERS, W.; CUYVERS, L. Combining the export promotion of products and services: the case of South Africa. Southern African Business Review, v. 18, n. 3, p. 93-118, 2014.

GRAY, B. J. Profiling Managers to Improve Export Promotion Targeting. Journal of International Business Studies, v. 28, n. 2, p. 387-420, 1997.

GREENER, I. Theorising path-dependency: how does history come to matter in organizations? Management Decision, v. 40, n. 6, p. 614-619, 2002.

GRIPSRUD, G. The determinants of export decisions and attitudes to a distant market: Norwegian fishery exports to Japan. Journal of International Business Studies, v. 21, n. 3, p. 469-485, 1990.

GROKE, P.O.; KREIDLE, J.R. Export! Why or why not? Managerial attitude and action for smaller-sized business firms. Business and Society, v. 8, n. 1, p. 7-12, 1967.

GUERRIERI, P.; PIETROBELLI, C. Industrial districts' evolution and technological regimes: Italy and Taiwan. Technovation, v. 24, n. 11. p. 899-914, 2004.

GUPTA, D.; SHUKLA, G. Problems and Solutions of Export Promotion Measures in India. Journal of Commerce \& Trade, v. IX, n. 2, 2014.

HADDOUD, M. Y.; JONES, P.; NEWBERRY, R. Export promotion programmes and SMEs' performance. Journal of Small Business and Enterprise Development, v. 24, n. 1, p. 68-87, 2017.

HAJIAGHA, S. H. R.; ZAVADSKAS, E. K.; HASHEMI, S. S. Application of stepwise data envelopment analysis and grey incidence analysis to evaluate the effectiveness of export promotion programs. Journal of Business Economics and Management, v. 14, n. 3, p. 638-650, 2013.

HAMEL, J.; DUFOUR, S.; FORTIN, D. Case Study Methods. Newbury Park: Sage, 1993, 99p.

HANNAN, M.; FREEMAN, J. Structural inertia and organizational change. American Sociological Review, v. 49, p.149-164, 1984. 
HAYAKAWA, K.; LEE, H. H.; PARK, D. Are Investment Promotion Agencies Effective in Promoting Outward Foreign Direct Investment? The Cases of Japan and Korea. Asian Economic Journal, v. 28, n. 2, p. 111-138, 2014a.

Do Export Promotion Agencies Increase Exports?

The Developing Economies, v. 52, n. 3, p. 241-261, 2014b.

HERRANZ, J. Jr. Network performance and coordination: a theoretical review and framework, Public Performance and Management Review, v. 33, n. 3, p. 311$341,2010$.

The multisectoral trilemma of network management, Journal of Public Administration Research and Theory, v. 18, n.1, p. 1-31, 2008.

HERVAS-OLIVER, J. L.; GONZALEZ, G.; CAJA, P.; SEMPERE-RIPOLL, F. Clusters and industrial districts: Where is the literature going? Identifying emerging sub-fields of research. European Planning Studies, v. 23, n. 9, p. 1827-1872, 2015.

HILTON, G. Knocking down export barriers to smaller firms. Business and Economic Review, v. 51, n. 4, p. 18-20, 2005.

HOFSTEDE, G. Culture's Consequences: International Differences in WorkRelated Values. Abridged Ed. Newbury Park: Sage, 1980, 328p.

HOLDEN, A.C. Small business can market in Europe: results from a survey of US exporters. Journal of Small Business Management, v. 24, n. 1, p. 22-29, 1986.

HOOK, R.H.; CZINKOTA, M.R. Export activities and prospects of Hawaiian firms. European Journal of Marketing, v. 23, n. 11, p. 27-36, 1989.

HORNBY, G.; GOULDING, P.; POON, S. Perceptions of export barriers and cultural issues: the SME e-commerce experience. Journal of Electronic Commerce Research, v. 3, n. 4, p. 213-226, 2002.

HOWKINS, J. The Creative Economy: How People Make Money from Ideas. London: Penguin Books, 2013, 288p.

HUTCHINSON, K.; FLECK, E.; LLOYD-REASON, L. An investigation into the initial barriers to internationalization. Journal of Small Business and Enterprise Development, v. 16, n. 4, p. 544-568, 2009.

IAMMARINO, S.; SANNA-RANDACIO, F.; SAVONA, M. Obstacles to innovation and multinational firms in the Italian regions: firm-level evidence from the Third Community Innovation Survey. In: Tavares, A.T.; Teixeira, A. (Eds.) Multinationals, Clusters and Innovation: Does Public Policy Matter? New York: Palgrave, 2006, p. 63-83. 
IDB - INTERAMERICAN DEVELOPMENT BANK. Reporte de estado del proyecto. Washington: IDB Fondo Multilateral de Inversiones, 2015. Internal document ATN/ME-13075-BR.

IFJU, P.A.; BUSH, R.J. Export barriers and incentives in the eastern hardwood lumber industry. Forest Products Journal, v. 43, n. 3, p. 45-48, 1993.

ISETT, K.R., MERGEL, I. A., LeROUX, K., MISCHEN, P.A.; RETHEMEYER, R. K. Networks in public administration scholarship: understanding where we are and where we need to go. Journal of Public Administration Research and Theory, v. 21, n. Suppl. 1, p. i157-i173, 2011.

ITC - International Trade Centre. A Policy Road Map for Export Success. Geneva: ITC - International Trade Centre, 2014, 40p. Technical Paper, Doc No. TFPB-14-259.E.

Investing in Trade Promotion Generates Revenue. Geneva: ITC International Trade Centre, 2016b, 34p. Technical Paper, Doc. No. TS-2016-4.E.

Strengthening TSI Cooperation, 2016a. Available at: http://www.intracen.org/itc/trade-support/strengthening-tsi-cooperation/. Accessed 15 October 2016.

Trade Promotion Organizations Directory 2015. Geneva: ITC International Trade Centre, 2015. Trade Promotion Organizations Directory.

Public-Private Collaboration for Export Success: Case Studies from Barbados, Ghana, India, Thailand and Malaysia. Geneva: ITC - International Trade Centre, 2011, 101p. Compilation of case studies.

JOHANSON, J.; MATTSON, L.G. Internationalization in industrial systems - a network approach. In: Buckley, P.J.; Ghauri, P.N. (Eds.) The Internationalization of the Firm: a Reader. London: Academic Press, 1988, p. 303-321.

.; VAHLNE, J.-E. Markets as networks: implications for strategy-making. Journal of the Academy of Marketing Science, v. 39, n. 4, p. 484-491, 2011.

.; $ـ$ The internationalization process of the firm: a model of knowledge and increasing foreign market commitment. Journal of International Business Studies, v. 8, n. 1, p. 23-32, 1977.

The Uppsala internationalization process model revisited: from liability of foreignness to liability of outsidership. International Marketing Review, v. 30, n. 3, p. 189-210, 2013.

The Uppsala model on evolution of the multinational business enterprise - from internalization to coordination of networks. Journal of International Business Studies, v. 40, n. 9, p. 1411-1431, 2009. 
.; WIEDERSHEIM-PAUL, F. The internationalization of the firm: four

Swedish cases, Journal of Management Studies, v. 12, n. 3, p. 305-323, 1975.

JONES, G.; KHANNA, T. Bringing history (back) into international business. Journal of International Business Studies, v. 37, n. 4, p. 453-468, 2006.

JONES, G. J.; EDWARDS, M.; BOCARRO, J. N.; BUNDS, K. S. Collaborative Advantages: The Role of Inteorganizational Partnerships for Youth Sport Nonprofit Organizations, Journal of Sport Management, v. 31, n. 2, p.148-160, 2017.

JONES, H.R. Clearing the way for exporters. Business Horizons, v. 23, n. 5, p. $26-$ $32,1980$.

JULIAN, C. C.; AHMED, Z. U. The Impact of Barriers to Export on Export Marketing Performance. Journal of Global Marketing, v. 19, n. 1, p. 71-94, 2005.

.; O'CASS, A. The antecedents of export marketing performance: an Australian perspective. Journal of Asia Pacific Marketing, v. 3, n. 2, p. 99-113, 2004.

JULIEN, P.-A.; RAMANGALAHY, C. Competitive Strategy and Performance of Exporting SMEs: An Empirical Investigation of the Impact of Their Export Information Search and Competencies. Entrepreneurship Theory and Practice, v. 27, n. 3, p.227-245, 2003.

KAHIYA, E. T. Export barriers and path to internationalization: A comparison of conventional enterprises and international new ventures. Journal of International Entrepreneurship, v. 11, n. 1, p. 3-29, 20, 2013.

Export barriers as liabilities: near perfect substitutes. European Business Review, v. 29, n. 1, p. 61-102, 2017.

.; DEAN, D. L. Export barriers and business confidence: a quasilongitudinal examination. Asia Pacific Journal of Marketing and Logistics, v. 27, n. 2, p. 294-323, 2015.

.; Export stages and export barriers: revisiting traditional export development. Thunderbird International Business Review, v. 58 n. 1, p. 75-89, 2016.

; HEYL, J. Export barriers in a changing institutional

environment: A quasi-longitudinal study of New Zealand's manufacturing exporters. Journal of International Entrepreneurship, v. 12, n. 4, p. 331-364, 2014.

KAHLER, R.; KRAMER, R. L. International Marketing, $4^{\text {th }}$ ed., Cincinnati: South-Western Publishing Company, 1977, 425p. 
KALAFSKY, R.V.; DUGGAN, D.T. Overcoming trade impediments: considering SME exporters from Nova Scotia. The Professional Geographer, v. 68, n. 4, p. 613-623, 2016.

KALEKA, A.; KATSIKEAS, C.S. Exporting problems: the relevance of export development. Journal of Marketing Management, v. 5, n. 3, p. 499-515, 1995.

KAMATH, S.; ROSSON, P.J.; PATTON, D.; BROOKS, M. Research on success in exporting: past present and future. In: Rosson, P.J. and Reid, S.D. (Eds.), Managing Export Entry and Expansion, Praeger, New York, p. 398-421, 1986.

KANDA, W.; HJELM, O.; MEJÍA-DUGAND, S. Promoting the export of environmental technologies: An analysis of governmental initiatives from eight countries. Environmental Development, v. 17, p. 73-87, 2016.

.; MEJÍA-DUGAND, S.; HJELM, O. Governmental export promotion initiatives: awareness, participation, and perceived effectiveness among Swedish environmental technology firms. Journal of Cleaner Production, v. 98, p. 222228, 2015.

KANG, K. Overseas Network of Export Promotion Agency and Export Performance: The Korean Case. Contemporary Economic Policy, v. 29, n. 2, p. 274-283, 2011.

KAPUTA, V.; PALUŠ, H.; VLOSKY, R. Barriers for wood processing companies to enter foreign markets: a case study in Slovakia. European Journal of Wood and Wood Products, v. 74, n. 1, p. 109-122, 2016.

KARABAG, S. F.; BERGGREN, C. Antecedents of firm performance in emerging economies: Business groups, strategy, industry structure, and state support. Journal of Business Research, v. 67, n. 10, p. 2212-2223, 2014.

KARAFAKIOGLU, M. Export activities of Turkish manufacturers. International Marketing Review, v. 3, n. 4, p. 34-43, 1986.

KARAGOZOGLU, N.; LINDELL, M. Internationalization of small and mediumsized technology-based firms: an exploratory study. Journal of Small Business Management, v. 36, n. 1, p. 44-59, 1998.

KARAKAYA, F.; HARCAR, T. Barriers to export for non-exporting firms in developing countries. Academy of Marketing Studies Journal, v. 3, n. 2, p. 5774, 1999.

.; STAHL, M. J. Barriers to entry and market entry decisions in consumer and industrial goods markets. Journal of Marketing, v. 53, n. 2, p. 80-91, 1989.

.; YANNOPOULOS, P. Relationship between Export Support, Export Barriers and Performance for 4 Canadian SMEs. Journal of Euromarketing, v. 21, n. 1, p. 4-24, 2012. 
KARELAKIS, C.; MATTAS, K.; CHRYSSOCHOIDIS, G. Export problems perceptions and clustering of Greek wine firms. EuroMed Journal of Business, v. 3, n. 1, p. 6-22, 2008.

KATHAWALA, Y.; JUDD, R.; MONIPALLIL, M.; WEINRICH, M. Exporting Practices and Problems of Illinois Firms. Journal of Small Business Management, v. 27, n. 1, p. 53-59, 1989.

KATSIKEAS, C.S. Perceived export problems and export involvement: the case of Greek exporting manufacturers. Journal of Global Marketing, v. 7, n. 4, p. 29-58, 1994.

.; LEONIDOU, L.C. Export market expansion strategy: differences between market concentration and market spreading. Journal of Marketing Management, v. 12, n. 1/3, p. 113-134, 1996.

.; MORGAN, R.E. Differences in perceptions of exporting problems based upon firm size and export experience. European Journal Marketing, v. 28, n. 5, p. 17-35, 1994.

.; PIERCY, N.F.; IOANNIDIS, C. Determinants of export performance in a European context. European Journal of Marketing, v. 30, n. 6, p. 6-35, 1996.

KAYNAK, E.; EROL, C. The export propensity of Turkish manufacturing and trading house firms. Journal of Marketing Management, v. 5, n. 2, p. 211-229, 1989.

.; KOTHARI, V. Export behaviour of small manufacturers: a comparative study of American and Canadian firms. European Management Journal, v. 2, n. 2, p. 41-47, 1983.

Export behavior of small and medium-sized manufacturers: some policy guidelines for international marketers. Management International Review, v. 24, n. 2, p. 61-69, 1984.

.; GHAURI, P.N.; OLOFSSON-BREDENLOW, T. Export behavior of small Swedish firms. Journal of Small Business Management, v. 25, n. 2, p. 2632, 1987.

KEDIA, B.L.; CHHOKAR, J. Factors inhibiting export performance of firms: an empirical investigation, Management International Review, v. 26, n. 4, p. 33-43, 1986.

KENG, K.A.; JIUAN, T.S. Difference between small and medium sized exporting and non-exporting firms: nature and nurture. International Marketing Review, v. 6, n. 4, p. 27-40, 1989.

KENIS, P.; PROVAN, K. G. Towards an exogenous theory of public network performance, Public Administration, v. 87, n. 3, p. 440-456, 2009. 
KIM, S.; NAM, C. Opportunities and challenges for South Korean Tourism and creative industries. In: Long. P.; Morpeth, N.D. (Eds.). Tourism and the Creative Industries: Theories, Policies and Practice, London: Routledge, 2016, p.102-115.

KINNUCAN, H. W.; GONG, L. Goodwill and Export Promotion Dynamics. Journal of Agricultural and Applied Economics, v. 46, n. 1, p. 73-88, 2014.

KÖKSAL, M.H.; KETTANEH, T. Export problems experienced by high-and lowperforming manufacturing companies: a comparative study. Asia Pacific Journal of Marketing and Logistics, v. 23, n. 1, p. 108-126, 2011.

KORNELIUSSEN, T.; BLASIUS, J. The Effects of Cultural Distance, Free Trade Agreements, and Protectionism on Perceived Export Barriers. Journal of Global Marketing, v. 21, n. 3, p. 217-230, 2008.

KORTH, C.M. Managerial barriers to US exports. Business Horizons, v. 34, n. 2, p. 18-26, 1991.

KOTABE, M.; CZINKOTA, M. R. State Government Promotion of Manufacturing Exports: A Gap Analysis. Journal of International Business Studies, v. 23, n. 4, p. 637-658, 1992.

KWON, Y.C.; HU, M.Y. Comparative analysis of export-oriented and foreign production-oriented firms' foreign market entry decisions: a reply. Management International Review, v. 36, n. 4, p. 371-379, 1996.

LAGES, L. F.; MONTGOMERY, D. B. The relationship between export assistance and performance improvement in Portuguese export ventures: An empirical test of the mediating role of pricing strategy adaptation. European Journal of Marketing, v. 39, n. 7/8, p.755-784, 2005.

LAUFS, K.; SCHWENS, C. Foreign market entry mode choice of small and medium-sized enterprises: A systematic review and future research agenda. International Business Review, v. 23, n. 6, p. 1109-1126, 2014.

LECHNER, C., FRANKENBERGER, K.; FLOYD, S.W. Task contingencies in the curvilinear relationships between intergroup networks and initiative performance, Academy of Management Journal, v. 53, n. 4, p. 865-889, 2010.

LECY, J. D.; MERGEL, I. A.; SCHMITZ, H. P. Networks in public administration: current scholarship in review, Public Management Review, v. 16, n. 5, p. 643$665,2014$.

LEDERMAN, D., OLARREAGA, M.; PAYTON, L. Export Promotion Agencies Revisited. Washington: World Bank, 2009, 31p. Policy Research Working Paper Series No. 5125, 2009. Available at: https://ssrn.com/abstract=1509192. Accessed 1 November 2017.

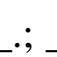
; Export promotion agencies: Do they work? Journal of Development Economics, v. 91, n. 2, p. 257-265, 2010. 
LEE, H.; KELLEY, D.; LEE, J.; LEE, S. SME Survival: The Impact of Internationalization, Technology Resources, and Alliances. Small Business Management, v.50, n.1, p. 1-19, 2012.

LEFEBVRE, E.; BOURGAULT, M.; PREFONTAINE, L.; LEFEBVRE, L. A. Understanding the driving forces behind the internationalisation process of fastmoving SMEs: implications for export assistance programmes. International Journal of Entrepreneurship and Innovation Management, v. 3, n. 5/6, p. 447467, 2003.

LEONIDOU, L. C. An Analysis of the Barriers Hindering Small Business Export Development. Journal of Small Business Management, v. 42, n. 3, p. 279-303, 2004.

Barriers to export management: an organizational and internationalization analysis. Journal of International Management, v. 6, n. 2, p. 121-148, 2000.

Empirical research on export barriers: review, assessment, and synthesis. Journal of International Marketing, v. 3, n. 1, p. 29-43, 1995a.

Export barriers: non-exporters' perceptions. International Marketing Review, v. 12, n. 1, p. 4-25, 1995 b.

; KATSIKEAS, C. S. Integrative assessment of exporting research articles in business journals during the period 1960-2007. Journal of Business Research, v. 63, n. 8, p. 879-887, 2010.

; COUDOUNARIS, D. N. Five decades of business research into exporting: A bibliographic analysis. Journal of International Management, v. 16, n. 1, p. 78-91, 2010.

.; SAMIEE, S. Marketing Strategy Determinants of Export Performance: A Meta-Analysis, Journal of Business Research, v. 55, n. 1, p. 5167, 2002.

.; __ PALIHAWADANA, D; SPYROPOULOU, S. An analytical review of the factors stimulating smaller firms to export. International Marketing Review, v. 24, n. 6, p. 735-770, 2007.

; PALIHAWADANA, D.; THEODOSIOU, M. National ExportPromotion Programs as Drivers of Organizational Resources and Capabilities: Effects on Strategy, Competitive Advantage, and Performance. Journal of International Marketing, v. 19, n. 2, p. 1-29, 2011.

LLOYD-REASON, LESTER; DEPREY, BRYNN; IBEH, K. Top Barriers and Drivers to SME Internationalisation. Paris: OECD - Organisation for Economic Co-operation and Development, 2009, 35p. Report by the OECD Working Party on SMEs and Entrepreneurship. Available at: http://www.oecd.org/industry/smes/43357832.pdf. Accessed 09 March 2017. 
LÓPEZ, N. V. Export Barriers and Strategic Grouping. Journal of Global Marketing, v. 20, n.2-3, p. 17-29, 2007.

LORENZEN, M. Ties, trust, and trade. International Studies of Management \& Organization, v. 31, n. 4, p. 14-34, 2002.

. Why do clusters change? European Urban and Regional Studies, v. 12, n. 3, p. $203-208,2005$.

MAFFIOLI, A.; PIETROBELLI, C.; STUCCHI, R. The Impact Evaluation of Cluster Development Programs: Methods and Practices. Washington: Interamerican Development Bank, 2016, 204p.

MAGGIONI, M.A. The rise and fall of industrial clusters: technology and the life cycle of region. Barcelona: Institut d'Economia de Barcelona, Espai de Recerca en Economia, Facultat de Ciències Econòmiques i Empresarials, Universitat de Barcelona, 2005, 39p. Working Paper 2004/6.

MAH, J. S. The effect of duty drawback on export promotion: The case of Korea. Journal of Asian Economics, v. 18, n. 6, p. 967-973, 2007.

MAHONE, C.E.; CHOUDHURY, P.K. Small and medium size manufacturers and traders. Multinational Business Review, v. 3, n. 2, p. 17-26, 1995.

MANDELL, M.; KEAST, R. L. A new look at leadership in collaborative networks: process catalysts. In: Raffel, J.; Leisink P. and Middlebrooks, A. (Eds.), Public Sector Leadership: International Challenges and Perspectives, Cheltenham: Edward Elgar, 2009, p. 163-178.

MARIN, D. Is the export-led growth hypothesis valid for industrialized countries? The Review of Economics and Statistics, v. 74, n. 4, p. 678-688, 1992.

MARIOTTI, S.; MUTINELLI, M.; PISCITELLO, L. The internationalization of production by Italian industrial districts' firms: structural and behavioural determinants. Regional Studies, v. 42, n. 5, p. 719-35, 2008.

MARTIN, R. Roepke lecture in economic geography - rethinking regional path dependence: beyond lock-in to evolution. Economic Geography, v. 86, n. 1, p. 127, 2010.

MARTINCUS, C. V.; CARBALLO, J. Beyond the average effects: The distributional impacts of export promotion programs in developing countries. Journal of Development Economics, v. 92, n. 2, p. 201-214, 2010a.

Entering new country and product markets: Does export promotion help? Review of World Economics, v. 146, n. 3, p. 437-467, 2010 b.

What Kind of Trade Do They Promote? Washington: IDB - Interamerican 
Development Bank, 2010c, 41p. Working Paper Series No. IDB-WP-202. Available at: https://publications.iadb.org/handle/11319/3180. Accessed 5 November 2016.

Export Promotion: Bundled Services Work Better. The

World Economy, v. 33, n. 12, p. 1718-1756, 2010 d.

;

. Export promotion activities in developing countries:

What kind of trade do they promote? The Journal of International Trade \& Economic Development: An International Comparative Review, v. 21, n. 4, p. 539-578, 2012.

Is export promotion effective in developing countries? Firm-level evidence on the intensive and the extensive margins of exports. Journal of International Economics, v. 76, n. 1, p. 89-106, 2008.

; .; GALLO, A. The impact of export promotion institutions on trade: is it the intensive or the extensive margin? Applied Economics Letters, v. 18, n. 1/3, p. 127-132, 2011. ; ; GARCIA, P. M. Public programmes to promote firms' exports in developing countries: are there heterogeneous effects by size categories? Applied Economics, v. 44, n. 4/6, p. 471-491, 2012.

.; ESTEVADEORDAL, A.; GALLO, A.; LUNA, J. Information barriers, export promotion institutions, and the extensive margin of trade. Review of World Economics, v. 146, n. 1, p. 91-111, 2010.

MARTÍNEZ-FERNÁNDEZ, M· T.; CAPÓ-VICEDO, J.; VALLET-BELLMUNT, T. The present state of research into industrial clusters and districts - Content analysis of material published in 1997-2006. European Planning Studies, v. 20, n. 2, p. 281-304, 2012.

MARZOUK, W. B. Non-market strategy competitiveness and export performance of Tunisian small and medium-sized enterprises (SMEs). International Journal of Technology Management \& Sustainable Development, v. 16, n. 3, p. 271 - 294, 2017.

MASKELL, P.; KEBIR, L. What Qualifies as a Cluster Theory? Copenhagen: DRUID, Copenhagen Business School, Department of Industrial Economics and Strategy, 2005, 19p. Working Paper No. 05-09.

MATHUR, L. K.; MATHUR, I. The Effectiveness of the Foreign-Trade Zone as an Export Promotion Program: Policy Issues and Alternatives. Journal of Macromarketing, v. 17, n. 2, p. 20-31, 1997.

MAVROGIANNIS, M. et al. Assessing export performance in the Greek food and beverage industry. British Food Journal, v. 110, n. 7, p. 638-654, 2008. 
MENZEL, M. P.; FORNAHL, D. Cluster life cycles - dimensions and rationales of cluster evolution. Industrial and Corporate Change, v. 19, n. 1, p. 205-238, 2010.

MEYER, H.; KLASEN, A. What Governments Can Do to Support their Economies: The Case for a Strategic Econsystem. Global Policy, v. 4, Suppl. 1, p. $1-9,2013$.

MEYER-STAMER, J. Path dependence in regional development: persistence and change in three industrial clusters in Santa Catarina, Brazil. World Development, v. 26, n. 8, p. 1495-1511, 1998.

MIESENBOCK, K.J. Small businesses and exporting: literature review. International Small Business Journal, v. 6, n. 2, p. 42-61, 1988.

MIOCEVIC, D. Exploring Export Promotion Policy from a Justice Perspective: A Case Study. Journal of Macromarketing, v. 33, n. 4, p. 342-353, 2013.

MOINI, A.H. Barriers inhibiting export performance of small and medium-sized manufacturing firms. Journal of Global Marketing, v. 10, n. 4, p. 67-93, 1997.

. Small Firms Exporting: How Effective Are Government Export Assistance Programs? Journal of Small Business Management, v. 36, n. 1, p. 1 $15,1998$.

MOISEICHYK, A. E., BRUM, T. M. M.; VEIGA, C. H. A.; VEIGA, D. B. Desempenho importador do segmento de moda praia brasileiro: uma proposta de análise. InternexT - Revista Eletrônica de Negócios Internacionais da ESPM, v. 7, n. 2, p. 70-88, 2012.

MOORE, W.; CARTER, J. Supporting the Growth of Service Exports in the Caribbean. Journal of Eastern Caribbean Studies, v. 40, n. 1, p. 81-109, 2015.

MOREIRA, S.V.; SANTOS, A. F. Políticas Públicas de Exportação: O Caso PROEX. Brasília: IPEA - Instituto de Pesquisa Econômica Aplicada, 2001, 43p. Discussion Paper.

MORGAN, R.E. Export stimuli and export barriers: evidence from empirical research studies. European Business Review, v. 97, n. 2, p, 68-81, 1997.

.; KATSIKEAS, C.S. Exporting problems of industrial manufacturers. Industrial Marketing Management, v. 27, n. 1, p. 161-176, 1998.

25, n. 6, p. 677-690, 1997.

Obstacles to export initiation and expansion. Omega, v.

MORTANGES, P. de; VAN GENT, A. P. International Marketing and Government Export Promotion in Netherlands. In: Seringhaus, F.H.R. and Rosson, P.J. (Eds.), Export Development and Promotion: The Role of Public Organizations, p.243271, Springer, New York, 1990. 
MÜLLER, L.; LÄMMER-GAMP, T.; MEIER zu KÔCKER, G.; CHRISTENSEN, T. A. Clusters are Individuals: New Findings from the European Cluster Management and Cluster Program Benchmarking. Copenhagen: The Danish Ministry of Science, Innovation and Higher Education, 2012, 260p. Technical Report.

MZUMARA, M.; MATTHEE, M.; STEENKAMP, E. Can a new export promotion strategy revitalise Zimbabwe's economy? African Insight, v. 43, n. 3, p. 63-79, 2013.

NAIDU, G. M.; CAVUSGIL, S. T.; MURTHY, B. K.; SARKAR, M. An export promotion model for India: Implications for public policy. International Business Review, v. 6, n. 2, p. 113-125, 1997.

; RAO, T. R. Public sector promotion exports: A needs-based approach. Journal of Business Research, v. 27, n. 1, p. 85-101, 1993.

NARAYANAN, V. Export Barriers for Small and Medium-sized Enterprises: A Literature Review based on Leonidou's Model. Entrepreneurial Business and Economics Review, v. 3, n. 2, p. 105-123, 2015.

NARAYAN, P.K.; NARAYAN, S; PRASAD, B, C.; PRASAD, A. Export-led growth hypothesis: Evidence from Papua New Guinea and Fiji. Journal of Economic Studies, v. 34, n. 4, p. 341-349, 2007.

NEGHANDI, A.R. Interorganizational Theory, Kent: Kent State University Press, 1980.

NEUPERT, K. E.; BAUGHN, C. C.; THANH LAM DAO, T. SME exporting challenges in transitional and developed economies. Journal of Small Business and Enterprise Development, v. 13, n. 4, p. 535-545, 2006.

NEWBIGIN, J. What is the creative economy? Available at: https://www.creativeeconomy.britishcouncil.org/guide/what-creative-economy/. Accessed 19 February 2018.

NEWIG, J., GUNTHER, D.; PAHL-HOST, C. Synapses in the network: learning in governance networks in the context of environmental management, Ecology and Society, v. 15, n. 4, 16p., 2010.

NGO, V. D. et al. Domestic institutional attributes as drivers of export performance in an emerging and transition economy. Journal of Business Research, v. 69, n. 8, p. 2911-2922, 2016.

NODA, T.; COLLIS, D. J. The evolution of intraindustry firm heterogeneity: insights from a process study. Academy of Management Journal, v. 44, n. 4, p. 897-925, 2001.

NOHRIA, N.; ECCLES, R.G. Networks and Organizations: Structure, Form and Action. Boston: Harvard Business School Press, 1992, 544p. 
NORTH, D. Institutions, Institutional Change and Economic Performance. Cambridge: Cambridge University Press, 1990.

OECD. Enhancing the Contributions of SMEs in a Global and Digitalised Economy. Paris: OECD - Organisation for Economic Co-operation and Development, 2017, 23p. Report of the Meeting of the OECD Council at Ministerial Level.

OGRAM, E.W. Jr. Exporters and nonexporters: A profile of small manufacturing firms in Georgia. In: Czinkota, M. R. and G. Tesar, G. (Eds.), Export management: An international context. New York: Praeger Publishers, 1982, p.70-84.

OLARREAGA, M., SPERLICH, S.; TRACHSEL, V. Export Promotion: What Works? Geneva: University of Geneva, 2015. Working Paper. Available at: https://www.unige.ch/degit/files/3714/4102/9892/Trachsel.pdf. Accessed 25 October 2016.

OLIVEIRA, J. M. de; ARAUJO, B. C. de; SILVA, L. V. Panorama da econômica criativa no Brasil. Brasília: IPEA - Instituto de Pesquisa Econômica Aplicada, 2013, 49p. Discussion Paper 1880.

ONKVISIT, S.; SHAW, J.J. Marketing barriers in international trade. Business Horizons, v. 31, n. 3, p. 64-72, 1988.

OPARAOCHA, G.O. SMEs and international entrepreneurship: an institutional perspective, International Business Review, v. 24, n. 5, p. 861-873, 2015.

OZGEN, E.; BARON, R. A. Social sources of information in opportunity recognition: Effects of mentors, industry networks, and professional forums. Journal of Business Venturing, v. 22, n. 2, p. 174-192, 2007.

PAARLBERG, L.; VARDA, D. Community carrying capacity: A network perspective. Nonprofit and Voluntary Sector Quarterly, v. 38, n. 4, p.597-613, 2009.

PANICCIA, I. One, a hundred, thousands of industrial districts. Organizational variety in local networks of small and medium-sized enterprises. Organization Studies, v. 19, n. 4, p. 667-699, 1998.

PAQUIN, R. L.; HOWARD-GRENVILLE, J. Blind dates and arranged marriage: longitudinal processes of network orchestration, Organization Studies, v. 34, n. 11, p. 1623-1653, 2013.

PARRILLI, M. D.; SACCHETTI, S. Linking learning with governance in networks and clusters: key issues for analysis and policy. Entrepreneurship \& Regional Development, v. 20, n. 4, p. 387-408, 2008.

PATTERSON, P.G. A study of perceptions regarding service firms' attitudes towards exporting. Australasian Marketing Journal, v. 12, n. 2, p. 19-38, 2004. 
PAUWELS, P.; MATTHYSSENS, P. The architecture of multiple case study research in international business. In: Marschan-Piekkari, R. and Welch C. (Eds.) Handbook of Qualitative Research Methods in International Business. Cheltenham: Edward Elgar, 2004, p. 125-143.

PAVORD, W.C.; BOGART, R.G. The dynamics of the decision to export. Akron Business and Economic Review, v. 6, n. 1, p. 6-11, 1975.

PEEL, M.J.; ECKART, H. Language and export barriers in the manufacturing sector. Management Research News, v. 19, n. 3, p. 52-61, 1996.

PEIRIS, I. K.; AKOORIE, M. E. M.; SINHA, P. International entrepreneurship: A critical analysis of studies in the past two decades and future directions for research. Journal of International Entrepreneurship, v. 10, n. 4, p. 279-324, 2012.

PEIXOTO, F. O Local e os Sistemas de Inovações em Países Subdesenvolvidos: O Caso do Arranjo Produtivo de Moda Praia de Cabo Frio/RJ. Rio de Janeiro, 2005. Unpublished Master thesis (Economics) - Universidade Federal do Rio de Janeiro.

PENROSE, E. T. The theory of the growth of the firm, $4^{\text {th }}$ ed. Oxford: Oxford University Press, 2009, 304p.

PEREIRA, C. A. M.; REIS, P. Comunicação, cultura e sustentabilidade: desenvolvimento sustentável nos APLs de Cabo Frio e Santo Antônio de Pádua. Rio de Janeiro: E-papers, 2008, 129p.

PETERS, M. A. Three forms of the knowledge economy: learning, creativity and openness, Management and Financial Markets, v. 5, n. 4, p. 63-92, 2010.

PIEKKARI, R.; WELCH, C. Pluralism in international business and international management research: making the case. In: Piekkari, R. and Welch, C. Rethinking the Case Study in International Business and Management Research. Cheltenham: Edward Elgar, 2011, p. 3-23. .; _ PAAVILAINEN, E. The case study as disciplinary convention: evidence from international business journals. Organizational Research Methods, v. 12, n. 3, p. 567-589, 2009.

PINHO, J. C.; MARTINS, L. Exporting barriers: Insights from Portuguese smalland medium-sized exporters and non-exporters. Journal of International Entrepreneurship, v. 8, n. 3, p. 254-272, 24 set. 2010.

POINTON, T. Measuring the gains from government export promotion. European Journal of Marketing, v. 12, n. 6, p. 451-462, 1978.

PORTER, M. Clusters and the new economics of competition. Harvard Business Review, p. 77-90, Nov.-Dec.1998. 
POTTER, A.; WATTS, H.D. Evolutionary agglomeration theory: increasing returns, diminishing returns, and the industry life cycle. Journal of Economic Geography, v. 11, n. 3, p. 417-455, 2011.

PRESS, K. A Life-Cycle for Clusters? The Dynamics of Agglomeration, Change, and Adaptation. Heidelberg: Physica-Verlag, 2006, 227p.

PROCOLOMBIA. Colombia Bring IT on. Bogota: Procolombia, 2013. Procolombia Report, 36p.

PROVAN, K.G. Interorganizational cooperation and decision-making autonomy in a consortium multihospital system, Academy of Management Review, v. 9, n. 3, p. 494-504, 1984.

.; KENIS, P. Modes of network governance: structure, management and effectiveness, Journal of Public Administration Research and Theory, v. 18, n. 2, p. 229-252, 2008.

; MILWARD, H.B. A preliminary theory of interorganizational network effectiveness: a comparative study of four community mental health systems, Administrative Science Quarterly, v. 40, n. 1, p. 1-33, 1995.

PRUNELLO, J. The changing role of trade promotion, International Trade Forum, n. 4, p. 14-15, 2014.

QUAYE, D. M.; SEKYERE, K. N.; ACHEAMPONG, G. Export promotion programmes and export performance: A study of selected SMEs in the manufacturing sector of Ghana. Review of International Business and Strategy, v. 27, n. 4, p. 466-483, 2018.

RABINO, S. An examination of barriers to exporting encountered by small manufacturing companies. Management International Review, v. 20, n. 1, p. 6773, 1980.

RAHMAN, M.; UDDIN, M.; LODORFOS, G. Barriers to Enter into Foreign Markets: Evidence from SMEs in an Emerging Economy. International Marketing Review, v. 34, n. 1, p. 68-86, 2017.

RAMASESHAM, B.; SOUTAR, G.N. Combined effects of incentives and barriers on firms' export decisions. International Business Review, v. 5, n. 1, p. 53-65, 1996.

RAMASWANI, S. N.; YANG, Y. Perceived barriers to exporting and export assistance requirements. In: Cavusgil, S.T. and Czinkota, M. R. (Eds.), International perspectives on trade promotion and assistance. Westport: Greenwood Press, 1990, p. 187-206.

RAMAZZOTTI, P. Industrial districts, social cohesion, and economic decline in Italy. Cambridge Journal of Economics, v. 34, n. 6, p. 955-974, 2010. 
RAUCH, J. E. Business and Social Networks in International Trade. Journal of Economic Literature, v. 39, n. 4, p. 1177-1203, 2001.

RAZAVI, S. H.; HASHEMI, S. S.; ZAVADSKAS, E. K. Prioritization of Export Promotion Programs by Fuzzy Linear Assignment Method. Inzinerine Ekonomika-Engineering Economics, v. 23, n. 5, p. 462-470, 2012.

REID, S. D. The decision-maker and export entry and expansion. Journal of International Business Studies, v. 12, n. 2, p. 101-112, 1981.

RIETJENS, B., VAN FENEMA, P.C.; VAN BAALEN, P., Conceptualizing coordination problems in temporary interorganizational networks. In: Academy of Management Annual Meeting 2007. Academy of Management Annual Meeting Proceedings, Public and Non-profit Conference Paper Abstracts, 2007.

RØISELAND, A. Understanding local governance: institutional forms of collaboration, Public Administration, v. 89, n. 3, p. 879-893, 2011.

ROLF SERINGHAUS, F. H. The Impact of Government Export Marketing Assistance. International Marketing Review, v. 3, n. 2, p. 55-66, 1986.

ROY, A.; SEKHAR, C.; VYAS, V. Barriers to internationalization: a study of small and medium enterprises in India. Journal of International Entrepreneurship, v. 14, n. 4, p. 513-538, 2016.

RUSSELL, J. 1.; MEREDITH, J.; CHILDS, J.; STEIN, M. K.; PRINE, D. W. Designing Inter-Organizational Networks to Implement Education Reform: An Analysis of State Race to the Top Applications, Educational Evaluation and Policy Analysis, v. 37, n. 1, p. 92-112, 2015.

SAEED, A.; VINCENT, O. Financial Obstacles to Firm Export: Insight from a Developing Country. Journal of Transnational Management, v. 16, n. 4, p. 204$220,2011$.

SAMMARRA, A.; BELUSSI, F. Evolution and relocation in fashion-led Italian districts: evidence from two case studies. Entrepreneurship \& Regional Development, v. 18, n. 6, p. 543-572, 2006.

SCHMIDT, F. de H. O efeito das políticas públicas brasileiras de apoio à exportação: implicações para o desempenho exportador das firmas em uma abordagem longitudinal. Rio de Janeiro, 2012. 342p. Unpublished $\mathrm{PhD}$ thesis (Business Adminisration) - IAG Business School, Pontifical Catholic University of Rio de Janeiro - PUC-Rio.

SCHMIDT, F. H.; SILVA, J.F. Export Assistance: A Literature Review and Challenges for Future Research. Brasília: IPEA - Instituto de Pesquisa Econômica Aplicada, 2015. 32p. Discussion Paper No. 191. Available at: http://repositorio.ipea.gov.br/bitstream/11058/5141/1/DiscussionPaper_191.pdf. Accessed 13 July 2016. 
SCHMITZ, H. Global Competition and local cooperation: success and failure in the Sinos Valley, Brazil. World Development, v. 27, n. 9, p. 1627-1650, 1999a.

Collective efficiency and increasing returns. Cambridge Journal of Economics, v. 23, n. 4, p. 465-483, 1999 b.

SCHNEIBERG, M. What's on the path? Path dependence, organizational diversity and the problem of institutional change in the US economy, 1900-1950. SocioEconomic Review, v. 5, n. 1, p. 47-80, 2006.

SCHROATH, F.W.; KORTH, C.M. Managerial barriers to the internationalization of US property and liability insurers: theory and perspectives. Journal of Risk and Insurance, v. 56, n. 4, p. 630-648, 1989.

SCOTT, A. J. Regional motors of the global economy. Futures, v. 28, n. 5, p. 391411, 1996.

.; GAROFOLI, G. The regional question in economic development. In: Scott, A. J.; Garofoli, G. (Eds.) Development on the Ground: Clusters, Networks and Regions in Emerging Economies. London: Routledge, 2007, p.3-22.

SCOTT, P.; THOMAS, C. Do collaborative groups enhance interorganizational networks? Public Performance \& Management Review, v. 38, n. 4, p. 654-683, 2015 .

SEAR, L.; HAMILTON, R. T. Business support for internationalisation in England. In: DANA, L.-P. (Ed.). Handbook of Research on International Entrepreneurship. Cheltenham; Northampton: Edward Elgar, 2004, p. 352-369.

SEBRAE/RJ. Plano estratégico - Pólo de moda praia de Cabo Frio e Região. Rio de Janeiro: SEBRAE/RJ - Serviço Brasileiro de Apoio às Micro e Pequenas Empresas. SEBRAE/RJ Internal document, Feb. 2005.

SEBRAE/RJ. Diagnóstico das empresas do projeto: Polo de confecção de Cabo Frio e Região. Rio de Janeiro: Sebrae, Área de Estratégias e Diretrizes. Internal document, 2008.

SELDEN, S.C., SOWA, J.E.; SANDFORT, J. The impact of nonprofit collaboration in early child care and education on management and program outcomes, Public Administration Review, v. 66, n. 3, p. 412-425, 2006.

SERINGHAUS, F. H. R.; BOTSCHEN, G. Cross-National Comparison of Export Promotion Services: The Views of Canadian and Austrian Companies. Journal of International Business Studies, v. 22, n. 1, p. 115-133, mar. 1991.

., ROSSON, P.J. Export promotion and public organizations: the stateof-the-art. In: Seringhaus, F.H.R. and Rosson, P.J. (Eds.) Export Development and Promotion: The Role of Public Organizations, New York: Springer, 1990, p.3-18. 
$1^{\text {st }}$ ed. London: Routledge, 1990, 295p.

SHAMSUDDOHA, A. K.; YUNUS ALI, M. Mediated effects of export promotion programs on firm export performance. Asia Pacific Journal of Marketing and Logistics, v. 18, n. 2, p. 93-110, 2006.

; ;; NDUBISI, N. O. Impact of government export assistance on internationalization of SMEs from developing nations. Journal of Enterprise Information Management, v. 22, n. 4, p. 408-422, 2009a.

A conceptualisation of direct and indirect impact of export promotion programs on export performance of SMEs and entrepreneurial ventures. International Journal of Entrepreneurship, v. 13, n. Special Issue, p. 87-106, 2009b.

SHARKEY, T.W.; LIM, J.S.; KIM, K.I. Export development and perceived export barriers: an empirical analysis of small firms. Management International Review, v. 29, n. 2, p. 33-40, 1989.

SHARMA, D.D.; BLOMSTERMO, A. The internationalization process of born globals: a network view. International Business Review, v. 12, n. 6, p.739-753, 2003.

SHAW, V.; DARROCH, J. Barriers to Internationalisation: A Study of Entrepreneurial New Ventures in New Zealand. Journal of International Entrepreneurship, v. 2, n. 4, p. 327-343, 2004.

SHIH, T.-Y.; WICKRAMASEKERA, R. Export decisions within Taiwanese electrical and electronic SMEs: The role of management characteristics and attitudes. Asia Pacific Journal of Management, v. 28, n. 2, p. 353-377, 2011.

SHIN, D.J.; HASSINK, R. Cluster life cycles: the case of the shipbuilding industry cluster in South Korea. Regional Studies, v. 45, n. 10, p. 1387-1402, 2011.

SHOHAM, A.; ALBAUM, G. S. Reducing the impact of Barriers to Exporting: A Managerial Perspective. Journal of International Marketing, v. 3, n. 4, p. 85-105, 1995.

SILIVERSTOVS, B.; HERZER, D. Export-led growth hypothesis: Evidence from Chile. Applied Economics Letters, v. 13, n. 5, p. 319-324, 2006.

SIMÕES, K. Marcas apostam em coleções de luxo. Valor, p. F2, 30.01.2015.

SIMPSON, C.L. Jr.; KUJAWA, D. The export decision process: an empirical inquiry. Journal of International Business Studies, v. 5, n. 1, p. 107-117, 1974.

SINGER, T. O. The role of export promotion in export management: The case of the Minnesota trade office. Washington, 1990. Unpublished $\mathrm{PhD}$ thesis (Economics). The George Washington University. 
.; CZINKOTA, M. R. Factors Associated with Effective Use of Export

Assistance. Journal of International Marketing, v. 2, n. 1, p. 53-71, 1994.

SMITH, D.; GREGOIRE, P.; LU, M. Managers' Perceptions of Export Barriers. Journal of Transnational Management, v. 12, n. 1, p. 51-68, 2006.

SOUSA, C. M. P.; BRADLEY, F. Effects of Export Assistance and Distributor Support on the Performance of SMEs: The Case of Portuguese Export Ventures. International Small Business Journal, v. 27, n. 6, p. 681-701, 2009.

SOUZA, N. DE J. DE. Exportação e Crescimento Econômico do RS - 1951-2001. Ensaios FEE, v. 23, Special Issue, 2002.

STINCHCOMBE, A. Social structure and organizations. In J. March (Ed.), Handbook of organizations. Chicago: Rand McNally, 1965, p. 260-290.

STOIAN, M.-C., RIALP-CRIADO, A. Analyzing Export Behavior Through Managerial Characteristics and Perceptions: A Multiple Case-Based Research. Journal of Global Marketing, v. 23, n. 4, p. 333-348, 2010.

SUAREZ-ORTEGA, S. Export barriers: insights from small and medium-sized firms. International Small Business Journal, v. 21, n. 4, p. 403-420, 2003.

SULLIVAN, D.; BAUERSCHMIDT, A. Common factors underlying barriers to export: a comparative study in the European and US paper industry. Management International Review, v. 29, n. 2, p. 17-32, 1989.

SWANN, G. M. P. Towards a model of clustering in high-technology industries. In: Swann, G. M. P.; Prevezer, M. and Stout, D. (Eds.) The Dynamics of Industrial Clustering. Oxford: Oxford University Press, 2002, p.52-76.

SYDOW, J.; LERCH, F.; STABER, U. Planning for path dependence? The case of a network in the Berlin-Brandenburg optics cluster. Management International Review, v. 86, n. 2, p. 173-195, 2010.

; SCHREYOGG, G.; KOCH, J. Organizational path dependence: opening the black box. Academy of Management Review, v. 34, n. 4, p. 689-709, 2009.

TAN, A.; BREWER, P.; LIESCH, P. W. Before the first export decision: Internationalisation readiness in the pre-export phase. International Business Review, v. 16, n. 3, p. 294-309, 2007.

TANNOUS, G. F. Financing export activities of small Canadian businesses: Exploring the constraints and possible solutions. International Business Review, v. 6, n. 4, p. 411-431, 1997.

TANSU BARKER, A.; KAYNAK, E. An Empirical Investigation of the Differences between Initiating and Continuing Exporters. European Journal of Marketing, v. 26, n. 3, p. 27-36, mar. 1992. 
Te VELDE, D. W. Understanding developed country efforts to promote foreign direct investment to developing countries: the example of the United Kingdom. Transnational Corporations, v. 16, n. 3, p. 83-104, 2007.

TESAR, G.; MOINI, A.H. Longitudinal study of exporters and non-exporters: a focus on smaller manufacturing enterprises. International Business Review, v. 7, n.3, p. 291-313, 1998.

.; TARLETON J.S. Comparison of Wisconsin and Virginian small and medium-sized exporters: aggressive and passive exporters. In: Czinkota, M.R. and Tesar, G. (Eds.) Export Management: An International Context, New York: Praeger, 1982, p.85-112.

TESFOM, G.; LUTZ, C. A classification of export marketing problems of small and medium sized manufacturing firms in developing countries. International Journal of Emerging Markets, v. 1, n. 3, p. 262-281, 2006.

; Evaluating the effectiveness of export support services in developing countries. International Journal of Emerging Markets, v. 3, n. 4, p. 364-377, 2008.

THOMAS, M.J.; ARAUJO, L. Theories of export behaviour: a critical analysis. European Journal of Marketing, v. 19, n. 2, p. 42-52, 1985.

TICHY, G. Clusters: Less Dispensable and More Risky than Ever. In: Steiner, M. (Eds.), Clusters and Regional Specialisation: On Geography Technology and Networks. London: Pion Limited, 1998, p. 226-237.

TIJAN, Y. Re-Thinking Intellectual Property: The Political Economy of Copyright Protection in the Digital Era. London: Routledge-Cavendish, 2009, $337 p$.

TOMLINSON, P.R.; JACKSON, I. Cooperative ties and the impact of external factors upon innovation in an industrial district: some insights from the North Staffordshire table and giftware sector. Regional Studies, v. 47, n. 4, p. 580-596, 2013.

TORRES, M. M.; CLEGG, L. J.; VARUM, C. A. The missing link between awareness and use in the uptake of pro-internationalization incentives. International Business Review, v. 25, n. 2, p. 495-510, 2016.

TRIPPL, M.; TÖDTLING, F. Cluster renewal in old industrial regions: continuity or radical change. In: Karlsson, C. (Ed.) Handbook of Research on Cluster Theory. Cheltenham: Edward Elgar, p. 203-218, 2008.

TSENG, J.Y.; YU, C.M.J. Export of industrial goods to Europe: the case of large Taiwanese firms. European Journal of Marketing, v. 25, n. 9, p. 51-63, 1991. 
TUK, W. The Korean Wave: Who Are Behind the Success of Korean Popular Culture? Leiden, 2012. 57p. Unpublished Master thesis - The Hague, Leiden University. Available

at: https://openaccess.leidenuniv.nl/bitstream/handle/1887/20142/hallyu\%20version \%207.pdf?sequence=1. Accessed May 25, 2016.

UNCTAD. Creative Economy Outlook and Country Profiles: Trends in international trade in creative industries. Geneva: UNCTAD - United Nations Conference on Trade and Development, 2015. 169p. UNCTAD Report.

WHITE, D. S.; GUNASEKARAN, A.; ROY, M. H. Performance measures and metrics for the creative economy. Benchmarking: An International Journal, v. 21, n. 1, p. 46-61, 2014.

UNDP. Human Development Report 2016. New York: United Nations Development Programme, 2016. 286p. UNDP Report.

UNER, M. M. et al. Do barriers to export vary for born globals and across stages of internationalization? An empirical inquiry in the emerging market of Turkey. International Business Review, v. 22, n. 5, p. 800-813, 2013.

VALDALISO, J.M.; ELOLA, A.; FRANCO, S. Do clusters follow the industry life cycle? Competitiveness Review, v. 26, n. 1, p. 66-86, 2016.

VAN BIESEBROECK, J.; YU, E.; CHEN, S. The impact of trade promotion services on Canadian exporter performance. Canadian Journal of Economics, v. 48, n. 4, p. 1481-1512, 2015.

VAN DE VEN, A.H. On the nature, formation, and maintenance of relationships among organizations, Academy of Management Review, v. 1, n. 4, p. 24-36, 1976.

VERGNE, J. P.; DURAND, R. The missing link between the theory and empirics of path dependence: conceptual clarification, testability issue, and methodological implications. Journal of Management Studies, v. 47, n. 4, p. 736-759, 2010.

VILLELA, L. E.; SOARES, L. C. Gestão participativa, informação e acesso a financiamentos no Banco do Brasil S/A, na percepção de atores locais e de empresários de micro e pequenas empresas dos APLs de Cabo Frio - RJ e Nova Friburgo - RJ. Administração Pública e Gestão Social - APGS, v. 1, n. 3, p. 274293, 2009.

WANG, X.; CHEN, A.; WANG, H.; LI, S. Effect of export promotion programs on export performance: evidence from manufacturing SMEs, Journal of Business Economics and Management, v. 18, n. 1, p. 131-145, 2017.

WEAVER, K.M.; PAK, J.M. Export behavior and attitudes of small-and mediumsized Korean manufacturing firms. International Small Business Journal, v. 8, n. 4, p. 59-70, 1990. 
WELCH, C.L.; WELCH, D.E., HEWERDINE, L. Gender and export behavior: evidence from women-owned enterprises. Journal of Business Ethics, v. 83, n.1, p. 113-126, 2008.

WIEDERSHEIM-PAUL, F.; OLSON, H.C.; WELCH, L. S. Pre-Export Activity: The First Step in Internationalization. Journal of International Business Studies, v. 9, n. 1, p. 47-58, 1978.

WILKINSON, T. J.; BROUTHERS, L. E. An Evaluation of State Sponsored Promotion Programs. Journal of Business Research, v. 47, n. 3, p. 229-236, 2000.

International Business Review, v. 15, n. 3, p. 233-252, 2006.

WILLIAMS, D. A. Export stimulation of micro- and small locally owned firms from emerging environments: New evidence. Journal of International Entrepreneurship, v. 6, n. 3, p. 101-122, 2008.

WILLIAMSON, N.C., KSHETRI, N.B.; WILKINSON, T.J. Recent trends in export promotion in the United States, Marketing Management Journal, v. 21, n. 2, p. 153-166, 2011.

WRIGHT, M.; WESTHEAD, P.; UCBASARAN, D. Internationalization of Small and Medium-sized Enterprises (SMEs) and International Entrepreneurship: A Critique and Policy Implications. Regional Studies, v. 41, n. 7, p. 1013-1030, Oct. 2007.

WOLFE, D. A.; GERTLER, M. S. Clusters from the inside and out: local dynamics and global linkages. Urban Studies, v. 41, n. 5/6, p. 1071-1093, 2004.

WTO. World Trade Statistical Review 2017. Geneva: World Trade Organization, 2017, 179p. Technical Report.

WOLTER, K. A Life Cycle for Clusters? The Dynamics Governing Regional Agglomerations. In: Clusters, Industrial Districts and Firms: The Challenge of Globalization of Modena and Reggio Emilia Conference, Modena, Italy, 2003. Conference Presentation.

WU, R.; SHI, H. Trade Liberalization and Exports Promotion: A Dynamic and Heterogeneous Analysis Under the Case of Chile. Emerging Markets Finance and Trade, v. 52, n. 11, p. 2636-2645, 2016.

YANG, Y.S.; LEONE, R.P.; ALDEN, L. A market expansion ability approach to identify potential exporters, Journal of Marketing, v. 56, n. 1, p. 84-96, 1992.

YANNOPOULOS, PETER; KEFALAKI, M. An Empirical Investigation of Perceptions of Export Barriers Using Mental Models Theory. In: Annual Hawaii International Business Research Conference 2010. Annual Hawaii International Business Research Conference 2010 Proceedings. Available at: http://www.wbiconpro.com/1. Peter-Canada.pdf. Accessed 09 March 2017. 
YANNOPOULOS, PETER; KEFALAKI, M. Export Barriers Facing Canadian Exporters: The Role of Mental Models. Journal of Business and Policy Research, v. 5, n. 2, p. 54-68, 2010.

YAPRAK, A. An empirical study of the differences between small exporting and non-exporting US firms. International Marketing Review, v. 2, n. 2, p. 72-83, 1985.

YIN, R. K. Case Study Research Design and Methods. $5^{\text {th }}$ edition. Thousand Oaks: Sage, 2014, 282 p.

YOUNG, S., HAMILL, J., WHEELER, C. and Davis, J. R. International Market Entry and Development: Strategies and Management. Hemel Hempsted: Harvester Wheatsheaf, 1989, 305p.

ZAHEER, S. Overcoming the Liability of Foreignness. Academy of Management Journal, v. 38, n. 2, p. 341-363, 1995.

ZIA, B. H. Export incentives, financial constraints, and the (mis)allocation of credit: Micro-level evidence from subsidized export loans. Journal of Financial Economics, n. 87, p. 498-527, 2008.

ZOU, S.; STAN, S. The determinants of export performance: a review of the empirical literature between 1987 and 1997. International Marketing Review, v. 15 , n. 5, p. 333-356, 1998.

ZUCCHELLA, A. Local cluster dynamics: trajectories of multiple districts between decline and multiple embeddedness. Journal of Institutional Economics, v. 2, n. 1, p. 21-44, 2006.

.; BRUGNOLI, A.; DAL BIANCO, A. Barriers to the Internationalization of SMEs: An Analysis from the Perspective of Support Service Providers, in Dimitratos, P.; Jones, M. V. (Eds.), Resources, Efficiency and Globalization. The Academy of International Business. Palgrave Macmillan, London, 2010. 


\section{Appendix 1 - Cultural and creative sectors and their range of activities}

\begin{tabular}{|l|l|}
\hline Sectors & Range of activities \\
\hline Advertising & Advertising agencies \\
\hline Architecture & Architectural firms \\
\hline Books & $\begin{array}{l}\text { Physical and digital books sales (including scientific, technical and } \\
\text { medical books) }\end{array}$ \\
\hline Gaming & Video game publishers, developers and retailers; equipment sales \\
\hline Music & Sound recording and music publishing industry, live music \\
\hline Movie & Motion picture production, post-production and distribution \\
\hline $\begin{array}{l}\text { Newspapers } \\
\text { magazines }\end{array}$ & $\begin{array}{l}\text { Newspapers and magazine publishing industry (B2C and B2B, new } \\
\text { agencies) }\end{array}$ \\
\hline Performing Arts & $\begin{array}{l}\text { Performing arts activities: dance, theatre, live music, opera, ballet } \\
\text { etc. }\end{array}$ \\
\hline Radio & Radio broadcasting activities \\
\hline TV & $\begin{array}{l}\text { TV programming, production and broadcasting including cable and } \\
\text { satellite }\end{array}$ \\
\hline Visual arts & $\begin{array}{l}\text { Visual arts creation, museums, photographic and design activities, } \\
\text { including fashion }\end{array}$ \\
\hline
\end{tabular}

Source: Adapted from Cultural Times: The first global map of cultural and creative industries, 2015 


\section{Appendix 2 - Export Barriers Literature Review (1967-2017)}

\begin{tabular}{|c|c|c|}
\hline \multicolumn{3}{|c|}{ List of Articles in Chronological Order } \\
\hline 1. Groke; Kreidle, 1967 & 2. Alexandrides, 1971 & 3. Simpson; Kujawa, 1974 \\
\hline 4. $\quad$ Pavord; Bogart, 1975 & 5. $\quad$ Bilkey; Tesar, 1977 & 6. Jones, 1980 \\
\hline 7. Rabino, 1980 & 8. $\quad$ Ogram, 1982 & 9. $\quad$ Tesar; Tarleton, 1982 \\
\hline 10. Albaum, 1983 & 11. Czinkota; Ursic, 1983 & 12. Cavusgil, 1984a \\
\hline 13. Kaynak; Kothari, 1984 & $\begin{array}{l}\text { 14. Barrett; Wilkinson, } \\
1985\end{array}$ & 15. Bauerschmidt et al., 1985 \\
\hline 16. Yaprak, 1985 & 17. Bodur, 1986 & 18. Holden, 1986 \\
\hline 19. Karafakioglu, 1986 & 20. Kedia; Chhokar, 1986 & 21. Burton; Schlegelmilch, 1987 \\
\hline 22. Christensen et al., 1987 & 23. Kaynak et al., 1987 & 24. Cheong; Chong, 1988 \\
\hline 25. Hook; Czinkota, 1988 & 26. Onkvisit; Shaw, 1988 & 27. Kathawalla et al., 1989 \\
\hline 28. Kaynak; Erol, 1989 & 29. Keng; Jiuan, 1989 & 30. Schroath; Kroth, 1989 \\
\hline 31. Sharkey et al., 1989 & $\begin{array}{l}\text { 32. Sullivan; } \\
\text { Bauerschmidt. } 1989\end{array}$ & 33. Diamantopoulos et al., 1990 \\
\hline $\begin{array}{l}\text { 34. Sullivan; Bauerschmidt, } \\
1989\end{array}$ & 35. Gripsrud, 1990 & 36. Ramaswami; Yang, 1990 \\
\hline 37. Dichtl et al, 1990 & 38. Weaver; Pak, 1990 & 39. Brooks; Frances, 1991 \\
\hline 40. Czinkota; Ursic, 1991 & 41. Korth, 1991 & 42. Tseng; Yu, 1991 \\
\hline 43. Barker; Kaynak, 1992 & 44. Eshghi, 1992 & 45. Yang et al., 1992 \\
\hline 46. Ifju; Bush, 1993 & 47. Naidu; Rao, 1993 & 48. Katsikeas, 1994 \\
\hline $\begin{array}{l}\text { 49. Katsikeas; Morgan, } \\
1994\end{array}$ & 50. Al-Aali, 1995 & 51. Leonidou, 1995a \\
\hline 52. Leonidou, 1995b & $\begin{array}{l}\text { 53. Kaleka; Katsikeas, } \\
1995\end{array}$ & 54. Mahone; Choudhury, 1995 \\
\hline 55. Shoham; Albaum, 1995 & 56. Campbell, 1996 & 57. Katsikeas et al., 1996 \\
\hline 58. Kwon; Hu, 1996 & 59. Peel; Eckart, 1996 & 60. Ramaseshan; Soutar,1996 \\
\hline 61. Bell, 1997 & 62. Bennet, 1997 & 63. Crick; Chaudhry, 1997 \\
\hline 64. Moini, 1997 & 65. Morgan, 1997 & 66. Tannous, 1997 \\
\hline 67. Crick et al., 1998 & $\begin{array}{l}\text { 68. Morgan; Katsikeas, } \\
1997\end{array}$ & 69. Dean et al., 1998 \\
\hline $\begin{array}{l}\text { 70. Karagozoglu; Lindell, } \\
1998\end{array}$ & $\begin{array}{l}\text { 71. Morgan, Katsikeas, } \\
1998\end{array}$ & 72. Tesar; Moini, 1998 \\
\hline 73. Bagchi-Sem, 1999 & $\begin{array}{l}\text { 74. Karakaya; Harcar, } \\
1999\end{array}$ & 75. Crick; Chaudhry, 2000 \\
\hline 76. Dean et al., 2000 & 77. Leonidou, 2000 & 78. Da Silva, Da Rocha, 2001 \\
\hline 79. Crick, 2002 & 80. Fillis, 2002 & 81. Hornby et al., 2002 \\
\hline 82. Suarez-Ortega, 2003 & 83. Crick, 2004 & 84. Leonidou, 2004 \\
\hline 85. Patterson, 2004 & 86. Shaw; Darroch, 2004 & 87. Julian; Ahmed, 2005 \\
\hline 88. Barnes et al., 2006 & 89. Neupert et al., 2006 & 90. Smith et al, 2006 \\
\hline 91. Tesfom; Lutz, 2006 & 92. Altintas et al., 2007 & 93. Crick, 2007 \\
\hline 94. Wright et al., 2007 & 95. Ozgen; Baron, 2007 & 96. Ahmed et al., 2008 \\
\hline 97. Belwal; Chala, 2008 & 98. Da Rocha et al., 2008 & 99. Karelakis et al., 2008 \\
\hline $\begin{array}{l}\text { 100.Korneliussen; Blasius, } \\
2008\end{array}$ & $\begin{array}{l}\text { 101.Mavrogiannis et al., } \\
2008\end{array}$ & 102. Hutchinson et al., 2009 \\
\hline $\begin{array}{l}\text { 103.Arranz; de Arroyabe, } \\
2009\end{array}$ & 104.Doern, 2009 & $\begin{array}{l}\text { 105. Arteaga-Ortiz; Fernández- } \\
\text { Ortiz, } 2010\end{array}$ \\
\hline 106.Pinho; Martins. 2010 & $\begin{array}{l}\text { 107. Yannopoulos, } \\
\text { Kefalaki, } 2010 \\
\end{array}$ & 108.Awan, 2011 \\
\hline 109.Köksal; Kettaneh, 2011 & 110.Saeed; Vincent, 2011 & 111.Shih; Wickramasekera, 2011 \\
\hline 112.Al-Hyari et al., 2012 & $\begin{array}{l}\text { 113. Karakaya; } \\
\text { Yannopoulos, } 2012\end{array}$ & 114.Baum et al., 2013 \\
\hline $\begin{array}{l}\text { 115. Bianchi; } \\
\text { Wickramasekera, } 2013\end{array}$ & 116. Kahiya, 2013 & $\begin{array}{l}\text { 117.Adu-Gyamfi; Korneliussen, } \\
2013\end{array}$ \\
\hline 118.Uner et al., 2013 & 119.Kahiya et al., 2014 & 120.Bjarnason et al., 2015 \\
\hline 121.Kahiya; Dean, 2015 & 122. Narayanan, 2015 & 123.Kaputa et al., 2016 \\
\hline 124.Ngo et al., 2016 & 125. Cahen et al.; 2016 & 126.Kahiya; Dean; 2016 \\
\hline 127.Kalafksy; Duggan, 2016 & 128. Roy et al., 2016 & 129.Kahiya, 2017 \\
\hline 130.Rahman et al., 2017 & & \\
\hline
\end{tabular}

Source: elaborated by the author based on preliminary list prepared by Professor Eldrede T. Kahyia 


\section{Appendix 3 - Export Promotion Literature Review (1990-2018)}

\begin{tabular}{|c|c|}
\hline \multicolumn{2}{|c|}{ List of Articles in Chronological Order } \\
\hline 1. Seringhaus, 1990 & 42. Durmuşoğlu et al, 2001 \\
\hline 2. Seringhaus et al., 1991 & 43. Martincus et al, 2011 \\
\hline 3. Kotabe; Czinkota, 1992 & 44. Martincus; Carballo, 2012 \\
\hline 4. Diamantopoulos et al., 1993 & 45. Freixanet, 2012 \\
\hline 5. Singer; Czinkota, 1994 & 46. Faroque; Takahashi, 2012 \\
\hline 6. $\quad$ Cavusgil; Yeoh. 1994 & 47. Razavi et al, 2012 \\
\hline 7. Cuyvers et al., 1995 & 48. Martincus et al., 2012 \\
\hline 8. $\quad$ Crick; Czinkota, 1995 & 49. Coudounaris, 2012 \\
\hline 9. Leonidou, 1995 & 50. Cansino et al., 2013 \\
\hline 10. Naidu et al., 1997 & 51. Hajiagha et al, 2013 \\
\hline 11. Gray, 1997 & 52. Mzumara et al., 2013 \\
\hline 12. Moini, 1998 & 53. Miocevic, 2013 \\
\hline 13. Wilkinson; Brouthers, 2000 & 54. Creusen; Lejour, 2013 \\
\hline 14. Gençtürk; Kotabe, 2001 & 55. Meyer; Klasen, 2013 \\
\hline 15. Ahmed et al., 2002 & 56. Karabag; Berggren, 2014 \\
\hline 16. Lefebvre, 2003 & 57. Hayakawa et al., 2014a \\
\hline 17. Gillespie; Riddle, 2004 & 58. Grater et al., 2014 \\
\hline 18. Francis; Collins-Dodd, 2004 & 59. Hayakawa et al., 2014b \\
\hline 19. Alvarez, 2004 & 60. Kinnucan; Gong, 2014 \\
\hline 20. Eldik; Viviers, 2005 & 61. Ayob; Freixanet, 2014 \\
\hline 21. Lages; Montgomery, 2005 & 62. Gupta; Shukla, 2014 \\
\hline 22. Wilkinson; Brouthers, 2006 & 63. Bannò et al., 2014 \\
\hline 23. Shamsuddoha; Ali, 2006 & 64. Barisan et al., 2015 \\
\hline 24. Tan et al., 2007 & 65. Kanda et al., 2015 \\
\hline 25. Mah, 2007 & 66. Moore; Carter, 2015 \\
\hline 26. Martincus; Carballo, 2008 & 67. Van Biesebroeck et al., 2015 \\
\hline 27. Tesfom; Lutz, 2008 & 68. Torres et al, 2016 \\
\hline 28. Williams, 2008 & 69. Geldres-Weiss; Carrasco-Roa, 2016 \\
\hline 29. Shamsuddoha et al., 2009a & 70. Ngo et al., 2016 \\
\hline 30. Brewer, 2009 & 71. Kanda et al, 2016 \\
\hline 31. Sousa; Bradley, 2009 & 72. Cassey; Cohen, 2016 \\
\hline 32. Shamsuddoha et al., $2009 \mathrm{~b}$ & 73. Wu; Shi, 2016 \\
\hline 33. Martincus; Carballo, 2010a & 74. Francioni et al., 2016 \\
\hline 34. Martincus; Carballo, 2010b & 75. Haddoud et al., 2017 \\
\hline 35. Lederman et al., 2010 & 76. Wang et al., 2017 \\
\hline 36. Martincus; Carballo, 2010b & 77. Geldres-Weiss; Monreal-Pérez, 2017 \\
\hline 37. Bannò; Sgobbi, 2010 & 78. Dominguez, 2017 \\
\hline 38. Martincus et al, 2010 & 79. Marzouk, 2017 \\
\hline 39. Zucchella et al, 2010 & 80. Quaye et al., 2017 \\
\hline 40. Leonidou et al., 2011 & 81. Costa et al., 2017 \\
\hline 41. Kang, 2011 & 82. Coudounaris, 2018 \\
\hline
\end{tabular}

Source: elaborated by the author 


\section{Appendix 4-Sources of Secondary Data}

\begin{tabular}{|c|c|c|}
\hline \multicolumn{3}{|c|}{ Case: United Kingdom } \\
\hline Sources & Sources Description & Type of Documents \\
\hline $\begin{array}{l}\text { Department of } \\
\text { International Trade } \\
\text { (former UK Trade \& } \\
\text { Investment) }\end{array}$ & $\begin{array}{l}\text { Drives the government's policy of } \\
\text { increasing the number of exporters and } \\
\text { inward investors to the UK. }\end{array}$ & $\begin{array}{l}\text { Institutional presentation } \\
\text { booklets; Strategic plans; } \\
\text { Annual Corporate Reports; } \\
\text { Statistical Data Reports; } \\
\text { Research and Analysis } \\
\text { Reports; Policy papers; } \\
\text { Guidance notes for } \\
\text { companies. }\end{array}$ \\
\hline $\begin{array}{l}\text { British European } \\
\text { Design Group }\end{array}$ & $\begin{array}{l}100 \% \text { self-financed, non-profit and non- } \\
\text { commercial organization aiming to } \\
\text { promote creative excellence worldwide } \\
\text { and export British Creativity to global } \\
\text { markets. }\end{array}$ & $\begin{array}{l}\text { Institutional presentation } \\
\text { booklets; Articles ; Guidance } \\
\text { notes for companies. }\end{array}$ \\
\hline $\begin{array}{l}\text { Design Business } \\
\text { Association (DBA) }\end{array}$ & $\begin{array}{l}\text { Independent enterprising charity, the } \\
\text { Design industry's trade association, and } \\
\text { the UK government's adviser, aims to } \\
\text { promote the effective use of design } \\
\text { within business, encourage high } \\
\text { standards of business and professional } \\
\text { practice and provide a range of } \\
\text { services to member consultancies. }\end{array}$ & $\begin{array}{l}\text { Institutional presentation } \\
\text { booklets and videos; Statistical } \\
\text { data; Annual Reports. }\end{array}$ \\
\hline $\begin{array}{l}\text { D\&AD Foundation } \\
\text { (former British } \\
\text { Design \& Art } \\
\text { Direction) }\end{array}$ & $\begin{array}{l}\text { Non-profit advertising and design } \\
\text { professionals' association aiming to } \\
\text { stimulate, enable and award creative } \\
\text { excellence in design and advertising } \\
\text { worldwide. }\end{array}$ & $\begin{array}{l}\text { Institutional presentation } \\
\text { booklets and videos; Projects } \\
\text { Report. }\end{array}$ \\
\hline Design Council UK & $\begin{array}{l}\text { Enterprising charity considered a } \\
\text { leading authority on the use of strategic } \\
\text { design, being the UK government's } \\
\text { adviser. Its funding derives from a } \\
\text { combination of grants, partnerships and } \\
\text { paid-for services. }\end{array}$ & $\begin{array}{l}\text { Institutional presentation } \\
\text { booklets; Projects Reports; } \\
\text { Industry Reports; Research } \\
\text { Reports; Annual Reports; } \\
\text { Guides for companies; } \\
\text { Articles; Success Stories; Call } \\
\text { for Applications. }\end{array}$ \\
\hline The Crafts Council & $\begin{array}{l}\text { Enterprising charity to promote the UK's } \\
\text { contemporary craft, aiming to build a } \\
\text { strong economy and infrastructure; } \\
\text { increasing and diversifying the } \\
\text { audience; and championing high-quality } \\
\text { craft practice nationally and } \\
\text { internationally. }\end{array}$ & $\begin{array}{l}\text { Institutional presentation } \\
\text { booklets; Business Plan; } \\
\text { Annual Reports. }\end{array}$ \\
\hline British Council & $\begin{array}{l}\text { The UK's government organization to } \\
\text { promote cultural relations and } \\
\text { educational opportunities worldwide. }\end{array}$ & $\begin{array}{l}\text { Institutional presentation } \\
\text { booklets; Annual Reports; } \\
\text { Corporate Plan. }\end{array}$ \\
\hline $\begin{array}{l}\text { British Council's } \\
\text { Department of } \\
\text { Architecture Design } \\
\text { and Fashion (ADF) }\end{array}$ & $\begin{array}{l}\text { Department of the British Council - a } \\
\text { government organization - aiming to } \\
\text { create links between designers and } \\
\text { cultural institutions around the world, } \\
\text { through a diverse range of projects } \\
\text { across the three disciplines. }\end{array}$ & $\begin{array}{l}\text { Institutional presentation } \\
\text { booklets; Projects presentation } \\
\text { booklets; Papers exploring } \\
\text { new directions for the sectors. }\end{array}$ \\
\hline $\begin{array}{l}\text { University of } \\
\text { Cambridge }\end{array}$ & $\begin{array}{l}\text { One of the world's oldest universities } \\
\text { and leading academic centers, and a } \\
\text { self-governed community of scholars. }\end{array}$ & $\begin{array}{l}\text { International Design } \\
\text { Scoreboard. }\end{array}$ \\
\hline UNCTAD & $\begin{array}{l}\text { The main United Nations body dealing } \\
\text { with trade, investment and development } \\
\text { issues. }\end{array}$ & $\begin{array}{l}\text { Trade and Development } \\
\text { Reports; Statistics. }\end{array}$ \\
\hline
\end{tabular}




\begin{tabular}{|c|c|c|}
\hline \multicolumn{3}{|c|}{ Case: South Korea } \\
\hline Sources & Sources Description & Type of Documents \\
\hline $\begin{array}{l}\text { Korea Trade- } \\
\text { Investment } \\
\text { Promotion Agency - } \\
\text { KOTRA }\end{array}$ & $\begin{array}{l}\text { Government agency established to } \\
\text { promote exports, country's image, and } \\
\text { inward investments to South Korea. }\end{array}$ & $\begin{array}{l}\text { Institutional presentation } \\
\text { booklets; Corporate Report. }\end{array}$ \\
\hline $\begin{array}{l}\text { Korea Creative } \\
\text { Content Agency } \\
\text { (KOCAA) }\end{array}$ & $\begin{array}{l}\text { Government's agency to promote South } \\
\text { Korean creative content, both } \\
\text { domestically and internationally. }\end{array}$ & $\begin{array}{l}\text { Institutional presentation } \\
\text { booklets; Statistics. }\end{array}$ \\
\hline $\begin{array}{l}\text { Korean Culture } \\
\text { Center New York } \\
(\text { KCCNY) }\end{array}$ & $\begin{array}{l}\text { Government's institution to establish } \\
\text { and promote South Korean's culture } \\
\text { and aesthetics in New York. }\end{array}$ & $\begin{array}{l}\text { Institutional presentation } \\
\text { booklets; Programs' booklets; } \\
\text { press releases. }\end{array}$ \\
\hline $\begin{array}{l}\text { Korea Institute of } \\
\text { Design Promotion } \\
\text { (KIDP) }\end{array}$ & $\begin{array}{l}\text { Government's institution to promote } \\
\text { industrial design. }\end{array}$ & $\begin{array}{l}\text { Institutional presentation } \\
\text { booklets; Programs' booklets; } \\
\text { Statistics Report; News } \\
\text { Articles. }\end{array}$ \\
\hline $\begin{array}{l}\text { Korean Film Council } \\
\text { (KOFIC) }\end{array}$ & $\begin{array}{l}\text { Government's organization to support } \\
\text { and promote Korean films. }\end{array}$ & $\begin{array}{l}\text { Institutional presentation } \\
\text { booklets; Industry's Reports } \\
\text { and Guides; Statistics and } \\
\text { Infographics; Shooting Guide. }\end{array}$ \\
\hline $\begin{array}{l}\text { Korean Film Archive } \\
\text { (KOFA) }\end{array}$ & $\begin{array}{l}\text { Non-profit organization affiliated to the } \\
\text { International Federation of Film Archive } \\
\text { which aims at collecting, cataloging, } \\
\text { preserving and restoring Korean } \\
\text { audiovisual content. }\end{array}$ & $\begin{array}{l}\text { Institutional presentation } \\
\text { booklets. }\end{array}$ \\
\hline UNCTAD & $\begin{array}{l}\text { The main United Nations body dealing } \\
\text { with trade, investment and development } \\
\text { issues. }\end{array}$ & $\begin{array}{l}\text { Trade and Development } \\
\text { Reports; Statistics. }\end{array}$ \\
\hline $\begin{array}{l}\text { University of } \\
\text { Cambridge }\end{array}$ & $\begin{array}{l}\text { One of the world's oldest universities } \\
\text { and leading academic centers, and a } \\
\text { self-governed community of scholars. }\end{array}$ & $\begin{array}{l}\text { International Design } \\
\text { Scoreboard. }\end{array}$ \\
\hline $\begin{array}{l}\text { Academics and } \\
\text { specialists }\end{array}$ & - & $\begin{array}{l}\text { Books, papers and magazine } \\
\text { articles mentioned as } \\
\text { References. }\end{array}$ \\
\hline \multicolumn{3}{|c|}{ Case Colombia } \\
\hline Sources & Sources Description & Type of Documents \\
\hline $\begin{array}{l}\text { Procolombia } \\
\text { (former Proexport } \\
\text { Colombia) }\end{array}$ & $\begin{array}{l}\text { Government agency established to } \\
\text { promote exports, country's image and } \\
\text { inward investments to Colombia. }\end{array}$ & $\begin{array}{l}\text { Institutional presentation } \\
\text { booklets; Investment } \\
\text { Environment and Business } \\
\text { Opportunities' Report; } \\
\text { Industry's Report. }\end{array}$ \\
\hline $\begin{array}{l}\text { Colombia's Ministry } \\
\text { of Commerce, } \\
\text { Industry and } \\
\text { Tourism }\end{array}$ & Government public body. & $\begin{array}{l}\text { Institutional presentation } \\
\text { booklets, PowerPoint } \\
\text { presentations; Guides; } \\
\text { Business Plans, Statistics } \\
\text { regarding the Productive } \\
\text { Transformation Program } \\
\text { (PTP). Government policies. }\end{array}$ \\
\hline $\begin{array}{l}\text { McKinsey \& } \\
\text { Company }\end{array}$ & $\begin{array}{l}\text { Worldwide management consulting } \\
\text { firm. }\end{array}$ & $\begin{array}{l}\text { PowerPoint presentation } \\
\text { regarding the Productive } \\
\text { Transformation Program (PTP) }\end{array}$ \\
\hline $\begin{array}{l}\text { Proimágenes } \\
\text { Colombia and } \\
\text { Colombian Film } \\
\text { Commision }\end{array}$ & $\begin{array}{l}\text { Non-profit organization composed by } \\
\text { public and private entities to promote } \\
\text { and consolidate the Colombian film } \\
\text { industry. }\end{array}$ & $\begin{array}{l}\text { Institutional Presentation } \\
\text { Booklet; Film Act (Law } 1556 \text { of } \\
\text { 2012); Resource Allocation } \\
\text { Manual of the Colombia Film }\end{array}$ \\
\hline
\end{tabular}




\begin{tabular}{|l|l|l|}
\hline & $\begin{array}{l}\text { Division of Proimágenes to promote } \\
\text { Colombia as a destination for } \\
\text { audiovisual production and to } \\
\text { encourage the development and } \\
\text { improvement of the country's } \\
\text { audiovisual services and talents. }\end{array}$ & $\begin{array}{l}\text { Fund; Newsletters; Production } \\
\text { and Co-Production Guides. }\end{array}$ \\
\hline UNCTAD & $\begin{array}{l}\text { The main United Nations body dealing } \\
\text { with trade, investment and development } \\
\text { issues. }\end{array}$ & $\begin{array}{l}\text { Trade and Development } \\
\text { Reports; Statistics. }\end{array}$ \\
\hline
\end{tabular}

